\title{
Molecular analysis of vesicle biogenesis during autophagy
}

\author{
Dissertation \\ zur Erlangung des Doktorgrades \\ der Mathematisch-Naturwissenschaftlichen Fakultät \\ der Georg-August-Universität zu Göttingen
}

vorgelegt von

Sebastian Bremer

aus Hannover

Göttingen 2009 
Members of the thesis committee:

Advisor: Prof. Dr. M. Thumm

Institut für Biochemie II, Zentrum Biochemie und Molekulare Zellbiologie Georg-Auguts-Üniversität, Göttingen

Co-advisor: Prof. Dr. G. H. Braus

Institut fr Mikrobiologie und Genetik

Georg-Auguts-Üniversität, Göttingen

Dr. D. Fasshauer

Abteilung Neurobiologie

Max-Planck-Institut für biophysikalische Chemie, Göttingen 
I hereby declare that this thesis has been written independently and with no other sources and aids than quoted. 



\section{Contents}

I. CONTENTS

II. LIST OF FIGURES.

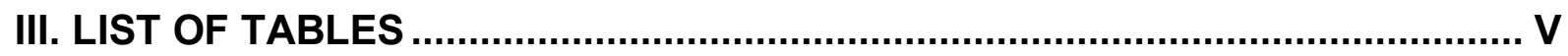

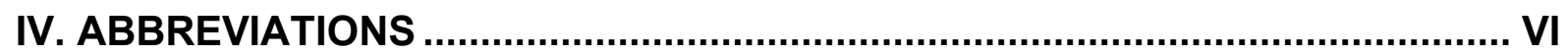

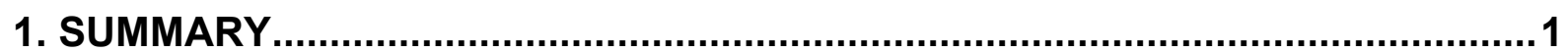

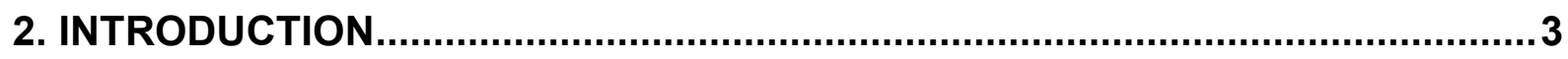

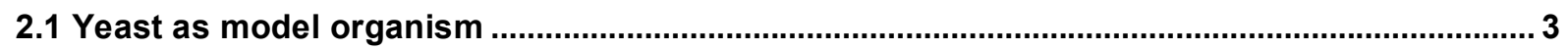

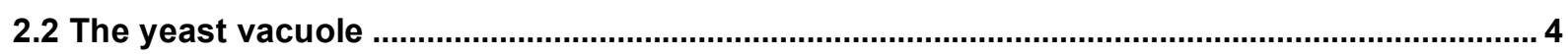

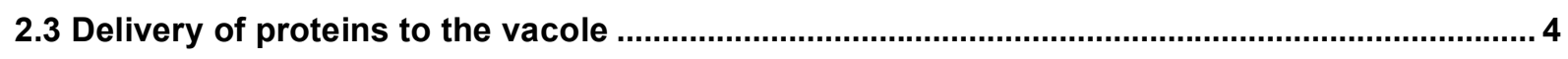

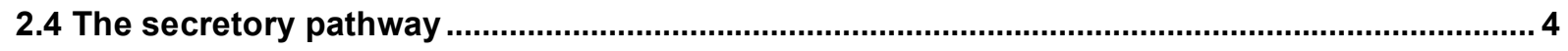

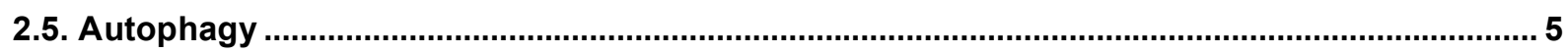

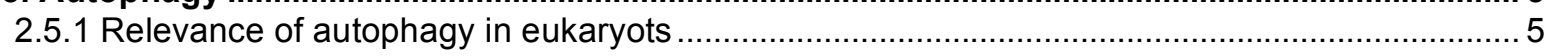

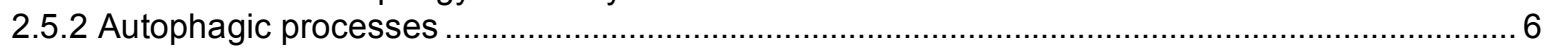

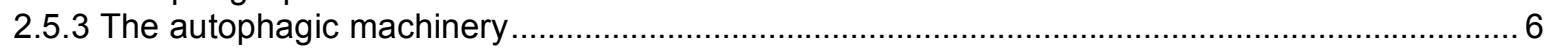

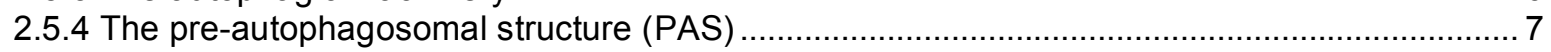

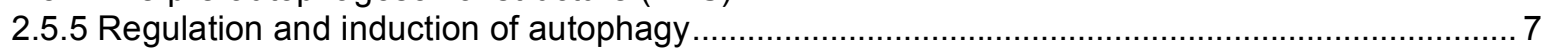

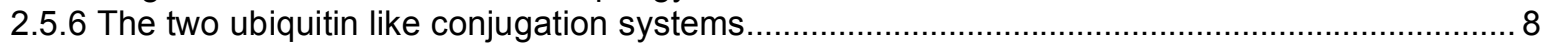

2.5.6.1 The Atg8-phosphatidylethanolamine conjugation system …......................................... 8

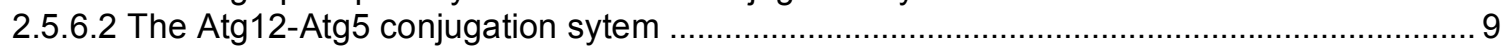

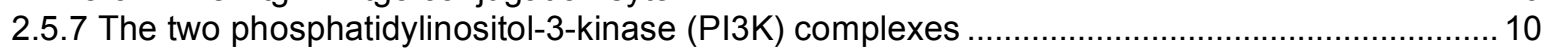

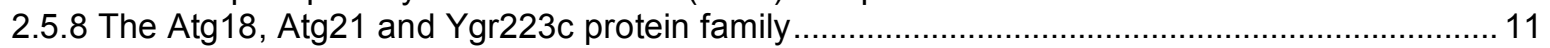

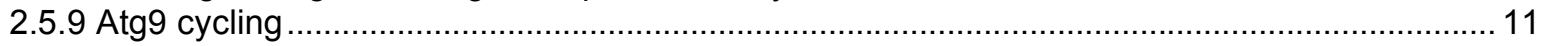

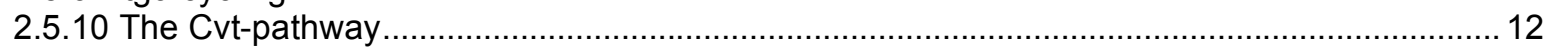

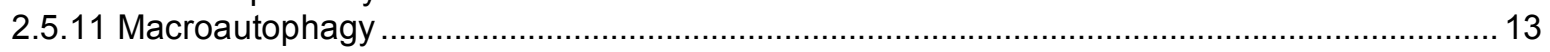

2.5.12 Fusion and breakdown of vesicles in the vacuole ......................................................... 13

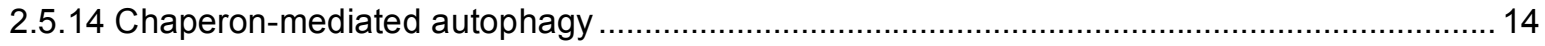

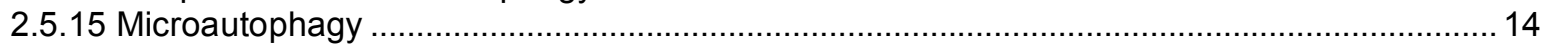

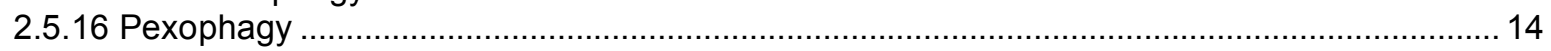

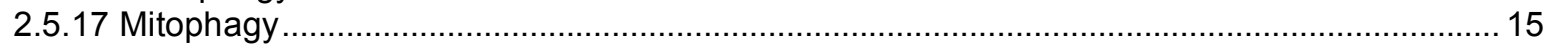

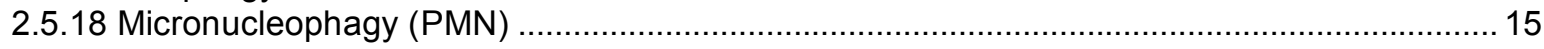

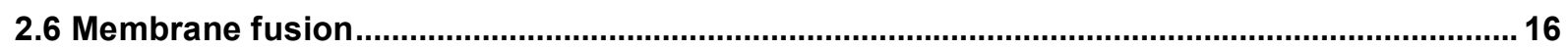

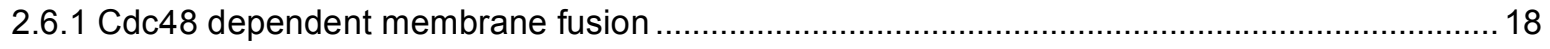

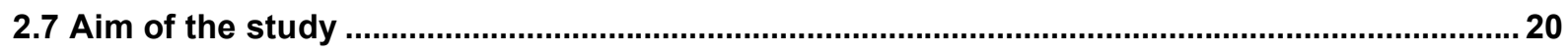

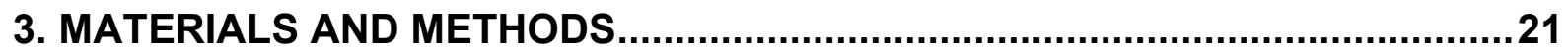

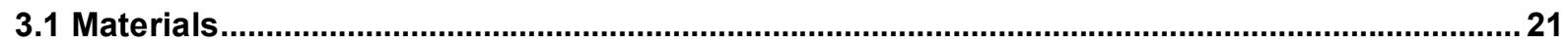

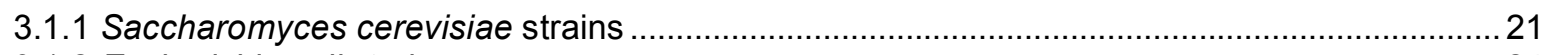

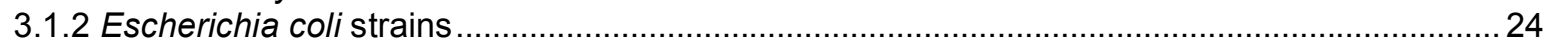

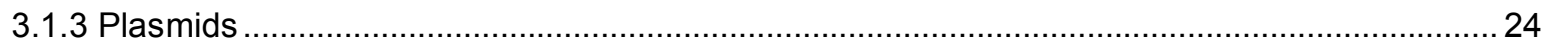




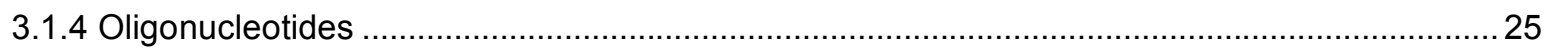

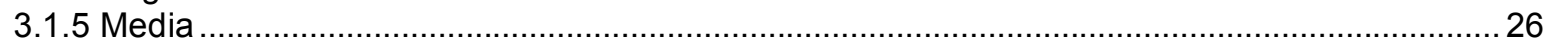

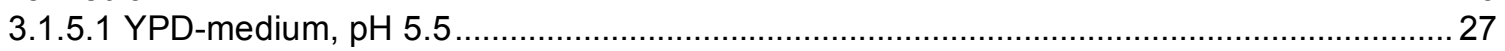

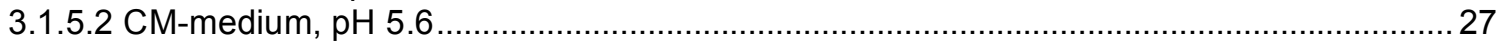

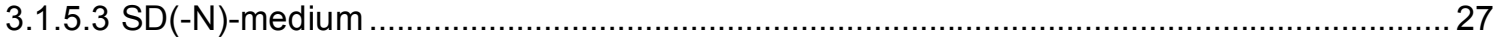

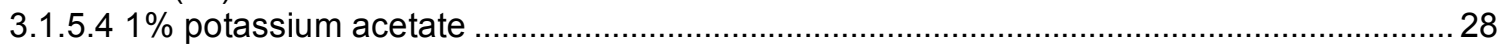

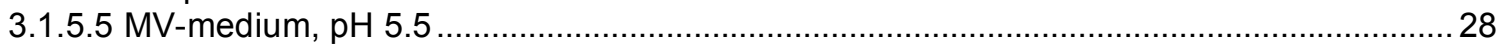

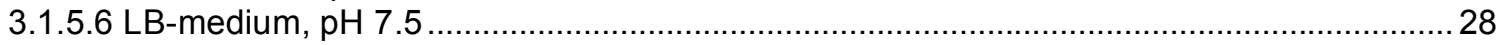

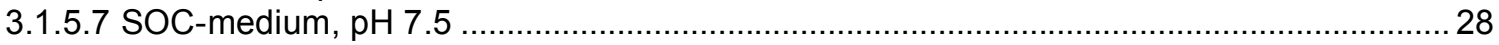

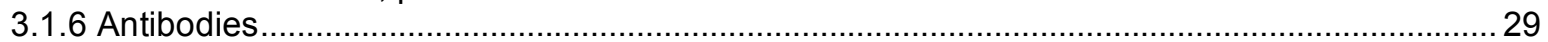

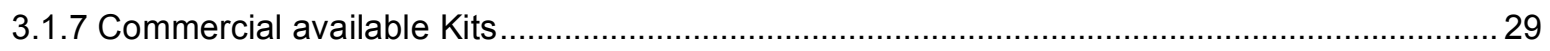

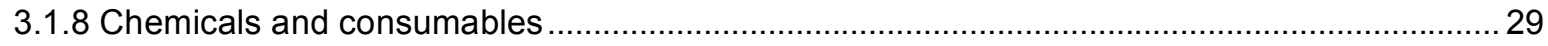

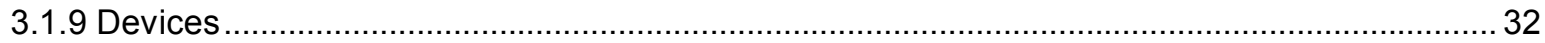

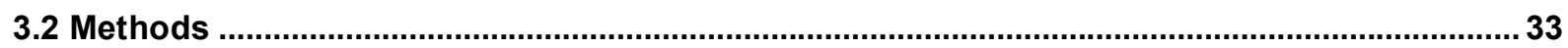

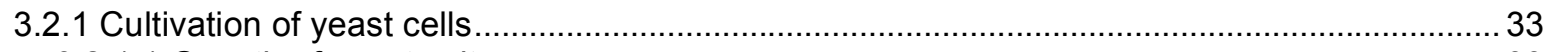

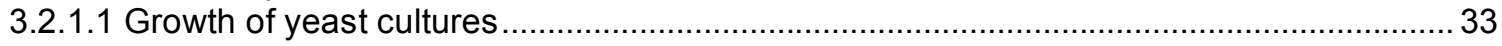

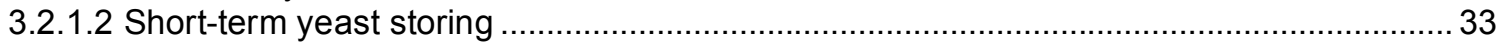

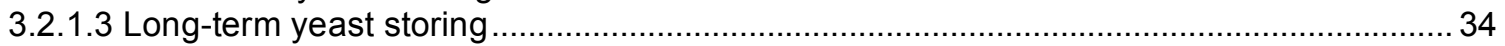

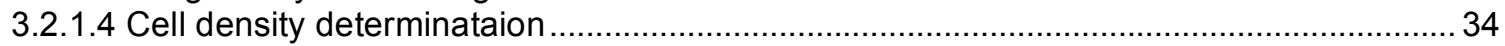

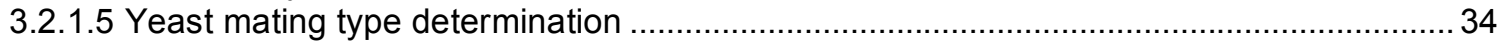

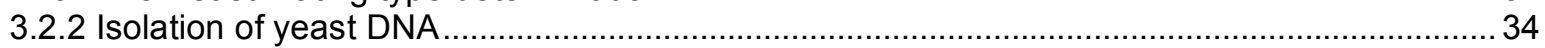

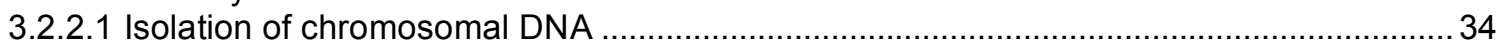

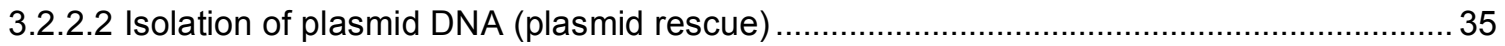

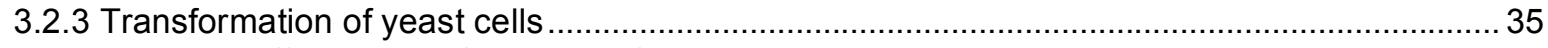

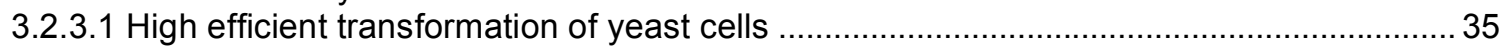

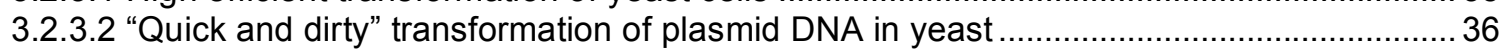

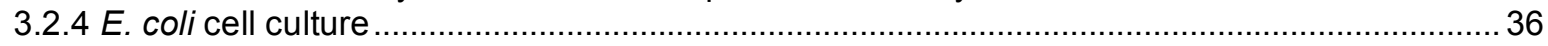

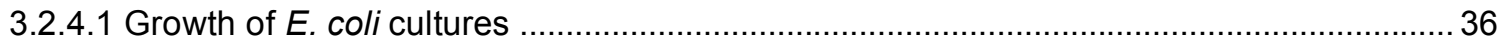

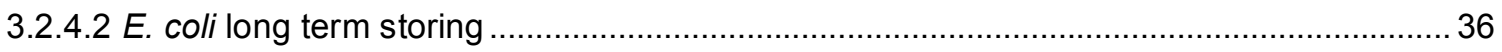

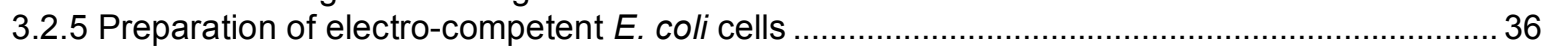

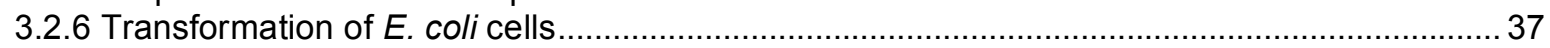

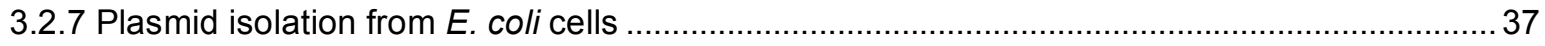

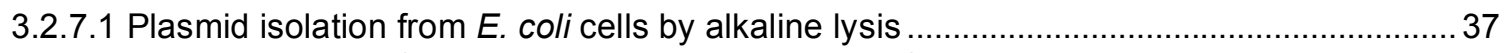

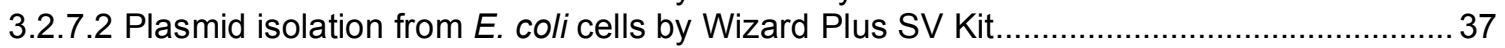

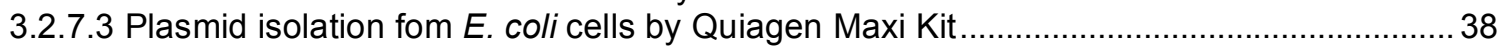

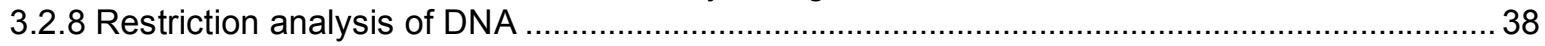

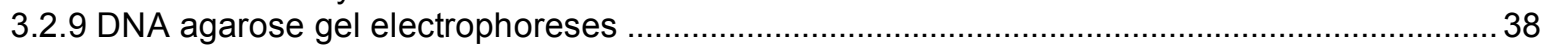

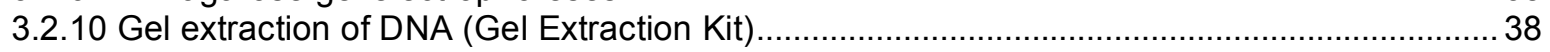

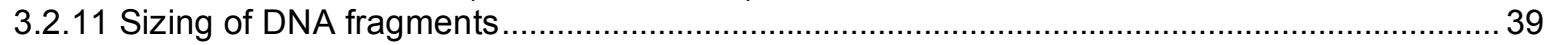

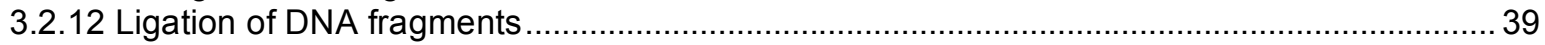

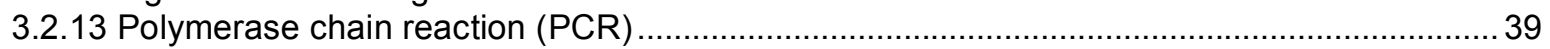

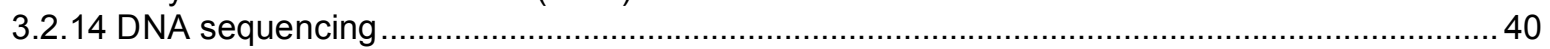

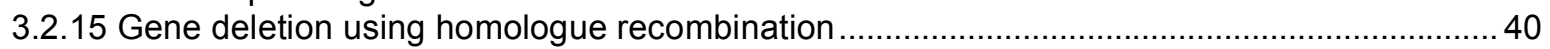

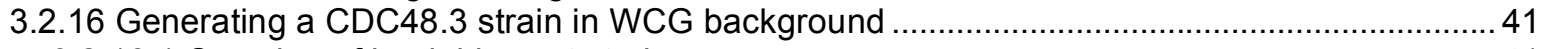

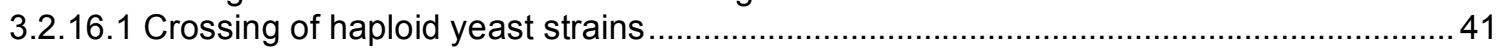

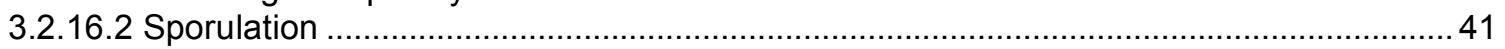

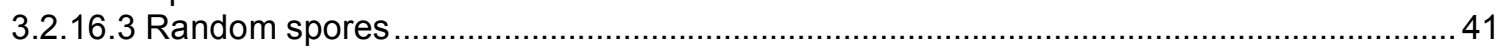

3.2.17 Chromosomal N-terminal fusion of GFP-Atg8 using the cre recombinase system ..............42

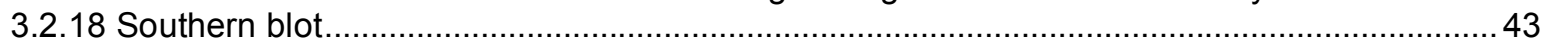

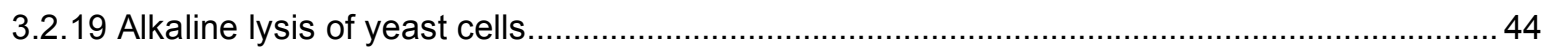

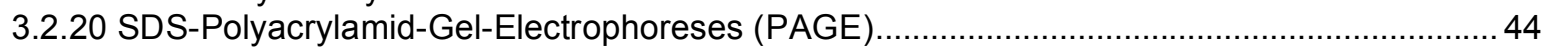

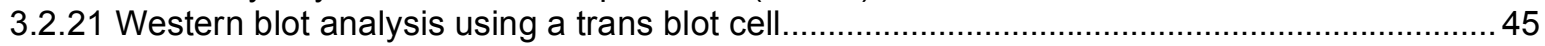

3.2.22 Stripping of once immunodetected membranes ........................................................ 46

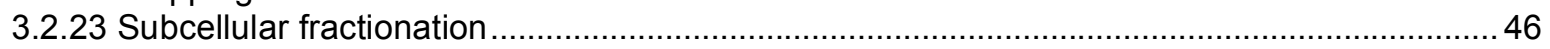

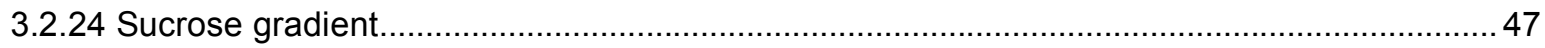

3.2.25 Measuring the breakdown of GFP fused proteins........................................................ 48

3.2.25.1 Measurement of the breakdown of GFP-Osh1p ..................................................... 48

3.2.25.2 Measurement of the breakdown of GFP-Osh1p or GFP-Atg8 in temperature sensitive strains

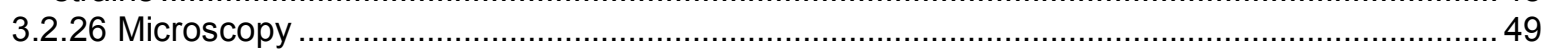

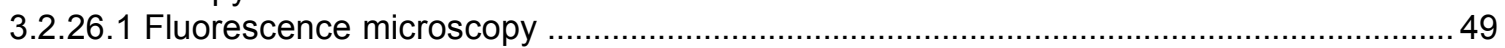




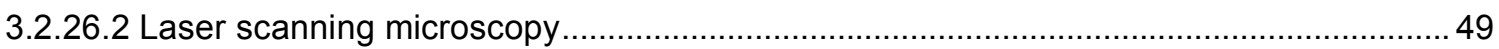

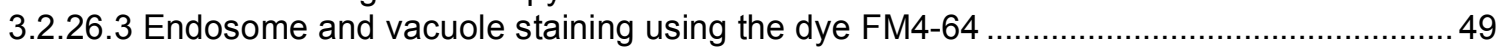

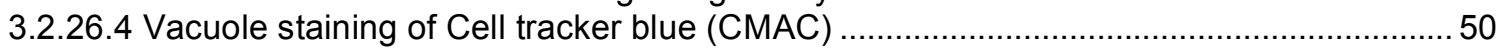

\section{RESULTS}

4.1 Where are the autophagic membranes coming from? .....................................................51

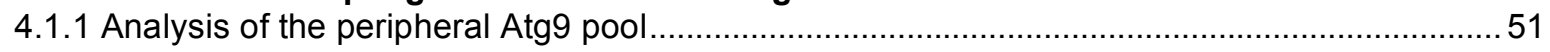

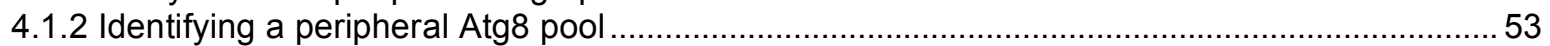

4.1.3 Lipidation of Atg8 is essential for its peripheral pool....................................................... 54

4.1.4 The peripheral pool of Atg8 localizes to a PI3P containing ring around the vacuole ..............57

4.1.5 The peripheral pool of Atg8 localizes to endosomes .......................................................... 58

4.1.6. Quantification of the Atg8 peripheral pool in different deletion strains .................................60

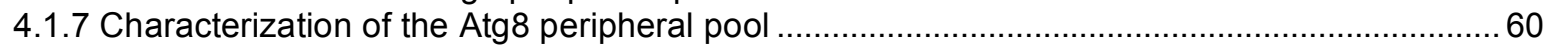

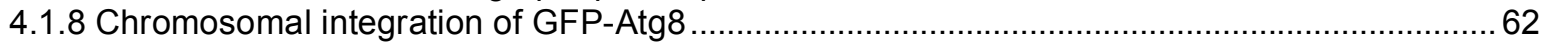

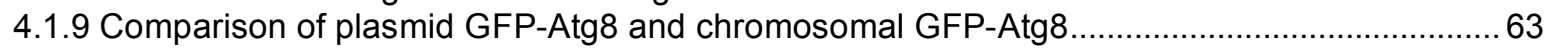

4.2 Piecemeal microautophagy of the nucleus (PMN / micronucleophagy) ................................64

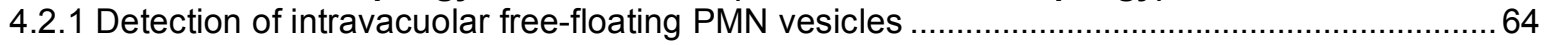

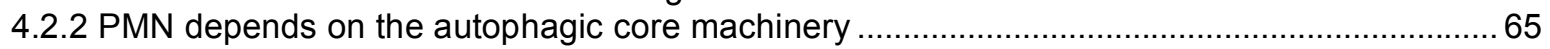

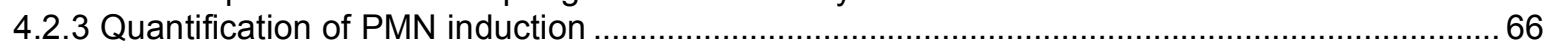

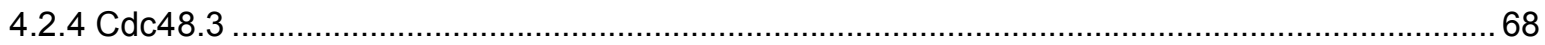

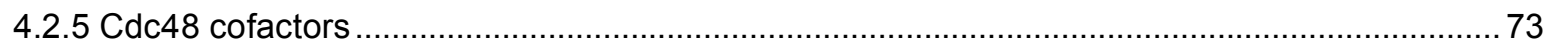

4.2.5.1 The substrate recruiting adaptor Shp1 is required for PMN and macroautophagy ........... 73

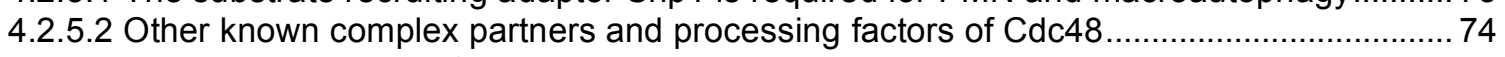

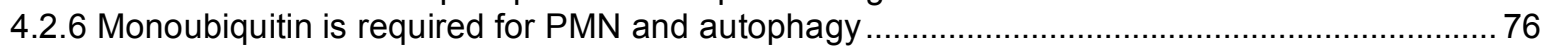

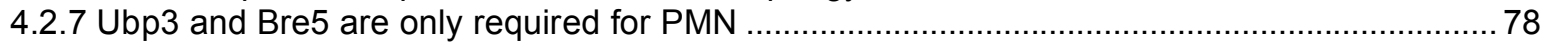

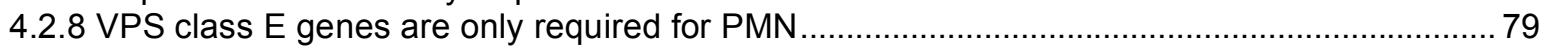

4.2.9 The Fatty acid elongation machinery is not required for PMN .......................................... 81

4.2.10 Proteins involved in cortical ER inheritance are not required for PMN ............................... 82

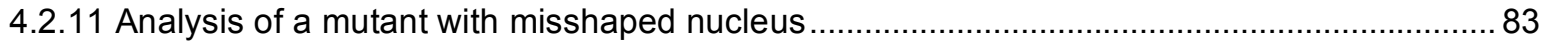

4.2.12 Summary of strains required for PMN identified in this study .......................................... 83

4.2.13 Summary of strains required for autophagy identified in this study .................................. 85

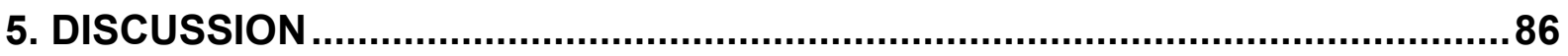

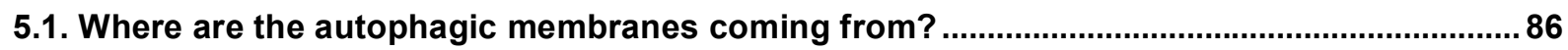

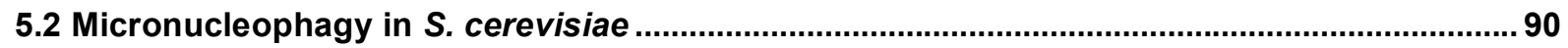

5.2.1 Micronucleophagy in S. cerevisiae requires the core autophagic genes ............................... 90

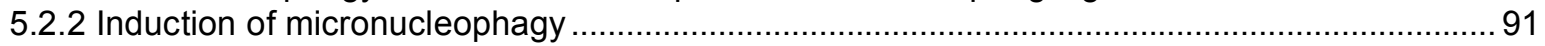

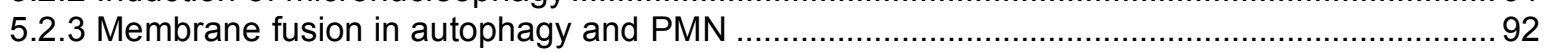

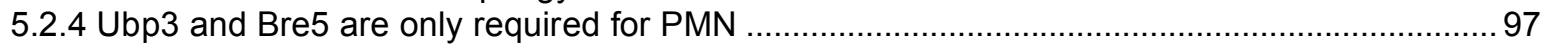

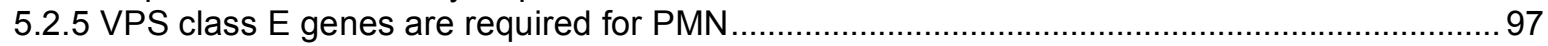

5.2.6 The fatty acid elongation machinery is not required for PMN ............................................ 98

5.2.7 Proteins for cortical ER inharitance are not required for PMN ............................................. 99

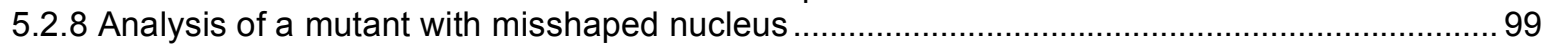

6. BIBLIOGRAPHY. 


\section{List of figures}

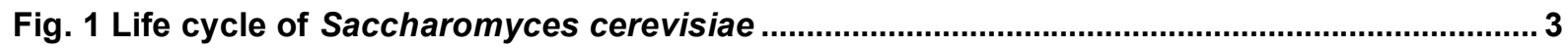

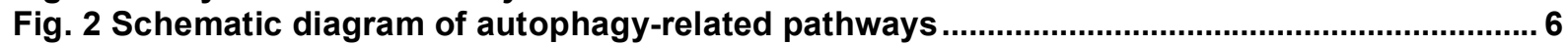

Fig. 3 Regulatory complex for autophagy induction .................................................................. 8

Fig. 4 Model of the three-dimensional structure of Atg8

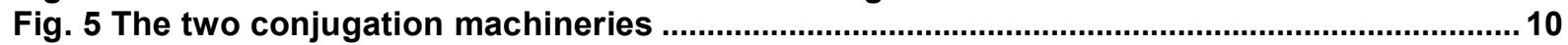

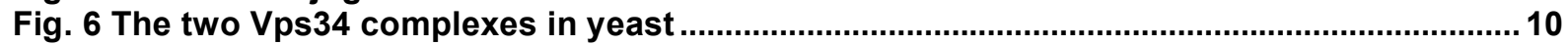

Fig. 7 Cycling of S. cerevisiae Atg9 between the PAS and a peripheral pool ..............................12

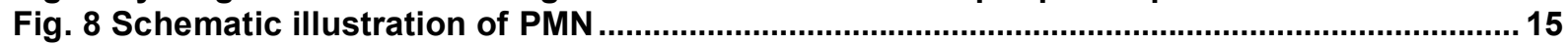

Fig. 9 Model of molecular composition of NV-junctions ..............................................................16

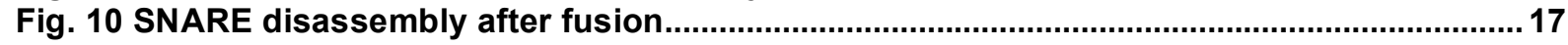

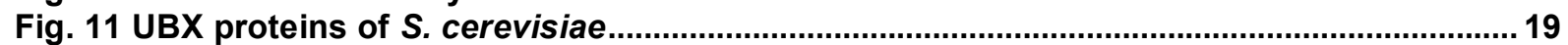

Fig. 12 p97 - Golgi membrane reassembly in humans...............................................................19

Fig. 13 Construction of the chromosomal n-terminal fusion protein GFP-Atg8 ….......................42

Fig. 14 Diffusion blot.............................................................................................................. 43

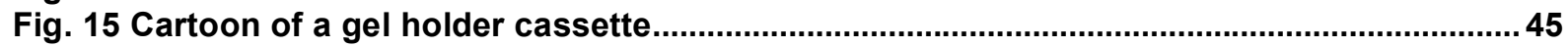

Fig. 16 Verification of the autophagic phenotype of the $\operatorname{atg} 27 \Delta, \operatorname{atg} 4 \operatorname{atg} 27 \Delta$ and $\operatorname{atg} 1 \Delta$ $\operatorname{atg} 27 \Delta$ strains using Ape1 (A.) or GFP-Atg9 (B.) as a marker................................................52

Fig. 17 Identifying a peripheral pool of Atg8 in $\operatorname{atg} 1 \Delta$ atg27 $\Delta$ cells .............................................. 53

Fig. 18 Analysis of GFP-Atg8 and a GFP-Atg8 mutant lacking the C-terminal arginine (GFP-Atg8*)

Fig. 19 Lipidation of Atg8 is essential for the peripheral pool...

Fig. 20 The peripheral pool of Atg8 localizes to a PI3P containing ring around the vacuole......56

Fig. 21 Accumulation of the peripheral Atg8 pool in vps $4 \Delta$ cells and colocalization with the endosomal protein SNF7.

Fig. 22 Quantification of the Atg8 peripheral pool in different deletion strains ............................60

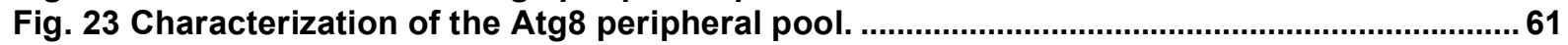

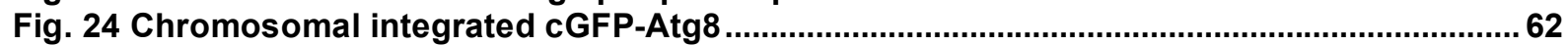

Fig. 25 Comparison of plasmid and chromosomal GFP-Atg8 .................................................63

Fig. 26 Detection of intravacuolar free-floating PMN vesicles by fluorescence microscopy......65

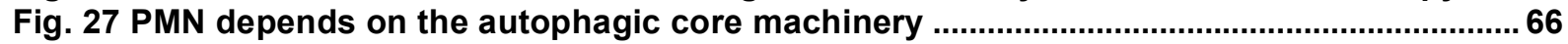

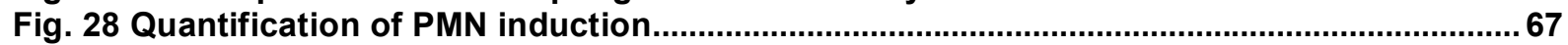

Fig. 29 Cdc48.3 (I.) WCG, (II.) BY4741 and (III.) W303 background ............................................. 71

Fig. 30 The Cdc48 substrate adaptor Shp1 is required for PMN and autophagy (A.), but non

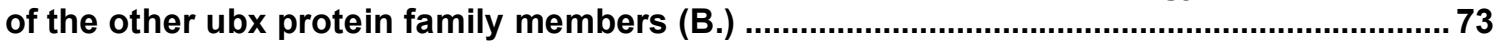

Fig. 31 Complex partners and processing factors of Cdc48 ...................................................75

Fig. 32 Monoubiquitin is required for PMN and autophagy .......................................................

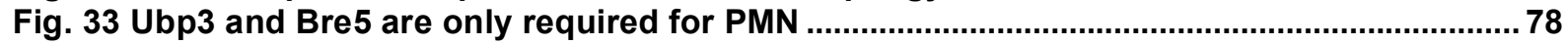

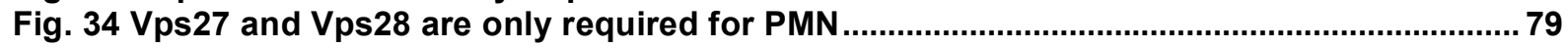

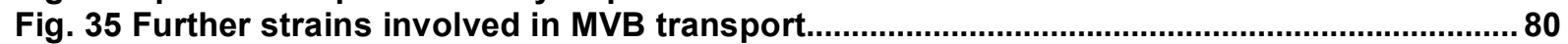

Fig. 36 Fatty acid elongation machinery is not required for PMN ....................................... 81

Fig. 37 Proteins involved in cortical ER inheritance are not required for PMN.............................82

Fig. 38 Analysis of a mutant with misshaped nucleus ................................................................8

Fig. 39 Composition of CDC48 complexes in membrane fusion events .......................................96 


\section{List of tables}

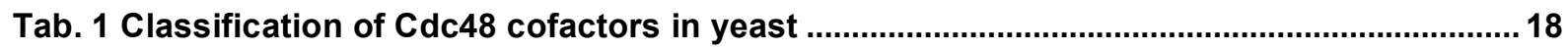

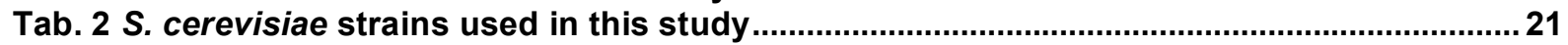

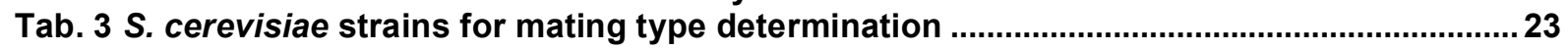

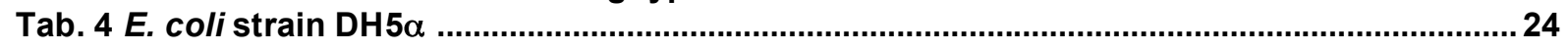

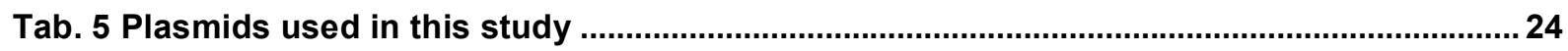

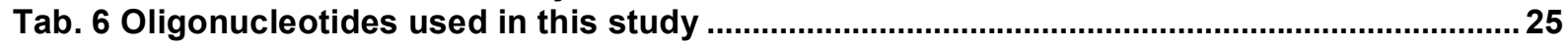

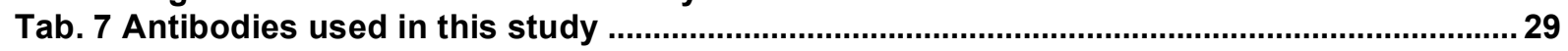

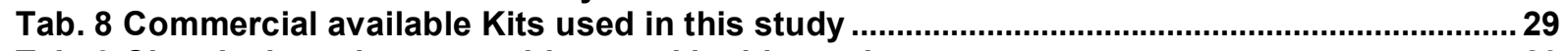

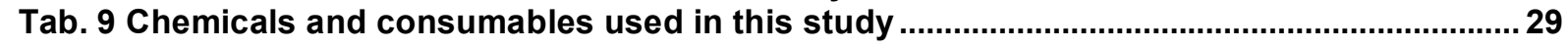

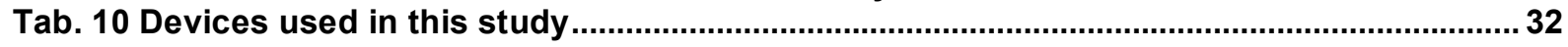

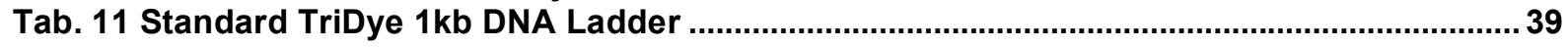

Tab. 12 Strains for the generation of CDC48.3 in WCG background ............................................. 41

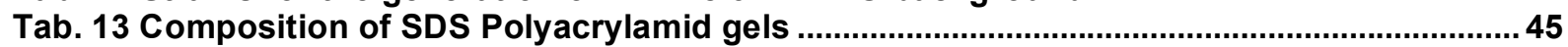

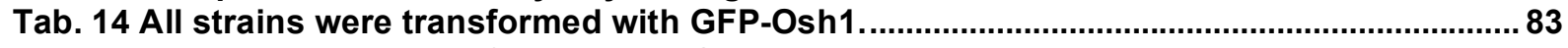

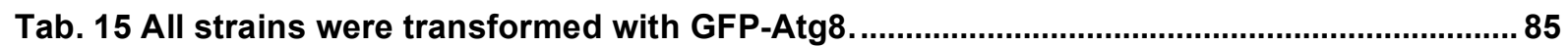




\section{Abbreviations}

\begin{tabular}{|c|c|}
\hline Abbreviation & \\
\hline - HIS & Without histidine \\
\hline - LEU & Without leucine \\
\hline - URA & Without uracil \\
\hline+ KAN & Containing kanamycin \\
\hline + NAT & Containing nourseotricine \\
\hline${ }^{\circ} \mathrm{C}$ & Degree Celsius \\
\hline aa & Amino acid(s) \\
\hline Amp & Ampicillin \\
\hline Ape1p & Aminopeptidase 1 \\
\hline APS & Ammonium persulfate \\
\hline ATP & Adenosine 5 -triphosphate \\
\hline BSA & Bovine serum albumine \\
\hline clonNAT & Nourseotricine \\
\hline CMAC & 7-amino-4-chloromethylcoumarin \\
\hline CPY & Carboxypeptidase Y (Pcr1) \\
\hline ct & Control \\
\hline $\mathrm{ddH}_{2} \mathrm{O}$ & Double distilled water \\
\hline DMSO & Dimethylsulfoxide \\
\hline DNA & Deoxyribonucleic acid \\
\hline dNTPs & $\begin{array}{l}\text { Deoxynucleosidetriphosphate (dATP, } \\
\text { dGTP, dCTP, dTTP) }\end{array}$ \\
\hline DTT & Dithiothreitol \\
\hline E. coli & Echerichia coli \\
\hline e.g. & for example \\
\hline EDTA & Ethylenediamintetraacetate-Disodium salt \\
\hline ER & Endoplasmic Reticulum \\
\hline $\mathrm{EtOH}$ & Ethanol \\
\hline Fig. & Figure \\
\hline g & Gram \\
\hline g & Gravity \\
\hline
\end{tabular}




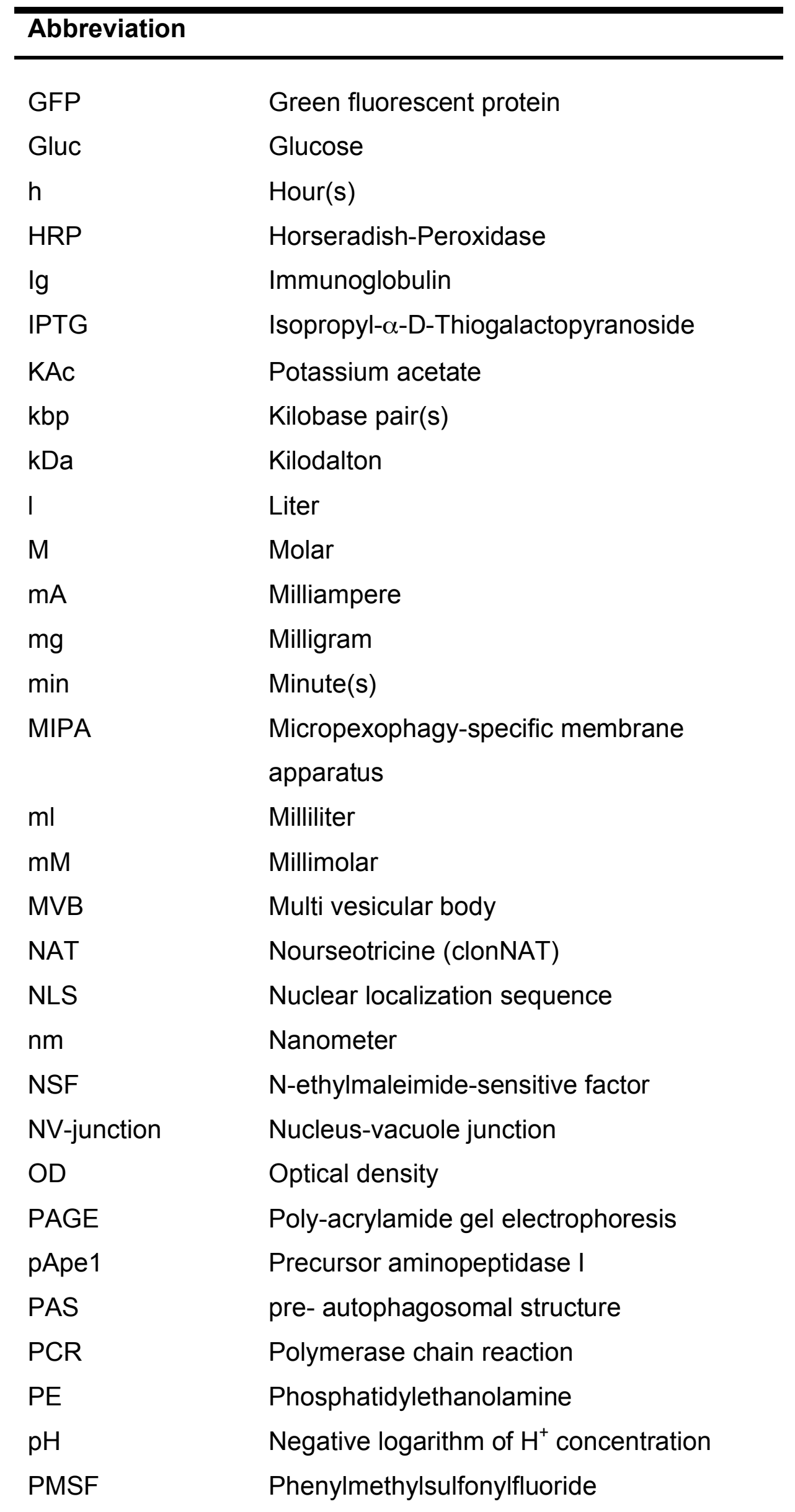




\begin{tabular}{|c|c|}
\hline Abbreviation & \\
\hline PVDF & Polyvinylidene Fluoride \\
\hline RAPA & Rapamycine \\
\hline rpm & Rounds per minute \\
\hline $\mathrm{rt}$ & Room temperature \\
\hline S. cerevisiae & Saccharomyces cerevisiae \\
\hline SDS & Sodium Dodecyl Sulfate \\
\hline sec & Second(s) \\
\hline $\sec$ & Secretory pathway \\
\hline SED & Standard Error of the Difference \\
\hline SMP & Skim milk powder \\
\hline SNARE & Soluble NSF attachment receptors \\
\hline sup & Supernatant \\
\hline TAE & Tris-acetate-EDTA-buffer \\
\hline TBS & Tris buffer saline \\
\hline TCA & Trichloroacatic acid \\
\hline TEMED & $\mathrm{N}, \mathrm{N}, \mathrm{N}^{\prime}, \mathrm{N}^{\prime}$-Tetramethylethylenediamine \\
\hline TGN & Trans Golgi network \\
\hline TOR & Target of rapamycin \\
\hline U & Units \\
\hline UV & Ultraviolet \\
\hline V & Volt \\
\hline $\mathrm{v} / \mathrm{v}$ & (Volume/volume) \\
\hline w / o & Without \\
\hline$w / v$ & (Weight/volume) \\
\hline wt & Wild type \\
\hline YPD & Yeast Peptone Dextrose \\
\hline$\mu$ & Micro \\
\hline
\end{tabular}




\section{Summary}

Autophagy in Saccharomyces cerevisiae comprises diverse processes that transport cytoplasm and even organelles into the vacuolar lumen for degradation. During macroautophagy out of the pre- autophagosomal structure (PAS) autophagosomes are formed that fuse with the vacuole for degradation. During microautophagy cargo is directly engulfed by the vacuolar membrane.

One aim of this study was to identify membrane sources needed for the formation of autophagosomes out of the PAS. Atg9 a transmembrane protein has been proposed to cycle between the PAS and a peripheral pool that may serve as a membrane source. In $S$. cerevisiae this pool has been described to colocalize in part with mitochondria. This was questioned in mammalian cells where this peripheral pool colocalizes with the trans Golgi network and endosomes.

Another suitable candidate to follow the membrane flow is Atg8 that is covalently coupled to membranes via phosphatidylethanolamine (PE).

This study describes for the first time a peripheral pool of Atg8 located at endosomes. Its formation is dependent on Atg1 and Atg27 as described for the Atg9 peripheral pool. Atg8 is conjugated to PE at the peripheral pool.

Micronucleophagy (piecemeal microautophagy of the nucleus; PMN) occurs at nucleus-vacuole (NV) junctions and results in the pinching-off and release of nonessential portions of the nucleus into the vacuole. In contrast to previous published results Krick et al. showed in a recent publication that PMN requires the core macroautophagy genes. They analysed the degradation of the PMN marker protein GFP-Osh1 by quantifying the release of hydrolase resistant free GFP in the vacuole using immuno-western blot analysis. In this study a microscopic assay was established which supports the finding that PMN is efficiently inhibited in atg mutant cells. A nuclear resident fluorescent protein (NLS-mCherry) is used as marker protein. Part of this fluorescent protein pinch-off the nucleus dependent on the autophagic machinery and is degraded in the vacuole.

The release of PMN vesicles at the NV-junctions requires at least three membrane fusion events. Krick et al. reported that the standard homotypic vacuolar fusion machinery is not required for the formation of PMN vesicles. This study indicates the requirement of Cdc48 and its major substrate-recruiting factor Shp1 for efficient PMN 
as well as macroautophagy. The human homologues of Cdc48 / Shp1 p97 / p47 are involved in human mitotic Golgi reassembly. This p97 / p47 complex is thought to extract a monoubiquitylated fusion inhibitor out of membranes and thereby mediate fusion. In this study the involvement of monoubiquitin in PMN as well as macroautophagy could be shown in S. cerevisiae.

The ubiquitin deconjugation enzyme Ubp3 and its cofactor Bre5 are also required for PMN but not for the Cvt-pathway or autophagy. The vps class E genes vps27 and vps28 are also exclusively required for PMN.

So far the fusion of the edges of double-membrane structures leading to autophagosomes was dubious, since neither NSF / Sec18 nor t-SNARES are required. Therefore a novel membrane fusion machinery requiring the Atg proteins has been proposed. In contrast this work supports the function of the previously excluded AAA ${ }^{+}$ATPase Cdc48 in autophagic membrane fusion events. 


\section{Introduction}

\subsection{Yeast as model organism}

The baker's yeast Saccharomyces cerevisiae belongs to the budding fungi. It is a single cell organism that has the typical compartment structure of eukaryotic cells like endoplasmic reticulum (ER), Golgi apparatus, peroxisomes, mitochondria, nucleus and vacuole (a homologue to the animal lysosome). S. cerevisiae cells have a simple lifespan. Two haploid yeast cells with different mating type (a and $\alpha$ ) can mate and form a diploid cell. The diploid cells use mitotic division to bud. Under starvation conditions a meiotic cell division occurs. In this step asci are formed containing 4 haploid spores. These asco-spores are more resistant to environmental influences. A change of growth conditions leads to budding of the spores as haploid yeast cells (Fig. 1).

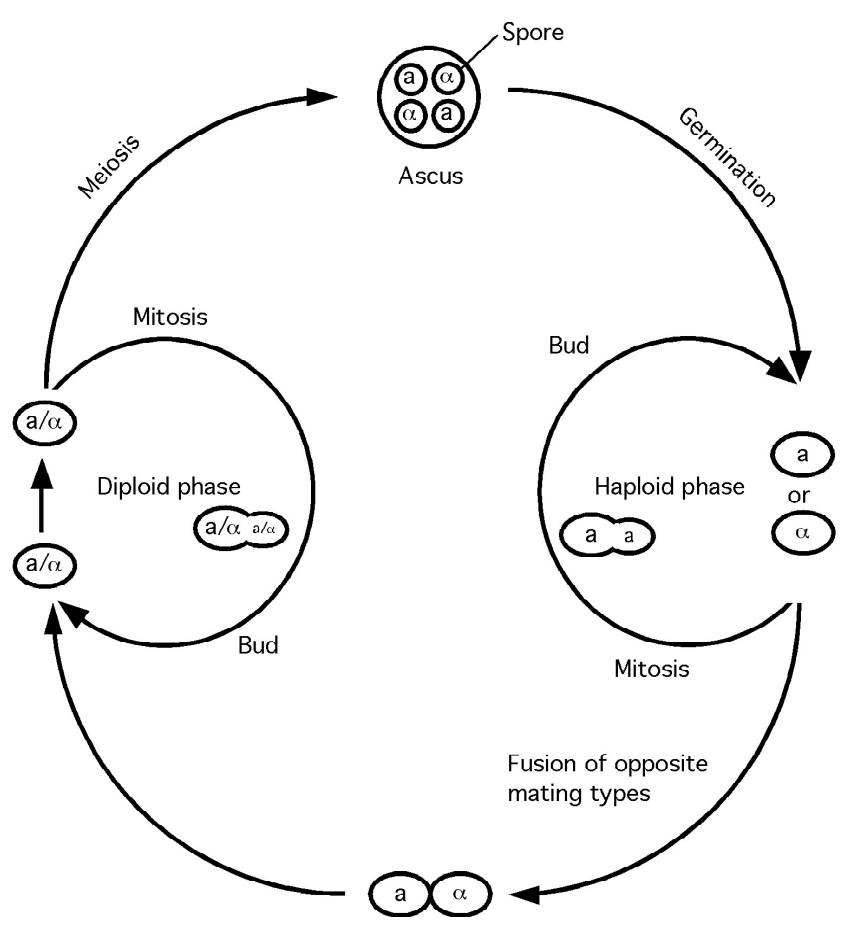

Fig. 1 Life cycle of Saccharomyces cerevisiae

S. cerevisiae has 16 chromosomes consisting of 14 million basepairs with about 6000 open reading frames (Goffeau, 1996). It is an ideal model organism for molecular genetics because of its haploid genome that can be easily modified genetically, its structured cellular compartments and only 90 min doubling time. Information gained in $S$. cerevisiae can often be transferred to higher eukaryotes. 


\subsection{The yeast vacuole}

The yeast vacuole is analogue to lysosomes in mammalian cells. It has an acetic $\mathrm{pH}$ and is rich in hydrolases. The yeast vacuole is the biggest organelle, occupying up to $60 \%$ of the cell volume.

It is involved in a wide variety of physiological processes, including $\mathrm{pH}$ and osmoregulation of the cell. During nitrogen starvation, amino acids are obtained by protein degradation in the vacuole. Diploid yeast cells lacking protease activities fail to sporulate. This indicates the importance of vacuolar proteolysis for survival and differentiation (Raymond, 1992).

\subsection{Delivery of proteins to the vacole}

Proteins can reach the vacuole by four transport routes: secretory pathway, endocytosis, multivesicular body (MVB) and autophagic pathways. Vacuolar resident proteins are either transported by the secretory, the MVB or the cytoplasm to vacuole targeting (Cvt) pathway, a selective variant of autophagy. Endocytosis and autophagic processes transport proteins and whole organelles destined for degradation to the vacuole.

\subsection{The secretory pathway}

In eukaryotic cells the secretory pathway is used to sort and transport proteins from their site of synthesis to several intracellular organelles, the plasma membrane or the periplasm. Proteins are synthesized on ER-bound ribosomes and translocated into the lumen of the ER. These proteins have an amino terminal clevage or noncleavage internal hydrophobic signal which targets the proteins to the ER membrane (Rapoport, 1996). Cleavage of the signal sequence releases the proteins into the ER lumen. $\mathrm{N}$-liked carbohydrate addition occurs co-translationally. Proteins are then transported via vesicles to the Golgi complex, where they undergo additional posttranslational modifications of the carbohydrate side chains before their transport to the trans-Golgi network. 


\subsection{Autophagy}

In eukaryotes autophagy is a highly conserved process. It has been morphologically identified in the 1960s in mammalian cells. One breakthrough studying the molecular basis of autophagy was the identification of the first genes involved in this process (Tsukada and Ohsumi, 1993) (Thumm, 1994) in S. cerevisiae. These genes were termed autophagy-related (ATG) genes (Klionsky, 2003). Further ATG genes have been discovered studying cytoplasm to vacuole targeting (Cvt) pathway and pexophagy (peroxisome degradation) in S. cerevisiae and Pichia pastoris (Harding, 1995) (Yuan, 1997).

Up to now 31 ATG genes have been identified and most of them are required for all autophagic processes (except chaperone-mediated autophagy).

\subsubsection{Relevance of autophagy in eukaryots}

Cellular growth and cell development require well regulated protein synthesis as well as degradation. Eukaryotic cells have two different protein degradation pathways: the ubiquitin-proteasome degradation system and autophagy. Proteasomal degradation is constantly active and degrades short-lived proteins, which are polyubiquitinated. Autophagy in contrast is induced by nutrient limitation and degrades unselective cellular proteins and whole organelles. The recycling of these non-essential protein components allows the cell to synthesize proteins that are essential for survival under nutrient limited conditions. Besides cellular homeostasis (Yorimitsu and Klionsky, 2005), autophagy is involved in cellular processes like autophagic programmed cell death (Yu, 2006), organelle homeostasis (Monastyrska and Klionsky, 2006), developmental processes (Ma, 2007) or ageing (Levine and Kroemer, 2009) (Mariño and López-Otín, 2008).

Autophagy is also implicated in many human diseases, like breast, ovarian and prostate cancer (Chen and Karantza-Wadsworth, 2009), pathogen infections (Orvedahl and Levine, 2009), fungal pathogens (Palmer, 2008), cardiomyopathy (Nishida, 2009) and neurodegenerative diseases like Alzheimer's, Parkinson's and Huntington's (Rubinsztein, 2005). 


\subsubsection{Autophagic processes}

Autophagic processes can be divided in three fundamentally different subtypes (Fig. 2): microautophagy, macroautophagiy and chaperone-mediated autophagy. For macroautophagic processes double membrane-layered vesicles are formed which contain diverse cargos (chapter 3.5.11). By fusion with the vacuolar membrane, a still monolayered vesicle is released into the vacuole, where it is degraded (chapter 3.5.12.).

During microautophagic processes invaginations of the vacuolar membrane are formed (chapter 3.5.15, 3.5.16 and 3.5.18). Chaperone-mediated autophagy is a mechanism allowing the degradation of cytosolic proteins via a protein complex in the lysosomal membrane (chapter 3.5.14) (Massey, 2004), (Majeski and Dice, 2004).

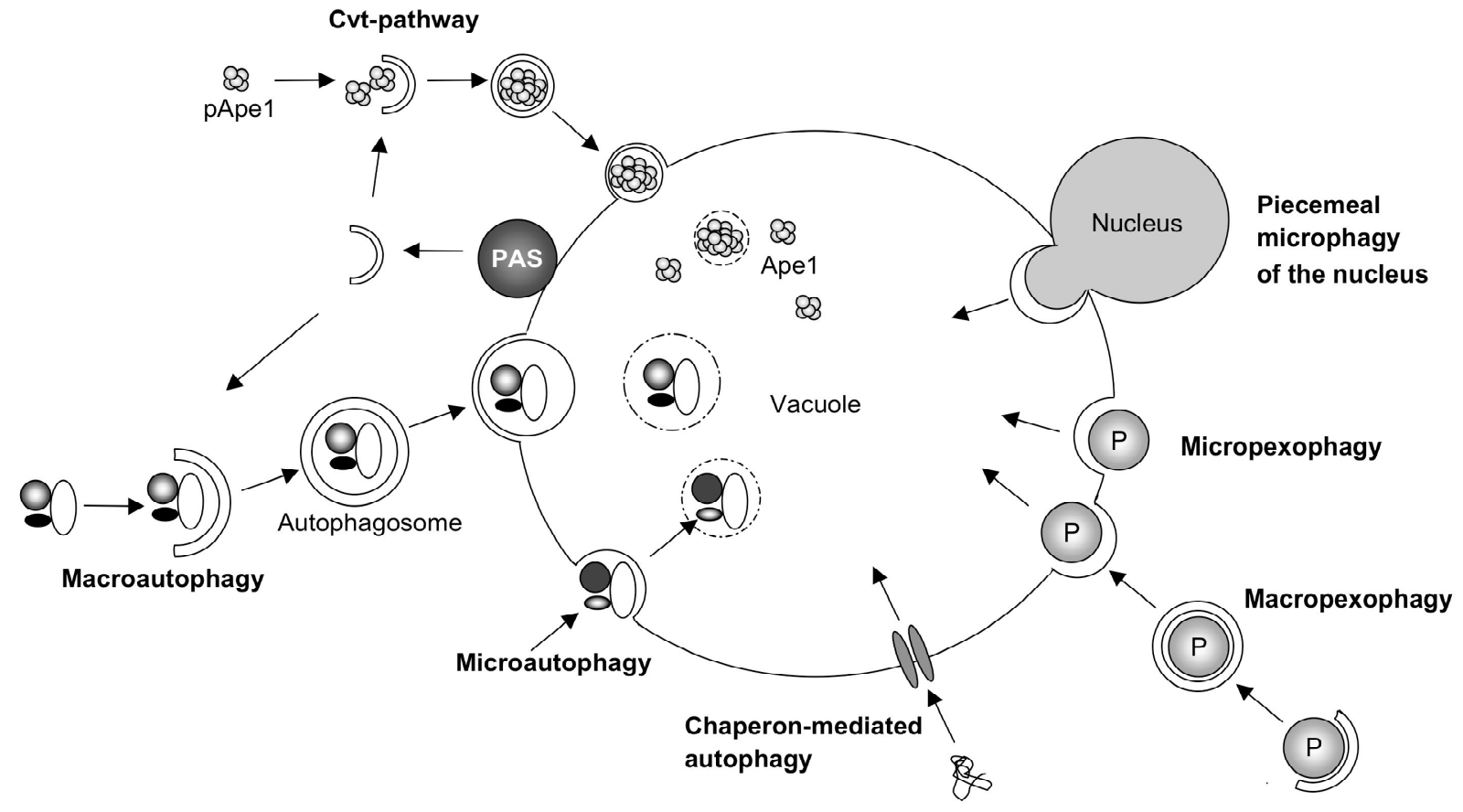

Fig. 2 Schematic diagram of autophagy-related pathways ((Huang and Klionsky, 2007) (Mühe, 2007); modified)

\subsubsection{The autophagic machinery}

The molecular machinerie of autophagy identified in yeast is also conserved in other eukaryotic cells. In S. cerevisiae the autophagic process can be separated into different steps: induction, vesicle nucleation, cargo recognition (for specific types of autophagy) and packaging, vesicle expansion and completion, Atg protein cycling, vesicle fusion with the vacuole, vesicle breakdown and cargo recycling. For example, 
the Atg1 kinase complex is involved in induction, Atg11 and Atg19 are required for cargo recognition, Atg8 and Atg12 ubiquitin like conjugation systems are involved in vesicle formation and Atg23 and Atg27 are proteins participating in the Atg9 cycling step (Yorimitsu and Klionsky, 2005) (Xie and Klionsky, 2007).

\subsubsection{The pre-autophagosomal structure (PAS)}

Fluorescence microscopy has shown that most Atg proteins localize to the preautophagosomal structure (PAS), which is considered to be the site of Cvt vesicle and autophagosome formation (Suzuki, 2001) (Suzuki, 2007). 16 ATG genes are essential for autophagosome formation (Atg1-Atg18 except Atg11 and Atg15) and all of these proteins show a PAS localization.

\subsubsection{Regulation and induction of autophagy}

Autophagy occurs at a basal level in growing cells but is induced by nutrient starvation, including nitrogen and carbon depletion. The protein kinase target of rapamycin (Tor) is a regulator that responds to the nitrogen level. Under nutrient-rich conditions, Tor kinase is active and inhibits autophagy, whereas Tor is inactive under nutrient-deficient conditions and autophagy is induced (Fig. 3). Tor kinase regulates the phosphorylation state of Atg13, which is important for the formation of the Atg1Atg13 complex. Atg13 is required for autophagy but not necessary for the Cvtpathway (Funakoshi, 1997) in contrast Atg1, a serine / threonine protein kinase, is essential for both, the Cvt-pathway and autophagy. For Atg1 and its kinase activity a more regulatory (Kamada, 2000) or structural role (Abeliovich, 2003) has been proposed, but this is still under debate. The Atg1-Atg13 complex interacts with several proteins as Vac8, Atg11, Atg20, Atg24 and Atg17, that is only strictly required

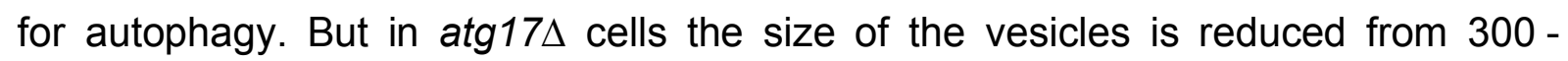
$600 \mathrm{~nm}$ to $200 \mathrm{~nm}$, causing a dramatic reduction in bulk autophagy because Atg17 acts as a scaffold protein in PAS organization (chapter 3.5.10 and 3.5.11) (Kabeya, 2005) (Cheong, 2005) (Suzuki, 2007). The interaction of Atg1-Atg13-Atg17 seems to be involved in size determination of the vesicles (Yorimitsu and Klionsky, 2005). The interaction of Atg17 with Atg29 and Atg31, both autophagy specific genes, has an 
essential function in the organisation of the PAS for autophagosome formation (Kawamata, 2008). Atg11 is only required for the Cvt-pathway.

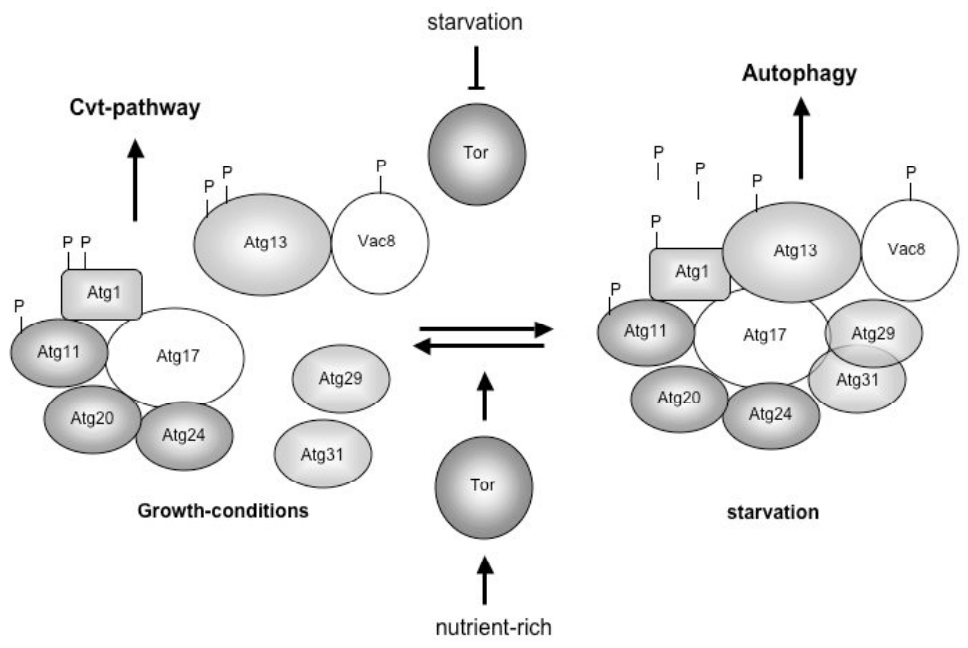

Fig. 3 Regulatory complex for autophagy induction

Atg20, Atg24, Atg11 and Vac8 might also be involved in autophagic induction, but a complete holocomplex has not been identified. ((Yorimitsu and Klionsky, 2005); modified)

\subsubsection{The two ubiquitin like conjugation systems}

Both ubiquitin like conjugation systems are highly conserved in eukaryots and required for the biogenesis of autophagosomes.

\subsubsection{The Atg8-phosphatidylethanolamine conjugation system}

Atg8 consists of 117 amino acids and has a molecular weight of $13.6 \mathrm{kDa}$. Homologues of Atg8 are found from yeast to human (Lang, 1998) (Elazar, 2003). The structures of the mammalian homologues revealed that Atg8 family members contain two domains: an N-terminal helical domain (NHD; aa 1 - 24) and a C-terminal ubiquitin-like domain (ULD; aa 24 -117) (Fig. 4) (Paz, 2000) (Coyle, 2002) (Sugawara, 2004) (Nakatogawa, 2007).

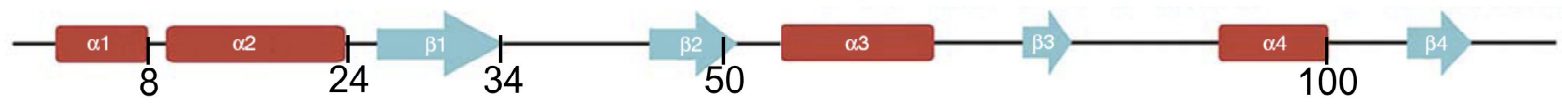

Fig. 4 Model of the three-dimensional structure of Atg8 ((Amar, 2006); modified) 
Atg8 is coupled via an ubiquitine like reaction to phosphatidylethanolamine (PE) (Ichimura, 2000). The cystein protease Atg4 removes a C-terminal arginine residue of Atg8, exposing a glycine that is now accessible to the E1-like Atg7. Atg7 activates Atg8, that is then transferred to the E2 like Atg3 and in a second step covalently coupled to PE through an amide bond. Atg8-PE is located to the inside and outside of the forming and completed autophagosomes but the coupling of Atg8 to PE is a reversible event. Atg8 can be cleaved of from the outer membrane of the completed vesicle by Atg4 and be reused (Fig. 5). Atg8 is used as marker protein for autophagosomes.

Atg21 is required for the efficient conjugation of Atg8 to PE under Cvt conditions whereas the specificity depends on the intracellular milieus such as cytosolic $\mathrm{pH}$ and acidic phospholipids (Strømhaug, 2004) (Oh-oka, 2008).

In an in vitro system Atg8 mediates the tethering and hemifusion of membranes, what is modulated by the deconjugation enzyme Atg4. These membrane-tethering and hemifusion activities of Atg8 are required for the expansion of the autophagosomal membranes (Nakatogawa, 2007).

\subsubsection{The Atg12-Atg5 conjugation sytem}

During the coupling of Atg12 to Atg5 an irreversible isopeptide bond is formed (Mizushima, 1998). Two additional proteins are required for its formation. The E1 like Atg7 and Atg10 which functions like an E2 ubiquitin-conjugating enzyme. The Atg12Atg5 conjugate binds Atg16 and forms a homo-oligomer, which is functionally important for autophagy (Fig. 5) (Kuma, 2002). 


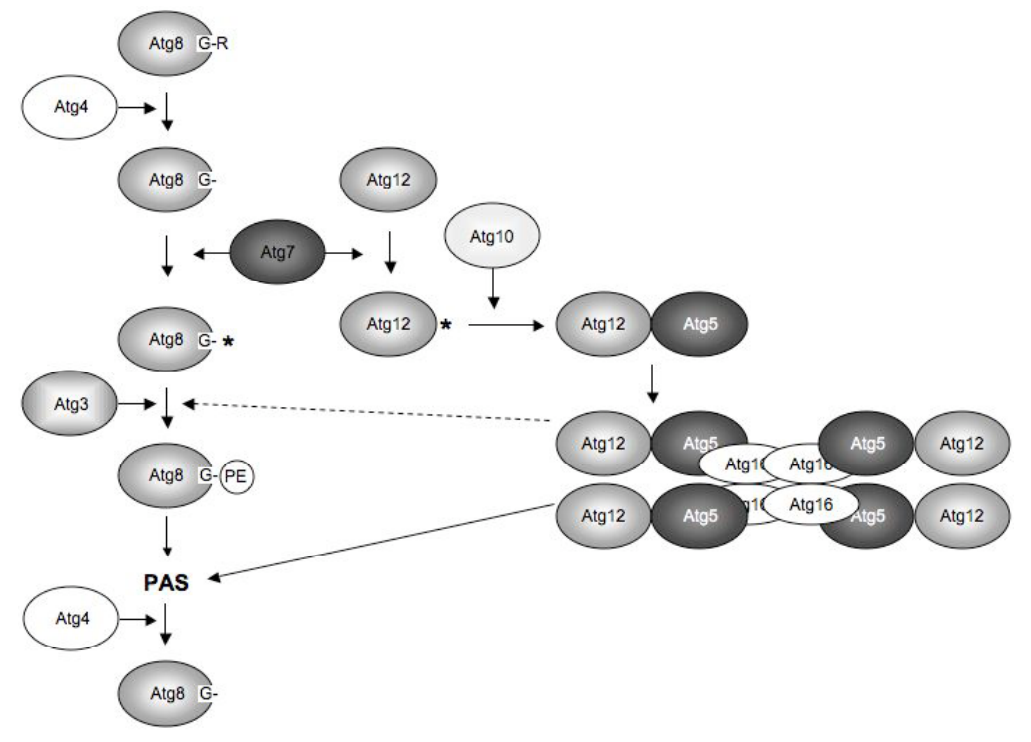

Fig. 5 The two conjugation machineries ((Yorimitsu and Klionsky, 2005); modified)

\subsubsection{The two phosphatidylinositol-3-kinase (PI3K) complexes}

Vps34, the only phosphatidylinositol 3-phosphate (Ptdlns(3)P)-kinase in yeast, is required for autophagy. It formes two complexes: Complex I and Complex II (Kihara, 2001). Complex I consists of Vps34, Atg14, Atg6/Vps30 and Vps15 and is required for the Cvt-pathway as well as autophagy. Complex II contains the same proteins, except that Atg14 is replaced by Vps38 (Fig. 6). Vps384 cells show defects in carboxypeptidase $Y$ (CPY; Pcr1) sorting and the MVB-pathway, but no autophagic defects (Kihara, 2001).

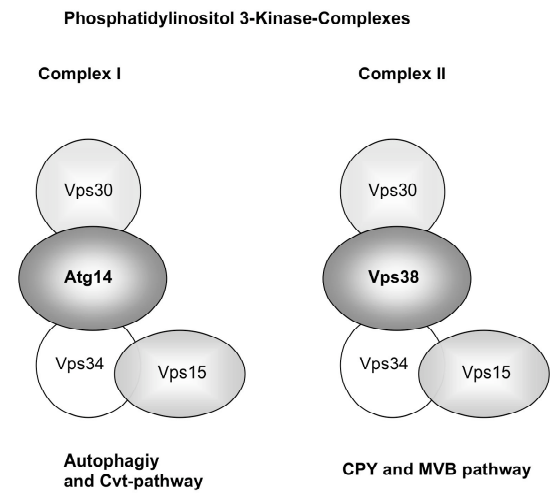

Fig. 6 The two Vps34 complexes in yeast ((Yorimitsu and Klionsky, 2005); modified) 


\subsubsection{The Atg18, Atg21 and Ygr223c protein family}

Atg18, Atg21 and Ygr223c are highly homologous proteins, but have distinct functions in autophagy. Atg18 is essential for macroautophagy, the Cvt-pathway and micronucleophagy, while the function of Atg21 is restricted to the Cvt-pathway and micronucleophagy (Barth, 2001) (Barth, 2002). Ygr223c, a third member of this family of homologous proteins, is only required for efficient micronucleophagy (Krick, 2008a). All three proteins have a WD-40 repeat and are expected to fold as seven bladed ß-propellers. As a common function WD-repeat proteins are thought to regulate the assembly of multiprotein complexes (Smith, 1999). All three homologues bind preferentially to Ptdlns(3)P and Ptdlns(3,5) $\mathrm{P}_{2}$ (Krick, 2006) (Krick, 2008a).

Atg2 and Atg18 form a complex, that is dependent on Ptdlns(3)P, Atg1, Atg9, Atg13 and the recruitment of Atg17 to the PAS (Suzuki, 2007). This complex then recruits further Atg proteins to the PAS (Fig. 7) (Obara, 2008b).

\subsubsection{Atg9 cycling}

The integral membrane protein Atg9, containing 6 predicted transmembrane domains, cycles in S. cerevisiae between the PAS and a peripheral pool. Its origin is still under debate. In yeast the peripheral pool has in part been localized to mitochondria (Reggiori, 2005) but in contrast to the yeast system, mammalian Atg9 cycles between the TGN (trans Golgi network) and late endosomes (Young, 2006) but not mitochondria (Yamada, 2005).

In yeast the anterograde transport from mitochondria to the PAS depends on Atg11, Atg23, Atg27, a functional VTF complex, the early secretory pathway and actin. The retrograde transport requires the Atg1-Atg13-complex, a functional Vps34 kinase complex I and the Atg2-Atg18 complex (Fig. 7) (Reggiori and Klionsky, 2006) (He, 2006) (Yen, 2007). This shuttling of Atg9 could contribute to the delivery of membrane material to the PAS (Reggiori, 2005). 


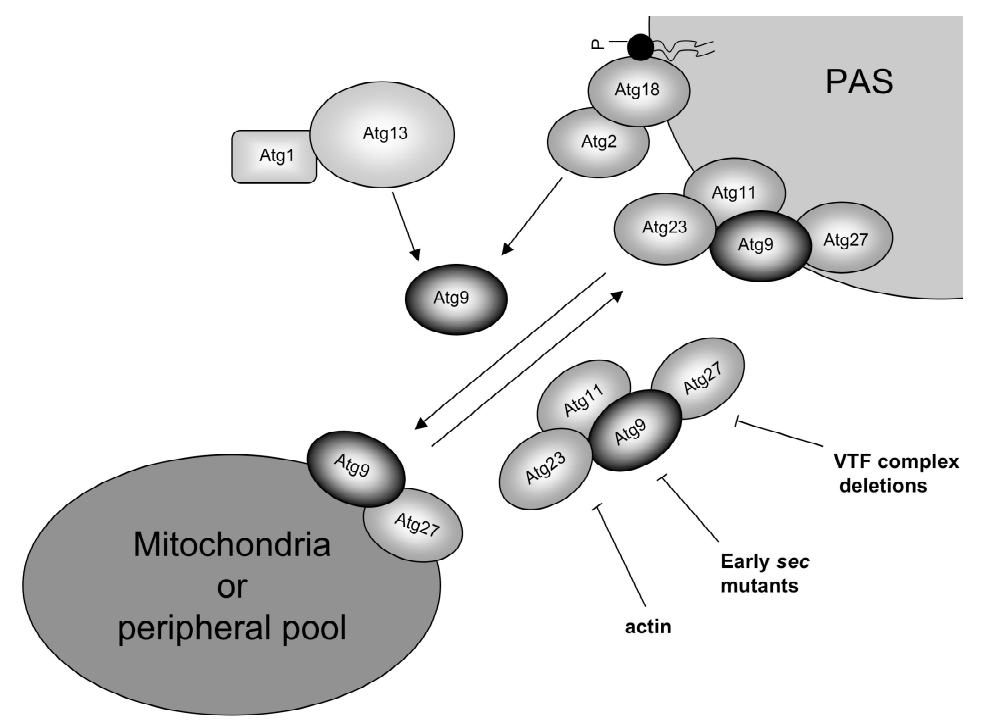

Fig. 7 Cycling of S. cerevisiae Atg9 between the PAS and a peripheral pool ((He, 2006) (Reggiori and Klionsky, 2006) (Yen, 2007); modified)

Atg27 was described as an effector of Vps34, the only Ptdlns 3-kinase in S. cerevisiae (Wurmser and Emr, 2002). Due to a sequencing error in the Saccharomyces Genome Database, the full length Atg27 contains 75 additional amino acids at the $\mathrm{N}$ terminus and is a transmembrane protein described to locate at the PAS, the mitochondria and the Golgi complex (Yen, 2007). The earlier detected Ptdlns(3)P binding site of Atg27 does either not bind Ptdlns(3)P or is at least not required for its localization (Yen, 2007). In $\operatorname{atg} 1 \Delta$ atg27 $\Delta$ double mutant cells the localization of Atg9 to a peripheral pool, which corresponds in part to mitochondria, is increased (Yen, 2007).

\subsubsection{The Cvt-pathway}

The Cvt-pathway is a selective transport pathway process of at least two specific cargoes the resident vacuolar hydrolases, aminopeptidase I (Ape1) and $\alpha$ mannosidase (Ams1) (Scott, 1997) (Hutchins and Klionsky, 2001). The Ape1 protein is synthesized as a pro form (pApe1) in the cytosol, where it forms a dodecameric complex that further assembles to a large oligomeric structure, called Ape1-complex. The Ape1-receptor protein Atg19 binds to the Ape1-complex to form the Cvtcomplex, which is dependent on Atg11 dependent recruited to the PAS (preautophagosomal structure). This complex is sequestered within a double membrane layered vesicle. These vesicles are formed at the PAS and have a consistent size of 140 - $160 \mathrm{~nm}$ in diameter and exclude bulk cytosolic material (Baba, 1997) (Fig. 2). 
The Cvt vesicles fuse with the vacuole and a single-membrane vesicle (Cvt body) is released into the vacuolar lumen. The Cvt body is lysed and pApe1 is matured (mApe1).

\subsubsection{Macroautophagy}

Macroautophagy is a starvation induced degradative protein transport pathway. Autophagosomes are also formed at the PAS, but in contrast to the selective Cvtpathway, autophagosomes contain unspecific cytosolic material and whole organelles. Completed autophagosomes, measuring $300-900 \mathrm{~nm}$ in diameter, fuse with the vacuole and a single-membrane vesicle (autophagic body) is released into the lumen and degraded (Baba, 1994).

\subsubsection{Fusion and breakdown of vesicles in the vacuole}

The fusion of autophagosomes as well as Cvt vesicles with the vacuole requires the homotypic vacuolar fusion machinery. The degradation of the monolayered vesicles in the vacuole is dependent on two vacuolar proteases (Pep4 and Prb1) and an acidification of the vacuole (Takeshige, 1992) (Nakamura, 1997). Additionally the transmembrane protein Atg15 is required for the lysis step (Epple, 2001). Atg15 has a conserved lipase motive and is transported to the vacuole via the multi vesicular body (MVB) pathway (Epple, 2003).

The autophagosomal cargo is degraded, recycled and reused for the synthesis of proteins essential for survival.

Atg22 was described to be involved in the lysis step (Suriapranata, 2000). Recent reports point to an indirect role of Atg22 in the breakdown of the autophagic bodies inside the vacuole. Indeed Yang et al. demonstrated that Atg22 is a partially redundant vacuolar effluxer, that mediates the efflux of leucine resulting from autophagic degradation (Yang, 2006). The supply of amino acids by autophagy allows the maintenance of protein synthesis and viability during nitrogen starvation. Cells respond to nitrogen starvation by up-regulation of genes, including those for vacuolar proteases (such as Pep4, Prb1, and Prc1) (Gasch, 2000). Therefore atg22 cells lack leucine for the production of these proteases leading to indirect stabilization of the vesicles (Yang, 2006). 


\subsubsection{Chaperon-mediated autophagy}

Chaperone-mediated autophagy allows the degradation of cytosolic proteins that contain a particular pentapeptide consensus motif (KFERQ) via a protein complex in the lysosomal membrane (Massey, 2004), (Majeski and Dice, 2004) (Fig. 2). In human cell lines chaperone-mediated autophagy modulates the neuronal survival machinery. Dysregulation of this pathway is associated with Parkinson's disease (Yang, 2009). At present chaperone-mediated autophagy has only been discovered in mammalian cells. There is no similar process described in S. cerevisiae so far (Klionsky, 2007).

\subsubsection{Microautophagy}

During microautophagy, cytosolic components are directly engulfed by the vacuole by invagination of the organelle's limiting membrane (Fig. 2).

\subsubsection{Pexophagy}

Peroxisomes are cell organelles important for the lipid metabolism. Peroxisomes differ in size and number dependent on physiological conditions of the cell. A shift from methanol to glucose containing medium induces the selective microautophagic degradation of peroxisomes. Micropexophagy is best characterized in the methylotrophic yeast Pichia pastoris (Farré and Subramani, 2004) (Dunn, 2005) (Sakai, 2006) and has not been described in S. cerevisiae so far.

Macroautophagy and micropexophagy are morphologically very different processes (Fig. 2), but both depend on the same set of core Atg proteins. Micropexophagy requires an additional set of specific Atg proteins (e.g. Atg25, Atg26, Atg28, Atg30, Gcn1-3 and Pfk1) (Dunn, 2005) (Farré, 2008). During engulfment arm like extensions of the vacuolar membrane are formed around the peroxisome. The MIPA (micropexophagy-specific membrane apparatus), a double membrane cap-like structure, containing Atg8 and Atg26, is formed at the far end of the encircled peroxisome, where it is thought to mediate the vacuolar membrane fusion event (Dunn, 2005). 


\subsubsection{Mitophagy}

Mitophagy is a selctive variant of autophagy that degrades defective mitochondria and is reported to be involved in the cell death process (Tal, 2007). The mitochondrial protein Uth1 is selectively involved in mitophagy (Kissová, 2004). Additionally, Aup1 is required for efficient mitophagy. It localizes to the mitochondrial intermembrane space and may be part of a signal transduction mechanism that marks mitochondria for sequestration into autophagosomes (Tal, 2007). Primarily, Aup1 was identified in a screen for protein phosphatase homologues that functionally interact with Atg1 in yeast.

\subsubsection{Micronucleophagy (PMN)}

Piecemeal microautophagy of the nucleus (PMN) is a microautophagic process and was therefore named micronucleophagy (Krick, 2009).

Micronucleophagy occurs at nucleus vacuole (NV) junctions, that are formed by interactions between Vac8 in the vacuolar membrane and Nvj1 in the inner and outer nuclear membrane (Pan, 2000) (Roberts, 2003) (Millen, 2008). During PMN a portion of the nucleus is extruded along the NV junctions into an invagination of the vacuolar membrane, forming a tethered bleb. Scission of the ER and fusion of the vacuolar membrane then releases a PMN vesicle into the vacuolar lumen, where it is degraded by resident hydrolases (Kvam and Goldfarb, 2007). The intravacuolar PMN vesicles are limited by three membrane layers. The outer membrane is derived from the vacuolar membrane, and the two inner layers from the nuclear envelope (Fig. 8).

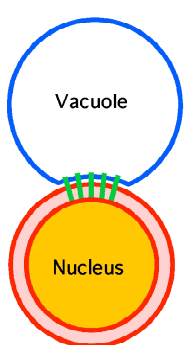

I

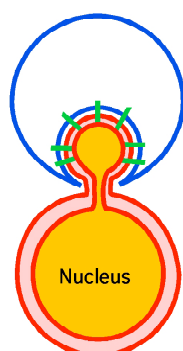

II

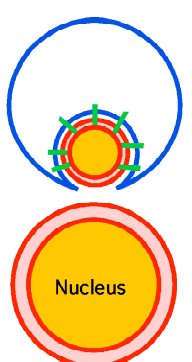

III

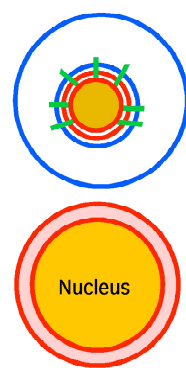

IV

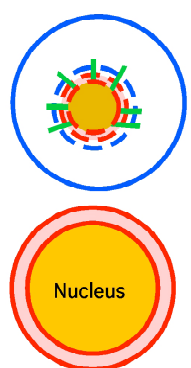

$\mathrm{V}$

Fig. 8 Schematic illustration of PMN

In stage I nucleus-vacuole (NV) junctions form. Then the nuclear ER bulges into invaginations of the vacuolar membrane (stage II), followed by fission of an ER-deduced vesicle (stage III). After fusion at the tips of the vacuolar membrane extensions (stage IV), a PMN vesicle is released into the vacuolar lumen, where it is finally degraded (stage V) ((Krick, 2008b); modified) 
PMN is induced by nutrient depletion and degrades nonessential portions of the nucleus (Krick, 2008b). Nvj1 recruits at least two additional proteins to the NV junctions: Tsc13 an enoyl-CoA reductase required for the synthesis of very-longchain fatty acids and Osh1 a homologoue to mammalian oxysterol-binding protein (OSBP) that may function in nonvesicular lipid trafficking (Fig. 9) (Kvam, 2005) (Kvam and Goldfarb, 2004).

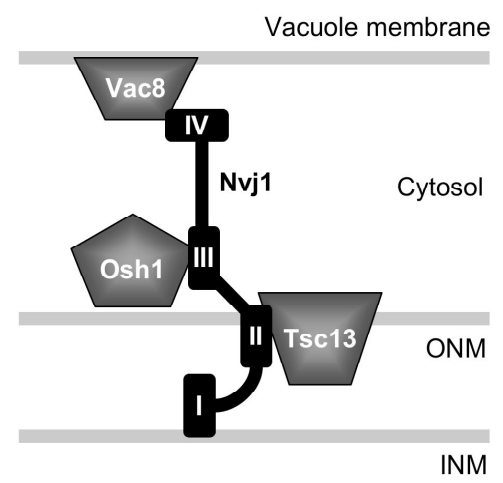

Fig. 9 Model of molecular composition of NV-junctions

The hydrophobic $\mathrm{N}$-terminus of Nvj1p links the inner- and outer-nuclear membranes by direct insertion (Millen, 2008). ONM = outer nuclear membrane; IMN = inner nuclear membrane ((Kvam and Goldfarb, 2006a); modified)

PMN has been categorized as an autophagic process based on morphological criteria and its induction under starvation conditions (Kvam and Goldfarb, 2007). First analysis by the Goldfarb lab neglected the involvement of the autophagic machinery in PMN. They measured the degradation of Nvj1-EYFP by western blot. Wild type and $\operatorname{atg} 7 \Delta$ cells showed a slight reduction in the Nvj1-EYFP band but in pep4 $\mathrm{Nvj1-}$ EYFP was stabilized (Roberts, 2003).

In contrast Krick et al. showed using two independent biochemical assays that the efficient production of PMN vesicles depends on the core Atg proteins (Krick, 2008b). They used Nvj1-GFP and GFP-Osh1 as marker proteins and followed their degradation in the vacuole by detection of free GFP. Free GFP accumulates in the vacuole because of its resistance to vacuolar hydrolases.

\subsection{Membrane fusion}

Eukaryotic cells contain membrane-enclosed organelles that exchange proteins and lipids through vesicular transport.

SNAREs (soluble $N$-ethylmaleimide-sensitive factor attachment protein receptor) 
have been identified as key components to drive membrane fusion. They localize to the vesicle and the acceptor membrane. During fusion the SNAREs on both membranes form a four helix bundle. The energy required for membrane fusion is provided by the free energy released during formation of the bundle (Jahn and Scheller, 2006).

SNAREs contain a 60 - 70 amino acids conserved SNARE motif. At their C-terminal ends most SNAREs have a single transmembrane domain that is connected to the SNARE motif by a short linker. Dependent on the presence of arginine or glutamine in the SNARE motif they are called R- or Q-SNAREs (Fasshauer, 1998). Functional SNARE complexes are hetero-oligomeric, parallel four-helix bundles, requiring one of each Qa-, Qb-, Qc- and R-SNAREs (Jahn and Scheller, 2006).

After fusion SNARE complexes exist in a biologically inactive configuration until the complex is dissociated. This recycling of SNARE complexes is mediated by the AAA $^{+}$ (ATPases associated with various cellular activities) protein NSF ( $N$-ethylmaleimidesensitive factor) by the dissociation of the helical bundle. To interact with SNAREs NSF requires a cofactor, the soluble NSF attachment protein ( $\alpha$-SNAP) (Fig. 10). In yeast the homologue of NSF is the Sec18 protein and Sec17 the corresponding $\alpha$ SNAP.

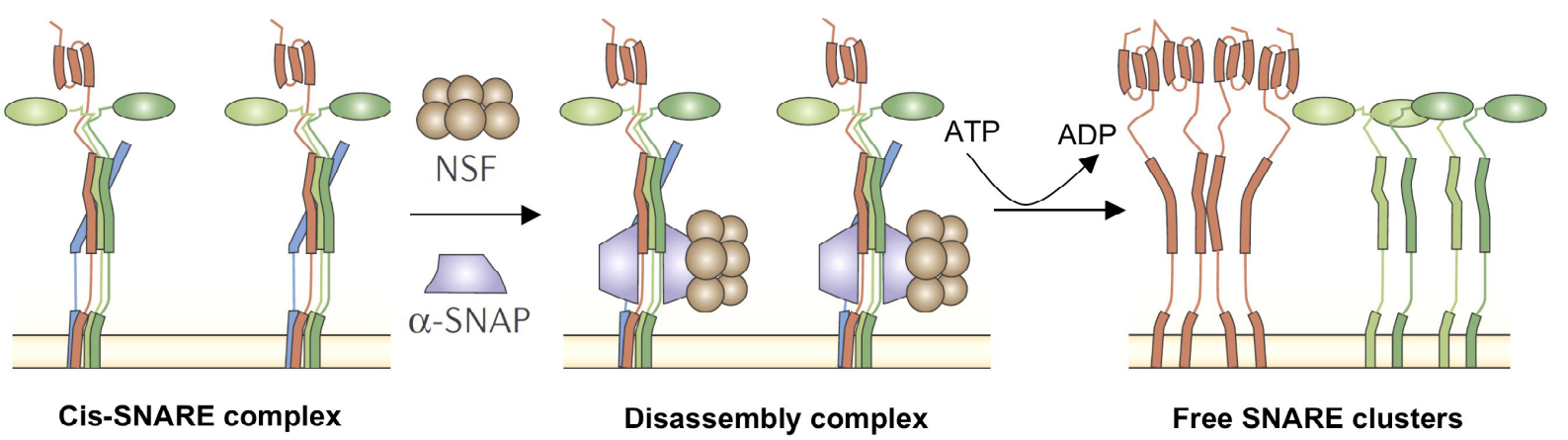

Fig. 10 SNARE disassembly after fusion

During fusion, the trans-complex relaxes into a cis-configuration. Cis-complexes are disassembled by the AAA+ (ATPases associated with various cellular activities) protein NSF ( $N$-ethylmaleimidesensitive factor) together with SNAPs (soluble NSF attachment proteins) that function as cofactors. ((Jahn and Scheller, 2006); modified) 


\subsubsection{Cdc48 dependent membrane fusion}

Cdc48 (the homologue of p97 in mammals) belongs to the family of AAA ${ }^{+}$ATPases (ATPases associated with various cellular activities). It is a highly conserved protein involved in many different cellular processes, including ubiquitin-dependent protein degradation, fusion of homotypic membranes, nuclear envelope reassembly and cell cycle progression (Schuberth, 2004) (Wang, 2004a) (Woodman, 2003).

The molecular mechanism of Cdc48/p97 action in all these processes is believed to be its "segregase" activity (Braun, 2002). Cdc48/p97 uses the energy provided by ATP hydrolysis to extract substrate proteins from protein complexes or lipid membranes (Schuberth and Buchberger, 2008).

In order to provide specificity for its various cellular functions, Cdc48/p97 activity is tightly regulated by numerous different cofactors in the cell (Tab. 1).

Tab. 1 Classification of Cdc48 cofactors in yeast

\begin{tabular}{|c|c|c|}
\hline Type of cofactor & Identified proteins & Function \\
\hline $\begin{array}{l}\text { Substrate-recruiting } \\
\text { - major }\end{array}$ & $\begin{array}{l}\text { Ufd1-Npl4 } \\
\text { Shp1 }\end{array}$ & $\begin{array}{l}\text { Decision between major } \\
\text { cellular pathways: protein } \\
\text { degradation versus membrane } \\
\text { fusion (and others) }\end{array}$ \\
\hline $\begin{array}{l}\text { Substrate-recruiting } \\
\text { - additional }\end{array}$ & $\begin{array}{l}\text { Ubx2, Ubx5, Dfm1*, } \\
\text { Der1* }\end{array}$ & $\begin{array}{l}\text { Co-adaptors for specific } \\
\text { pathways: improve substrate } \\
\text { binding and/or provide } \\
\text { additional spatial regulation }\end{array}$ \\
\hline Substrate-processing & Otu1, Ufd2, Ufd3 & $\begin{array}{l}\text { Additional enzymatic activities; } \\
\text { Regulation of substrate fate: } \\
\text { stabilization versus } \\
\text { degradation }\end{array}$ \\
\hline
\end{tabular}

*protein with functional human homologues ((Schuberth and Buchberger, 2008); modified)

The UBX proteins are one family of such cofactors. The UBX domain is a general Cdc48/p97-binding module (Decottignies, 2004) (Hartmann-Petersen, 2004). Cdc48/p97 can either bind directly to ubiquitin or the UBX domain, which turned out to be a close structural homologue of ubiquitin itself (Buchberger, 2001). In yeast there are seven UBX proteins and three of them possess an amino-terminal UBA domain, which binds ubiquitylated proteins in vivo (Schuberth, 2004) (Fig. 11). 


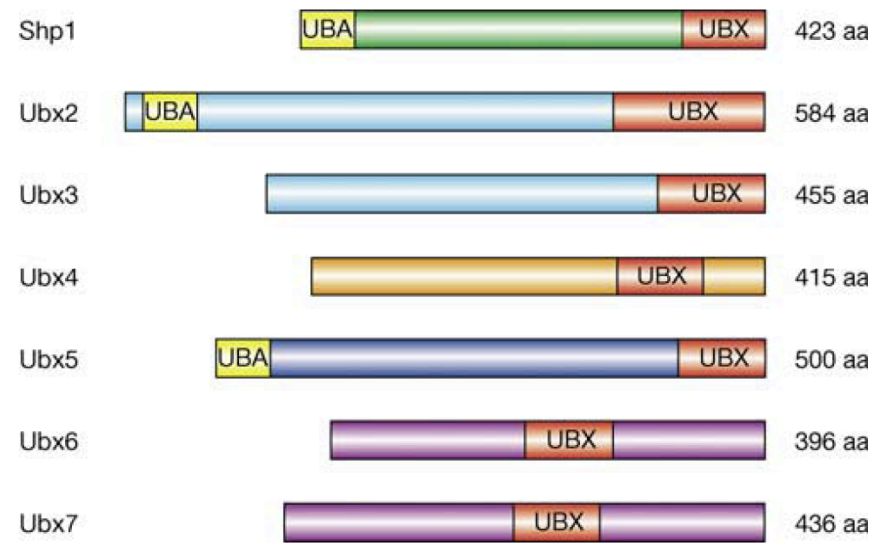

Fig. 11 UBX proteins of $S$. cerevisiae

UBX (red) and UBA (yellow) domains are labelled. Significant homology outside these domains is indicated by similar colours. Shp1 (alias Ubx1); Ubx2 (alias Sel1); (taken from (Schuberth, 2004))

During the homotypic fusion of Golgi and ER membranes, Cdc48/p97 was suggested to act on mono- ubiquitinated substrates during the remodeling of SNARE complexes and/or their regulators (Latterich, 1995) (Rabouille, 1998) (Wang, 2004b). The required cofactor of the mamalian p97 is p47 (Fig. 12) (Kondo, 1997) and the corresponding yeast homologue is Shp1.

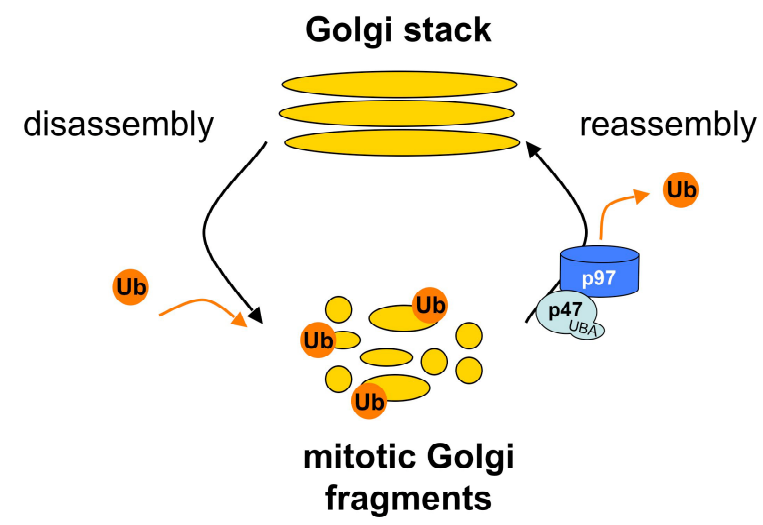

Fig. 12 p97 - Golgi membrane reassembly in humans ((Meyer, 2005); modified)

For the degradation of ubiquitinated protein substrates out of the ER Cdc48/p97 interacts with the heterodimeric substrate-recruiting cofactor Ufd1/Npl4. Simultaneous binding of Cdc48-Ufd1-Npl4 to the ER-membrane protein complex and the poly-ubiquitin chain on the substrate seems to trigger the segregase activity of Cdc48 which pulls substrates out of the ER (Braun, 2002) (Meyer, 2000) (Ye, 2001) (Jarosch, 2002) (Raasi and Wolf, 2007).

In the literature these two major functional distinct CDC48 complexes have been described. 
In contrast to the previously described function in membrane fusion shp1 $\Delta$ cells have been found to exhibit defects in ubiquitin-dependent degradation pathways (Schuberth, 2004). Furthermore the p97 Ufd1-Npl4 complex is involved in the reformation of the nuclear envelope double-membrane structure after mitosis (Anderson and Hetzer, 2007).

\subsection{Aim of the study}

I. Autophagy starts at the pre- autophagosomal structure (PAS). Out of this structure double membrane layered vesicles are formed and transported to the vacuole, where their outer membranes fuse with the vacuole, releasing a monolayered vesicle into the vacuolar lumen. The PAS is believed to be an organelle-like membrane structure. The origin of the membrane source for the formation of Cvt- and autophagic vesicles is still unclear. The transmembrane protein Atg9 is supposed to be involved in the transport of membranes from a peripheral pool to the PAS, where the vesicles are formed. Aim of this study was to investigate the localization and characteristics of this peripheral pool.

II. Micronucleophagy occurs at nucleus-vacuole (NV) junctions and results in the pinching-off and degradation of nonessential portions of the nucleus in the vacuole. In contrast to previous published results biochemical data from the Thumm lab indicated a strict requirement of the autophagic machinery in PMN. Therefore in this study a microscopy based assay should be established to support these results. Furthermore the molecular machinery for the membrane fusion events in autophagy and PMN should be analysed. 


\section{Materials and Methods}

\subsection{Materials}

\subsubsection{Saccharomyces cerevisiae strains}

Tab. 2 S. cerevisiae strains used in this study

\begin{tabular}{|c|c|c|}
\hline Strain & Genotype & Source \\
\hline $\operatorname{atg} 1 \Delta \operatorname{atg} 27 \Delta$ & $\begin{array}{l}\text { WCG4a MAT } \alpha \text { atg1 } 1 \Delta:: \text { KAN } \\
\operatorname{atg} 27 \Delta:: \text { HIS3 }\end{array}$ & This study \\
\hline $\operatorname{atg} 1 \Delta \operatorname{atg} 27 \Delta$ cGFP-Atg 8 & $\begin{array}{l}\text { WCG } 4 a \text { MAT } \alpha \text { atg } 1 \Delta:: \text { KAN } \\
\operatorname{atg} 27 \Delta:: \text { HIS3 cGFP-Atg8 }\end{array}$ & This study \\
\hline $\operatorname{atg} 1 \Delta \operatorname{atg} 27 \Delta$ Snf7-RFP & $\begin{array}{l}\text { WCG4a MATa atg1 } 1:: \text { KAN } \\
\text { atg27 } 2:: \text { HIS3 snf7-RFP::KAN }\end{array}$ & This study \\
\hline $\operatorname{atg} 1 \Delta \operatorname{atg} 4 \Delta$ & $\begin{array}{l}\text { WCG } 4 a \text { MAT } \alpha \text { atg1 } 1 \Delta:: \text { KAN } \\
\text { atg } 4 \Delta:: \text { HIS5 }\end{array}$ & \\
\hline $\operatorname{atg} 1 \Delta \operatorname{atg} 4 \Delta \operatorname{atg} 27 \Delta$ & $\begin{array}{l}\text { WCG } 4 a \text { MAT } \alpha \text { atg } 1 \Delta:: \text { KAN } \\
\text { atg } 4 \Delta:: \text { NAT atg27 } 2:: \text { HIS3 }\end{array}$ & This study \\
\hline $\operatorname{atg} 1 \Delta$ cGFP-Atg 8 & $\begin{array}{l}\text { WCG4a MATa atg1 } 1:: \mathrm{KAN} \\
\text { cGFP-Atg8 }\end{array}$ & This study \\
\hline $\operatorname{atg} 1 \Delta \operatorname{vps} 4 \Delta \operatorname{atg} 27 \Delta$ & $\begin{array}{l}\text { WCG4a MAT } \alpha \text { atg1 } 1 \Delta:: \text { KAN } \\
\text { vps4a::NAT atg27::HIS3 }\end{array}$ & This study \\
\hline $\operatorname{atg} 27 \Delta$ & WCG4a MAT $\alpha$ atg27 $::$ HIS3 & This study \\
\hline $\operatorname{atg} 4 \Delta \operatorname{atg} 27 \Delta$ & $\begin{array}{l}\text { WCG } 4 a \text { MAT } \alpha \text { atg } 4 \Delta:: \text { KAN } \\
\operatorname{atg} 27 \Delta:: \text { HIS3 }\end{array}$ & This study \\
\hline $\operatorname{atg} 8 \Delta$ & WCG4a MAT $\alpha$ atg8s::KAN & AG Thumm \\
\hline aut5delta & WCG4a MAT $\alpha$ atg15 $\triangle::$ KAN & AG Thumm \\
\hline BY4741 & $\begin{array}{l}\text { MATa his } 3 \Delta 1 \text { leu } 2 \Delta 0 \\
\text { met } 15 \Delta 0 \text { ura } 3 \Delta 0\end{array}$ & Euroscarf \\
\hline cdc48.3 BY & $\begin{array}{l}\text { BY } 4741 \text { CDC } 48.3 \\
\text { temperature sensitive at } 36^{\circ} \mathrm{C}\end{array}$ & T. Prick u. E. Welter \\
\hline cdc48.3 WCG & $\begin{array}{l}\text { WCG } 4 \text { a CDC } 48.3 \\
\text { temperature sensitive at } 38^{\circ} \mathrm{C}\end{array}$ & This study \\
\hline $\operatorname{cdc} 48-3$ & $\begin{array}{l}\text { pep } 4 \Delta:: \text { URA } 3 \text { cdc } 48-3 \\
\text { temperature sensitive at } 36^{\circ} \mathrm{C}\end{array}$ & F. Madeo \\
\hline Snf7 & $\begin{array}{l}\text { S288C MATa } \\
\text { Snf7-RFP::KAN }\end{array}$ & Falvo \\
\hline
\end{tabular}




\begin{tabular}{|c|c|c|}
\hline Strain & Genotype & Source \\
\hline WCG4 & $\begin{array}{l}\text { WCG4a MATa his3-11,15 } \\
\text { leu2-3,112 ura3 }\end{array}$ & $\begin{array}{l}\text { W. Heinemeyer, } \\
\text { Stuttgart }\end{array}$ \\
\hline wt cGFP-Atg8 & WCG4a MAT $\alpha$ cGFP-Atg8 & This study \\
\hline Y00379 & BY4741 MATa myo4d::KAN & Euroscarf \\
\hline Y00399 & BY4741 MATa spo7d::KAN & Euroscarf \\
\hline Y00560 & BY4741 MATa sel14::KAN & Euroscarf \\
\hline Y01375 & BY4741 MATa $u b x 6 \Delta::$ KAN & Euroscarf \\
\hline Y01481 & BY4741 MATa ice $2 \Delta:: K A N$ & Euroscarf \\
\hline Y02763 & BY4741 MATa vps28 $2:: K A N$ & Euroscarf \\
\hline Y03084 & BY4741 MATa shp1A::KAN & Euroscarf \\
\hline Y03269 & BY4741 MATa she3A::KAN & Euroscarf \\
\hline Y03298 & BY4741 MATa ifa38 $\Delta::$ KAN & Euroscarf \\
\hline Y03341 & BY4741 MATa der1 $1::$ KAN & Euroscarf \\
\hline Y03592 & BY4741 MATa rtn1 $\Delta:: K A N$ & Euroscarf \\
\hline Y03698 & BY4741 MATa $u b x 5 \Delta::$ KAN & Euroscarf \\
\hline Y03788 & BY4741 MATa $u b x 3 \Delta::$ KAN & Euroscarf \\
\hline Y03888 & BY4741 MATa ufd2A::KAN & Euroscarf \\
\hline Y04004 & BY4741 MATa doa44::KAN & Euroscarf \\
\hline Y04247 & BY4741 MATa $d f m 1 \Delta::$ KAN & Euroscarf \\
\hline Y04980 & BY4741 MATa she2 $\Delta:: \mathrm{KAN}$ & Euroscarf \\
\hline Y05063 & BY4741 MATa doa1A::KAN & Euroscarf \\
\hline Y05281 & BY4741 MATa elo3 $\Delta:: K A N$ & Euroscarf \\
\hline Y05381 & BY4741 MATa vps274::KAN & Euroscarf \\
\hline Y05447 & BY4741 MATa yop1s::KAN & Euroscarf \\
\hline Y05721 & BY4741 MATa ubx7 $\Delta::$ KAN & Euroscarf \\
\hline Y05763 & BY4741 MATa elo2A::KAN & Euroscarf \\
\hline Y06078 & BY4741 MATa bre5s::KAN & Euroscarf \\
\hline Y06119 & BY4741 MATa scs2 $2:: K A N$ & Euroscarf \\
\hline Y06148 & BY4741 MATa ubp3s::KAN & Euroscarf \\
\hline Y06200 & BY4741 MATa $u b x 4 \Delta::$ KAN & Euroscarf \\
\hline YCV9 & $\begin{array}{l}\text { WCG4a MAT } \alpha \text { atg } 4 \Delta:: \mathrm{KAN} \\
\operatorname{atg} 8 \Delta:: \mathrm{KAN}\end{array}$ & C. Voss \\
\hline YHB 1 & 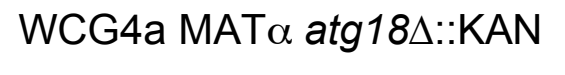 & H. Barth \\
\hline YHB 4 & WCG4a atg21 $::$ KAN & H. Barth \\
\hline
\end{tabular}




\begin{tabular}{|c|c|c|}
\hline Strain & Genotype & Source \\
\hline YMS30K1 & WCG4a MATa atg1 $1 \Delta:$ KAN & AG Thumm \\
\hline YMTA & WCG4a MATa pep4A::HIS3 & M. Thumm \\
\hline YSR3 & WCG4a MATa aut9A::KAN & S. Reiche \\
\hline YUE105-1B & $\begin{array}{l}\text { BY4741 MATa } b s d 2 \Delta:: \text { KAN } \\
\text { tul1 } 1:: \text { KAN }\end{array}$ & U. Epple \\
\hline YUE37 & $\begin{array}{l}\text { WCG4a MAT } \alpha \text { atg1 } 1 \Delta: \text { KAN } \\
\operatorname{atg} 15 \Delta:: \text { KAN }\end{array}$ & U. Epple \\
\hline YUE40 & $\begin{array}{l}\text { WCG } 4 a \text { MATa } \operatorname{atg} 1 \Delta:: \text { KAN } \\
\text { pep } 4 \Delta:: \text { HIS3 }\end{array}$ & U. Epple \\
\hline YWO 0377 & $\begin{array}{l}\text { BWG1-7a MATa ura3-52 } \\
\text { leu2-3,112 his4-519 ade1-100 }\end{array}$ & C. Taxis \\
\hline YW01018 & $\begin{array}{l}\text { BWG1-7a MATa ufd1_1 } \\
\text { pcr1_1 }\end{array}$ & C. Taxis \\
\hline YYH6 & W303 MATa & T. Rapoport \\
\hline YYH75 & $\begin{array}{l}\text { W303 CDC } 48.3 \text { temperature } \\
\text { sensitive at } 34^{\circ} \mathrm{C}\end{array}$ & T. Rapoport \\
\hline YYW09 & WCG4a MAT $\alpha$ vac8s::HIS3 & Y. Mühe \\
\hline yYW10 & WCG4a MATa $\operatorname{atg} 11 \Delta::$ HIS3 & Y. Mühe \\
\hline
\end{tabular}

Yeast strains for mating type determination

Tab. 3 S. cerevisiae strains for mating type determination

\begin{tabular}{lll}
\hline Strain & Genotype & Source \\
\hline YR312 & $\begin{array}{l}\text { Mata his1-123 test strain for } \\
\text { mating type determination }\end{array}$ & H. Rudolph, Stuttgart \\
& $\begin{array}{l}\text { Mata his1-123 test strain for } \\
\text { mating type determination }\end{array}$ & H. Rudolph, Stuttgart \\
\hline
\end{tabular}




\subsubsection{Escherichia coli strains}

Tab. 4 E. coli strain $\mathrm{DH} 5 \alpha$

\begin{tabular}{lll}
\hline Strain & Genotype & Source \\
\hline DH5 $\alpha$ & $\mathrm{F}^{\prime}(\Phi 80(\Delta l a c Z) M 15) \Delta$ & Hanahan et al., 1983 \\
& $($ lacZYA-argF $U 169$ recA1 & \\
& endA1 hsdR17 $\mathrm{r}_{k}-\mathrm{m}_{\mathrm{k}}+$ & \\
& supE44 thi-1 gyrA relA & \\
\hline
\end{tabular}

\subsubsection{Plasmids}

Tab. 5 Plasmids used in this study

\begin{tabular}{|c|c|c|}
\hline Name & Genotype & Source \\
\hline GFP-Atg8 & $\begin{array}{l}\text { pRS316 CEN6 URA3 } \\
\text { GFP-ATG8 }\end{array}$ & Suzuki et al., 2001 \\
\hline GFP-Atg8-cherry & $\begin{array}{l}\text { pRS316 CEN6 URA3 } \\
\text { GFP-Atg8-cherry }\end{array}$ & This study \\
\hline GFP-Atg9 & $\begin{array}{l}\text { CEN6 URA3 MET25 GFP- } \\
\text { Atg9 }\end{array}$ & T. Lang \\
\hline Nab 2 NLS-2m Cherry & $\begin{array}{l}\text { pYX242 2 } \mu \text { LEU2 TPI } \\
\text { Nab2NLS-2m cherry }\end{array}$ & $\begin{array}{l}\text { B. Timney and M. Rout at } \\
\text { the Rockefeller University }\end{array}$ \\
\hline pGFP-Atg8-FG & $\begin{array}{l}\text { pRS316 CEN6 URA3 } \\
\text { GFP-Atg8-FG }\end{array}$ & Suzuki et al., 2001 \\
\hline pJH1 & $\begin{array}{l}\text { pRS313 CEN6 HIS3 } \\
\text { Ape1-RFP }\end{array}$ & U. Epple \\
\hline $\begin{array}{l}\text { POM42 } \\
\text { pFA6-natNT2 }\end{array}$ & $\begin{array}{l}\text { POM40 URA3 yEGFP } \\
\text { natNT2 }\end{array}$ & $\begin{array}{l}\text { Euroscarf } \\
\text { Euroscarf; Janke et al., } \\
2004\end{array}$ \\
\hline pRS315 & $\begin{array}{l}\text { pRS315 CEN6 LEU2 } \\
\text { empty vector }\end{array}$ & K. Meiling-Wesse \\
\hline pRS315-APE1-RFP & $\begin{array}{l}\text { pRS315 CEN6 LEU2 } \\
\text { Ape1-RFP }\end{array}$ & R. Krick \\
\hline pRS315-mRFP-2xFYVE & $\begin{array}{l}\text { pRS315 CEN6 LEU2 TEF } \\
\text { mRFP-2xFYVE }\end{array}$ & S. Henke \\
\hline pRS316-PGK-GFP & $\begin{array}{l}\text { pRS316 CEN6 URA3 } \\
\text { PGK-GFP }\end{array}$ & P. Schlotterhose; Y. Mühe \\
\hline pRS416-GFP-OSH1 & $\begin{array}{l}\text { pRS416 CEN6 URA3 } \\
\text { GFP-Osh1 }\end{array}$ & Lowen et al. 2003 \\
\hline pSH65 & $\begin{array}{l}\text { CRE-recombinase with } \\
\text { GAL-promoter } \\
\text { phleomycin resistance }\end{array}$ & Euroscarf \\
\hline pUG23_Nvj1 & $\begin{array}{l}\text { pUG23 CEN6 HIS3 } \\
\text { MET25 Nvj1 }\end{array}$ & This study \\
\hline pUG23_Nvj1_GFP & pUG23 CEN6 HIS2 & This study \\
\hline & 24 & \\
\hline
\end{tabular}




\begin{tabular}{lll}
\hline Name & Genotype & Source \\
\hline pUG35_Nvj1 & $\begin{array}{l}\text { MET25 Nvj1-GFP } \\
\text { pUG35 CEN6 URA3 } \\
\text { MET25 Nv1 }\end{array}$ & This study \\
pUG35_Nvj1_GFP & $\begin{array}{l}\text { pUG35 CEN6 URA3 } \\
\text { MET25 Nv1-GFP } \\
\text { YEP96 TRP1 Cup1 } \\
\text { ubiquitin (K29R) } \\
\text { YEP96 TRP1 Cup1 } \\
\text { Ubiquitin (K48R) }\end{array}$ & This study \\
UbK48R & $\begin{array}{l}\text { YEP96 TRP1 Cup1 } \\
\text { ubiquitin (K63R) } \\
\text { YEP96 TRP1 Cup1 }\end{array}$ & Horak J. \\
UbK63R & $\begin{array}{l}\text { ubiquitin (no lysines) } \\
\text { 2u TRP1 Cup1 }\end{array}$ & Horak J. \\
Ub-noLys & Horak J. \\
YEp96 & & \\
\hline
\end{tabular}

\subsubsection{Oligonucleotides}

Tab. 6 Oligonucleotides used in this study

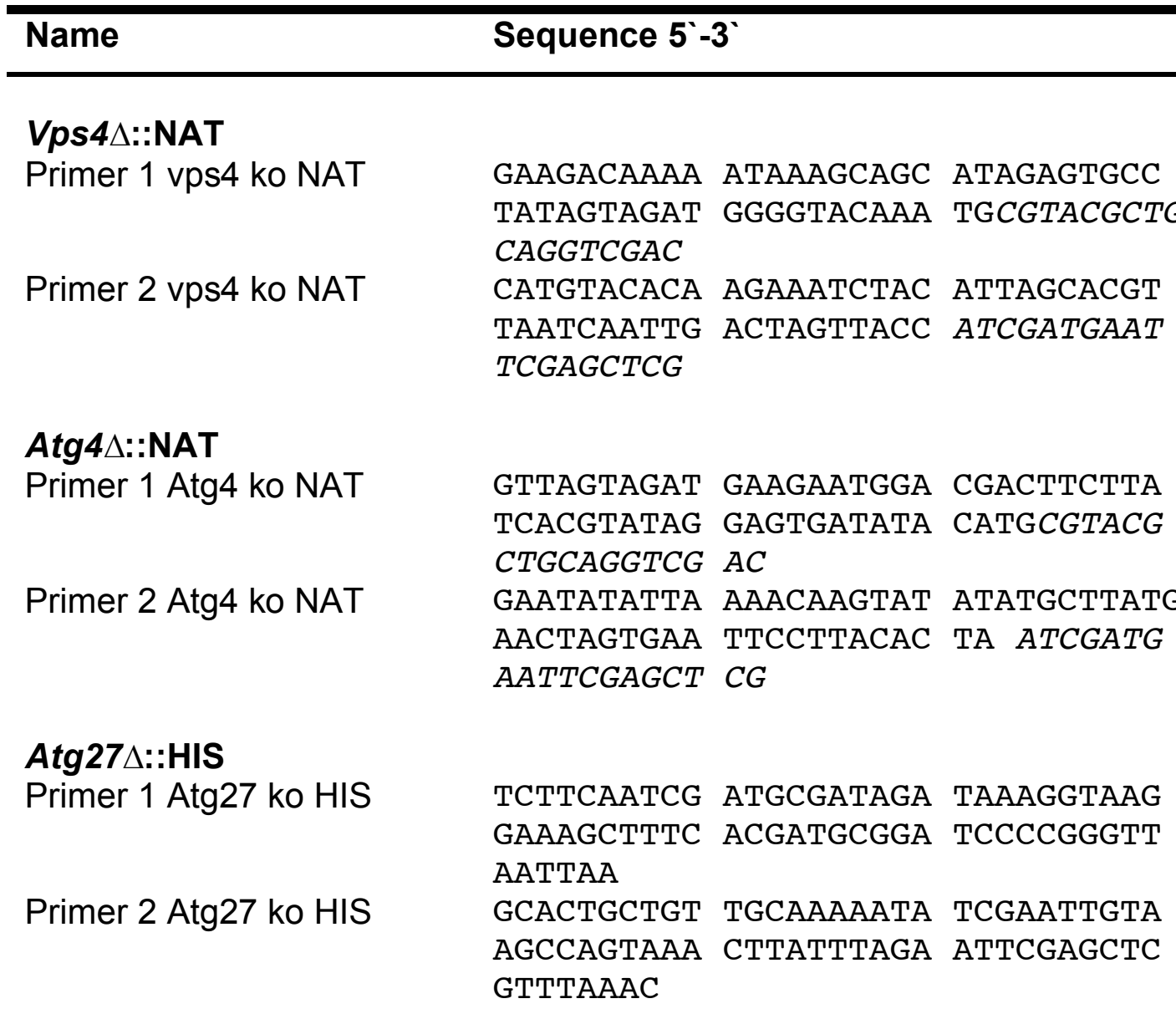




\begin{tabular}{|c|c|c|}
\hline Name & Sequence $5{ }^{\circ}-3^{\circ}$ & \\
\hline \multicolumn{3}{|l|}{ Chromosomal GFP-Atg8 } \\
\hline \multirow[t]{3}{*}{ cGFP-Atg8 1f } & TAATTGTAAA GTTGAGAAAA & TCATAATAAA \\
\hline & АATAATTACT AGAGACATGT & GCAGGTCGAC \\
\hline & ААСССТТААТ & \\
\hline \multirow[t]{2}{*}{ cGFP-Atg8 2r (linker) } & СGССТTССTT ТTTTCAААTG & GATATTCAGA \\
\hline & СТTAAATGTA GACTTGCGGC & CGCATAGGCC \\
\hline \multirow{2}{*}{\multicolumn{3}{|c|}{ Plasmid GFP-Atg8-cherry }} \\
\hline & & \\
\hline \multirow[t]{3}{*}{ GFP-Atg8-cherry $1 \mathrm{f}$} & CGGGTTTTTG TATGTCACTT & АСTCAGGAGA \\
\hline & АAATACATTT GGCAGGATGG & TGAGCAAGGG \\
\hline & CGAGGAGG & \\
\hline \multirow[t]{3}{*}{ GFP-Atg8-cherry $2 r$} & GCTCGGAATT ААСССТСАСT & AAAGGGAACA \\
\hline & AAAGCTGGGT ACCGGGCCTA & СTTGTACAGC \\
\hline & TCGTCCATGC & \\
\hline \multicolumn{3}{|l|}{ Sequence Primer Atg8 } \\
\hline Atg 8 seq of & GGAGGCCGGT TATTTTCGG & \\
\hline Atg8 seq 1f & GAAGGCGGAG TCGGAGAG & \\
\hline Atg8 seq $1 r$ & СТCTCCGACT CCGCCTTC & \\
\hline Atg8 seq $2 f$ & GGACGGGTTT TTGTATGTCA & $\mathrm{C}$ \\
\hline Atg8 seq $2 r$ & GTGACATACA AAAACCCGTC & C \\
\hline \multicolumn{3}{|l|}{ Sequence Primer Atg9 } \\
\hline Atg9 seq $1 f$ & GATGATTCTG TGCCCAAAGT & $\mathrm{C}$ \\
\hline Atg9 seq $1 r$ & GACTTTGGGC ACAGAATCAT & $\mathrm{C}$ \\
\hline Atg9 seq $2 f$ & СТGAАTTTAT ССТTGССТАT & TCC \\
\hline Atg9 seq $2 r$ & GGAATAGGCA AGGATAAATT & CAG \\
\hline Atg9 seq $3 f$ & GCGATTCATT TCTCAАCAАT & AAG \\
\hline Atg9 seq $3 r$ & СTTATTGTTG AGAAATGAAT & CGC \\
\hline Atg9 seq $4 r$ & CGGTTATTCT GTAAGATATG & $\mathrm{CC}$ \\
\hline Atg9 seq $5 f$ & ССTTTGGATG TTTTATTTCT & TCG \\
\hline Atg9 seq $6 f$ & GCAAGTATGC TATGTTTAAC & ATG \\
\hline \multicolumn{3}{|l|}{ Sequence Primer RFP } \\
\hline RFP seq $1 \mathrm{r}$ & CGTGGCCGTT CACGGAGC & \\
\hline
\end{tabular}

\subsubsection{Media}

All media were prepared with deionised water $\left(\mathrm{ddH}_{2} \mathrm{O}\right)$ and autoclaved $20 \mathrm{~min}$ at $121^{\circ} \mathrm{C}$ and 2 bar. To obtain solid media, $2 \%$ Bacto-Agar was added. The $\mathrm{pH}$ of the medium was adjusted with either $\mathrm{NaOH}$ or $\mathrm{HCl}$. All percent values in this chapter are weight per volume $(w / v)$. 


\subsubsection{YPD-medium, pH 5.5}

YPD is a rich medium for yeast cultures containing:
$1 \% \quad$ Bacto $^{\circledR}$ Yeast Extract
$2 \% \quad$ Bacto $^{\circledR}$ Pepton
$2 \%$ D-glucose

\subsubsection{CM-medium, pH 5.6}

CM-medium is a synthetic medium for yeast cultures consisting of:
$0.67 \%$
Yeast Nitrogen Base w/o amino acids
$2 \%$
D-glucose
$0.0117 \% \quad$ L-alanine
0.0117\% L-methionine*
$0.0117 \%$ L-arginine
$0.0117 \% \quad$ L-phenylalanine
$0.0117 \%$ L-asparagine
$0.0117 \% \quad$ L-proline
$0.0117 \% \quad$ L-aspartic acid
$0.0117 \%$ L-serine
$0.0117 \%$ L-cysteine
$0.0117 \% \quad$ L-threonine
$0.0117 \% \quad$ L-glutamine
$0.0117 \%$ L-tyrosine
$0.0117 \%$
L-glutamic acid
$0.0117 \%$
L-valine
$0.0117 \%$ L-glycine
$0.0117 \%$ myo-inositol
$0.0117 \% \quad$ L-isoleucine
$0.00117 \% \quad$ p-aminobenzoic acid

Depending on selection conditions the following supplements were added:
$0.3 \mathrm{mM} \quad$ L-histidine
$0.4 \mathrm{mM} \quad$ L-tryptophan
$1.7 \mathrm{mM} \quad$ L-leucine
$0.3 \mathrm{mM}$ adenine
$1 \mathrm{mM}$
L-lysine
$0.2 \mathrm{mM}$
uracil $^{* *}$

* For overexpression experiments using a MET25 promoter L-methionine was excluded from the drop out mix.

** Uracil was resuspended in $0.5 \%$ sodium hydrogen carbonate solution.

\subsubsection{SD(-N)-medium}

Nitrogen free $\mathrm{SD}(-\mathrm{N})$-medium was used as starvation medium for yeast cells.

$0.67 \% \quad$ Yeast Nitrogen Base w/o amino acid and w/o ammonium sulfate 


\subsubsection{1\% potassium acetate}

$1 \%$ potassium acetate medium was used to induce sporulation and tetrade formation of yeast cells and for carbon starvation.

$1 \%$ potassium acetate

\subsubsection{MV-medium, pH 5.5}

MV-medium was used as a minimal medium to determine the mating type of a haploid yeast strain.

$0.67 \% \quad$ Yeast Nitrogen Base w/o amino acids

$2 \% \quad D$-glucose

\subsubsection{LB-medium, pH 7.5}

LB-medium was used as standard growth medium for $E$. coli cultures.

$\begin{array}{ll}1 \% & \text { Bacto }^{\circledR} \text { Trypton } \\ 0.5 \% & \text { Bacto }^{\circledR} \text { Yeast extract } \\ 0.5 \% & \text { sodium chloride }\end{array}$

For plasmid selection $75 \mu \mathrm{g} / \mathrm{ml}$ ampicillin was added.

\subsubsection{SOC-medium, pH 7.5}

SOC-medium was used as a regeneration medium for electroporated $E$. coli cells.

$\begin{array}{llll}2 \% & \text { Bacto }^{\circledR} \text { Trypton } & & \\ 0.5 \% & \text { Bacto }^{\circledR} \text { Yeast extract } & & \\ 0.4 \% & \text { D-glucose } & & \\ 10 \mathrm{mM} & \text { sodium chloride } & 10 \mathrm{mM} & \text { magnesium sulfate } \\ 10 \mathrm{mM} & \text { magnesium chloride } & 2.5 \mathrm{mM} & \text { potassium chloride }\end{array}$




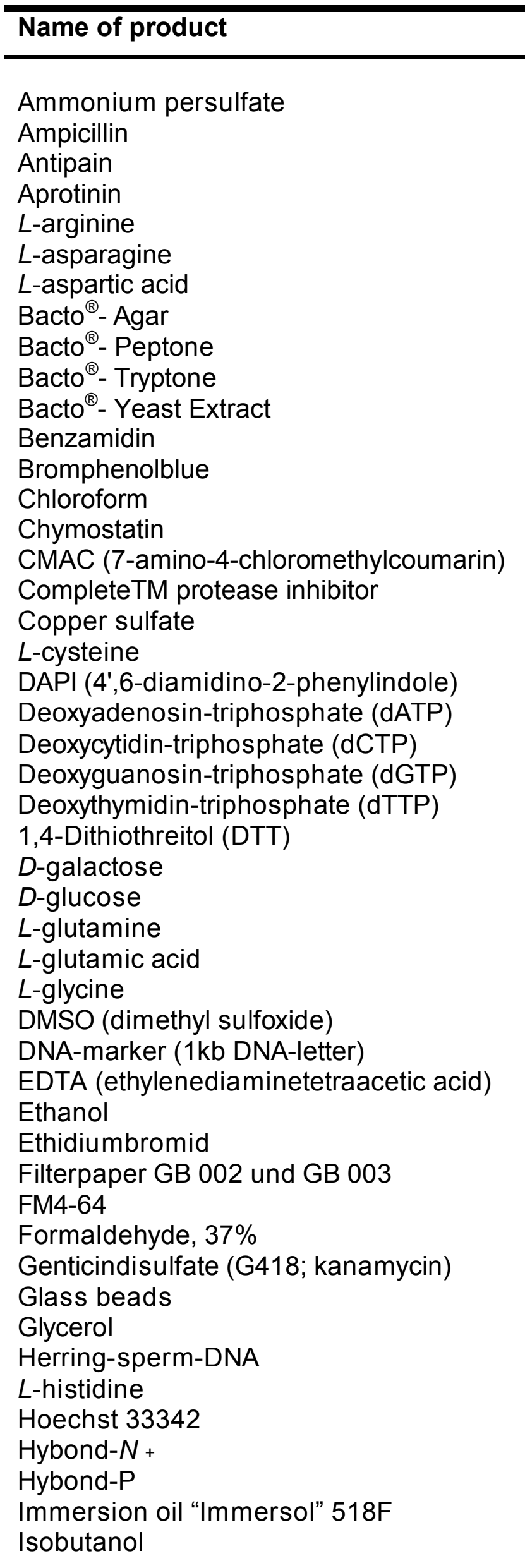

\section{Source}

Merck, Darmstadt

Boehringer Mannheim, Mannheim

Sigma-Aldrich, Deisenhofen

Merck, Darmstadt

Sigma, Deisenhofen

Sigma, Deisenhofen

Sigma, Deisenhofen

Becton Dickinson, Heidelberg

Becton Dickinson, Heidelberg

Becton Dickinson, Heidelberg

Becton Dickinson, Heidelberg

Merck, Darmstadt

Riedel-De Haën, Seelze

Roth, Karlsruhe

Merck, Darmstadt

Invitrogen, Karlsruhe

Roche, Mannheim

Roth, Karlsruhe

Sigma, Deisenhofen

Sigma, Deisenhofen

NEB, Frankfurt

NEB, Frankfurt

NEB, Frankfurt

NEB, Frankfurt

Roth, Karlsruhe

Roth, Karlsruhe

Roth, Karlsruhe

Sigma, Deisenhofen

Sigma, Deisenhofen

Sigma, Deisenhofen

Merck, Darmstadt

NEB, Frankfurt

Sigma, Deisenhofen

Roth, Karlsruhe

Sigma, Deisenhofen

Heinemann, Göttingen

Invitrogen, Karlsruhe

Sigma, Deisenhofen

Roth, Karlsruhe

Schütt, Göttingen

Riedel-De Haën, Seelze

Promega, Madison, USA

Sigma, Deisenhofen

Molecular Probes, Freiburg

Amersham Biosciences, GB

Amersham Biosciences, GB

Zeiss, Göttingen

Sigma, Deisenhofen 


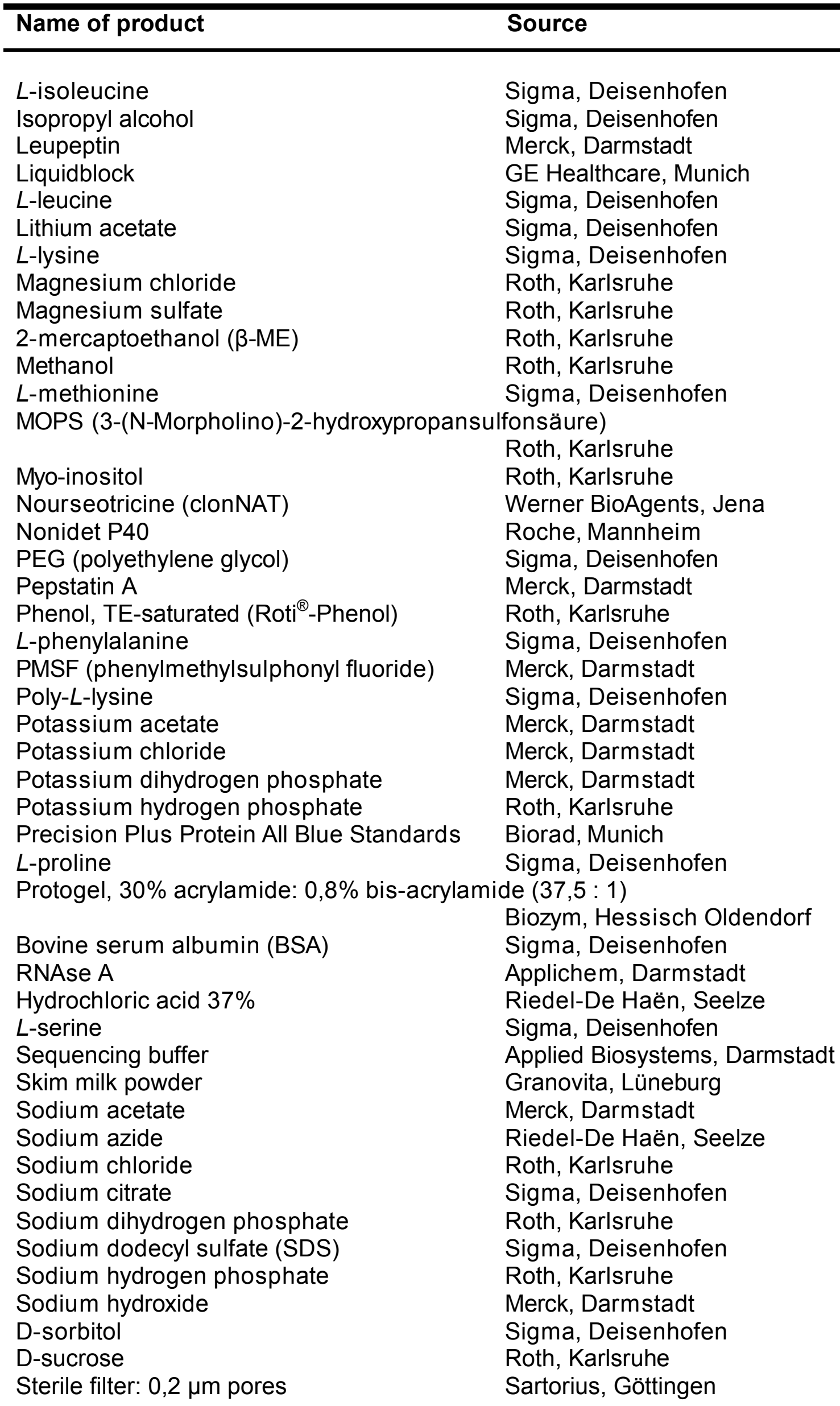




\begin{tabular}{ll}
\hline Name of product & Source \\
\hline \multicolumn{1}{c}{125 and $500 \mathrm{ml}$ vacuum filtration } & Schleicher \& Schuell, Dassel \\
TEMED (1,2-Bis(dimethylamino)ethane) & Merck, Darmstadt \\
L-threonine & Sigma, Deisenhofen \\
Trichloroacetic acid (TCA) & Roth, Karlsruhe \\
Tris (tris(hydroxymethyl)aminomethane) & Roth, Karlsruhe \\
TritonX-100 & Roth, Karlsruhe \\
L-tryptophan & Sigma, Deisenhofen \\
Tween 20 & Sigma, Deisenhofen \\
L-tyrosine & Sigma, Deisenhofen \\
Uracil & Sigma, Deisenhofen \\
L-valine & Sigma, Deisenhofen \\
Yeast nitrogen base & Becton Dickinson, Heidelberg \\
Difco Yeast nitrogen base w/o amino acids & Becton Dickinson, Heidelberg \\
Difco Yeast nitrogen base w/o amino acids and ammonium & Becton Dickinson, Heidelberg \\
Zymolyase T20 & Seikagaku, Japan \\
Zymolyase T100 & Seikagaku, Japan \\
\hline
\end{tabular}

\subsubsection{Devices}

Tab. 10 Devices used in this study

\begin{tabular}{ll}
\hline Name of product & Source \\
\hline & \\
Analysis scale & Sartorius, Göttingen \\
Autoclav: TECNOCLAV 50 & Tecnomara-Fedegari, Zürich, CH \\
Autoclav: Tuttnauer 3870 EL & Systec, Wettenberg \\
Axioscope2 mot plus microscope & Zeiss, Göttingen \\
Bunsen burner flammy S & Schütt, Göttingen \\
Centrifuge 5417C / 5415R & Eppendorf, Hamburg \\
Centrifuge J2-MC & Beckmann, Krefeld \\
DNA-gel electrophoresis apparatuses & Biorad, Munich \\
Electrophoresis chamber for SDS-PAGE & Biorad, Munich \\
Elektrophoresis Power Supply Consort E831 & Topac, USA \\
Electrophoresis system Mini PROTEAN 3 & Biorag, Munich \\
Elektroporator 2510 & Eppendorf, Hamburg \\
Hood & BDK Luft- und Reinraumtechnik, \\
& Sonnenbrühl-Genkingen \\
Hybridisation oven & Schütt, Göttingen \\
Incubators & Hereaus, Hanau \\
Inkubator 4200 & Innova, USA \\
Labshaker for diverse culture sizes & A. Kühner, Birsfelden, Schweiz \\
LAS-3000 Intelligent Dark Box & Fuji/ Raytest, Benelux \\
Leica TCS SP2 AOBS confocal LSM & Leica, Wetzlar \\
Magnetic stirrer MR 3001 & Heidolph, Kelheim \\
\end{tabular}




\begin{tabular}{ll}
\hline Name of product & Source \\
\hline Micromanipulator & Zeiss, Göttingen \\
Microprocessor pH Meter 537 & WTW, Weilheim \\
Microwave R-939 & Sharp, Hamburg \\
Mini Trans-Blot Cell & Biorad, Munich \\
Multivortex IKA VIBRAX VXR basic & IKA, Staufen \\
Over head shaker REAX2 & Heidolph, Kelheim \\
Photometer & Eppendorf, Hamburg \\
PCR Mastercycler gradient & Eppendorf, Hamburg \\
Photostation for agarose gels & Canon-Kamera \\
PowerPac Basic Power Supply & Biorad, Munich \\
PowerPac HC Power Supply & Biorad, Munich \\
Rotor JA 10 & Beckmann, Krefeld \\
Rotor JA 20 & Beckmann, Krefeld \\
Rotor TLA-100.3 & Beckmann, Krefeld \\
Table centrifuge 5804R & Eppendorf, Hamburg \\
Thermomixer comfort & Eppendorf, Hamburg \\
Trans-Blot Cell & Biorad, Munich \\
Transilluminator TI 1 & Whatman Biometra, Göttingen \\
Ultracentrifuge TL-100 and L8-M & Beckman, Krefeld \\
Vacuum pump & Vacuubrand, Wertheim \\
Vortex Genie2 & Scientific Industries, USA \\
Water bath SWB25 & Thermo Electron, Karlsruhe \\
\end{tabular}

\subsection{Methods}

\subsubsection{Cultivation of yeast cells}

\subsubsection{Growth of yeast cultures}

Yeast liquid cultures were inoculated with cells from an agar plate using a sterile toothpick or from a pre-culture with a defined dilution. The cells were incubated overnight (14 - $16 \mathrm{~h}$ ) on a shaker with $220 \mathrm{rpm}$ at $30^{\circ} \mathrm{C}$ (if not pointed out otherwise).

\subsubsection{Short-term yeast storing}

To prepare short-term yeast stocks, yeast strains on agar plates were duplicated every 4 - 6 weeks, incubated for 1 - 2 days at $30^{\circ} \mathrm{C}$ and stored at $4^{\circ} \mathrm{C}$. 


\subsubsection{Long-term yeast storing}

Long-term yeast stocks were prepared from fresh agar plates or liquid in $15 \%(\mathrm{v} / \mathrm{v})$ glycerol solution and stored at $-80^{\circ} \mathrm{C}$.

\subsubsection{Cell density determinataion}

The cell density was measured using the optical density at $600 \mathrm{~nm}\left(\mathrm{OD}_{600}\right)$ in a dilution of $1: 20$ (using empty medium as reference). $1 \mathrm{OD}_{600}$ of growing yeast cells correspond to $3 \times 10^{7}$ cells $/ \mathrm{ml}$.

\subsubsection{Yeast mating type determination}

To determine the mating type of a $S$. cerevisiae strain two tester strains YR312 (Mat a) and YR320 (Mat $\alpha$ ) were streaked in two separate lines on a MV-medium agar plate. Both strains have the rare His1 allele, while the other markers are wild type. To test a strain for its mating type it was streaked through each of the tester strain lines. The plates were incubated for 2 days at $30^{\circ} \mathrm{C}$. The tested strains will mate only with the tester strain of contrariwise mating type, resulting in a diploid strain that growth on MV-medium.

\subsubsection{Isolation of yeast DNA}

\subsubsection{Isolation of chromosomal DNA}

To isolate chromosomal yeast DNA $1.5 \mathrm{ml}$ of an overnight culture was harvested

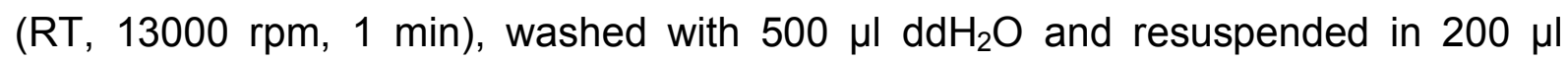
breaking buffer (10 mM Tris/HCl pH 8.0; $100 \mathrm{mM}$ sodium chloride; $1 \mathrm{mM}$ EDTA; $1 \%$ (w/v) SDS; $2 \%$ (v/v) TritonX-100). $200 \mu$ glass beads $(0.4-0.5 \mathrm{~mm}$; neutralised) and $200 \mu \mathrm{l}$ phenol/chloroform solution (50\% ( $/ \mathrm{v})$ phenol; $50 \%(\mathrm{v} / \mathrm{v})$ chloroform) were added and the reaction was mixed harsh four times for 1 min interrupted by 1 min on ice. Before centrifugation (RT, $13000 \mathrm{rpm}, 5 \mathrm{~min}$ ) $200 \mu \mathrm{ldd} \mathrm{H}_{2} \mathrm{O}$ were added. $200 \mu \mathrm{l}$ of the upper fraction were transferred to a new reaction cup and the DNA was precipitated with $1 \mathrm{ml}$ of ethanol $\left(-20^{\circ} \mathrm{C}, 100 \%\right)$ for $10 \mathrm{~min}$ at $-20^{\circ} \mathrm{C}$. After 
centrifugation (RT, $13000 \mathrm{rpm}, 10 \mathrm{~min}$ ) the sediment was resuspended in $400 \mu \mathrm{l}$ $\mathrm{ddH}_{2} \mathrm{O}$ containing $3 \mu \mathrm{l}$ RNAse A $(10 \mathrm{mg} / \mathrm{ml})$. The solution was incubated at $37^{\circ} \mathrm{C}$ for $5 \mathrm{~min}$ and again precipitated for $10 \mathrm{~min}$ at $-20^{\circ} \mathrm{C}$ using $10 \mu \mathrm{l} 5 \mathrm{M}$ ammonium acetate and $1 \mathrm{ml}$ of ethanol $\left(-20^{\circ} \mathrm{C}, 100 \%\right)$. The DNA was sedimented (RT, $13000 \mathrm{rpm}, 10$ $\mathrm{min}$ ), the supernatant quantitatively removed and the sediment dried for $5 \mathrm{~min}$ at $37^{\circ} \mathrm{C}$. The DNA sediment was resuspended in $30 \mu \mathrm{ddd} \mathrm{H}_{2} \mathrm{O}$ and stored at $-20^{\circ} \mathrm{C}$.

\subsubsection{Isolation of plasmid DNA (plasmid rescue)}

To isolate plasmid DNA, $2 \mathrm{ml}$ yeast overnight culture were harvested (RT, $1 \mathrm{~min}$, $13000 \mathrm{rpm})$ and resuspended in breaking buffer $(10 \mathrm{mM}$ Tris/HCl pH 8.0; $100 \mathrm{mM}$ sodium chloride; 1 mM EDTA; 1\% (w/v) SDS; 2\% (v/v) TritonX-100). $200 \mu$ l Phenol and $200 \mu \mathrm{l}$ glass beads $(0.4-0.5 \mathrm{~mm}$; neutralised) were added and the solution was incubated on a shaker for $10 \mathrm{~min}$ at $4^{\circ} \mathrm{C}$. After centrifugation (RT, $13000 \mathrm{rpm}, 10 \mathrm{~min}$ ) $200 \mu \mathrm{l}$ of the upper fraction were transferred to a new reaction cup. The DNA was precipitated using $1 / 10$ volume $3 \mathrm{M}$ sodium acetate solution and 2.5 times volume ice-cold ethanol (100\%). The DNA sediment was washed with $70 \%$ ethanol, dried and resuspended in $30 \mu \mathrm{ldd} \mathrm{d}_{2} \mathrm{O}$. This solution contained chromosomal DNA and plasmid DNA. DNA transformation in E. coli excluded chromosomal DNA resulting in enrichment of pure plasmid DNA (see chapter 3.2.6 Transformation of $E$. coli cells).

\subsubsection{Transformation of yeast cells}

\subsubsection{High efficient transformation of yeast cells}

A $50 \mathrm{ml}$ culture was prepared by dilution $1: 10$ from a log-phase pre-culture. Cells were grown to an $\mathrm{OD}_{600}$ of $0.5-0.8$, harvested (RT, $2000 \mathrm{rpm}, 5 \mathrm{~min}$ ), washed two

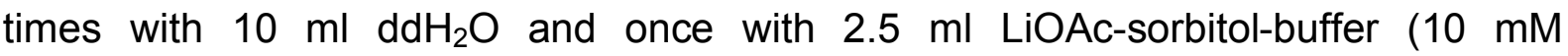
Tris/acetate $\mathrm{pH}$ 8.0; $100 \mathrm{mM}$ lithiumacatate; $1 \mathrm{mM}$ EDTA; $1 \mathrm{M}$ D-sorbitol). The cells were resuspended in $100 \mu \mathrm{L}$ LiOAc-sorbitol-buffer and incubated for $15 \mathrm{~min}$ at $30^{\circ} \mathrm{C}$ to make them competent. The cell suspension was separated in $50 \mu \mathrm{l}$ aliquots and mixed with $300 \mu \mathrm{l} \mathrm{PEG}$ in Li-TE-buffer $(10 \mathrm{mM}$ Tris/acetate $\mathrm{pH}$ 8.0; $100 \mathrm{mM}$ lithium acetate; $1 \mathrm{mM}$ EDTA; 40\% PEG 3350). $5 \mu \mathrm{l}$ herring-sperm DNA (10 mg / ml) and 1 - $5 \mu$ of the DNA were added. The samples were first incubated for $30 \mathrm{~min}$ at $30^{\circ} \mathrm{C}$ 
and shifted for $15 \mathrm{~min}$ at $42^{\circ} \mathrm{C}$, followed by a regeneration in $2 \mathrm{ml} \mathrm{YPD-medium} \mathrm{for}$ $1-4 \mathrm{~h}$ at $30^{\circ} \mathrm{C}$ at $220 \mathrm{rpm}$. The cells were sedimented (RT, $2000 \mathrm{rpm}, 3 \mathrm{~min}$ ), resuspended in water and spread on selection medium.

\subsubsection{2 "Quick and dirty" transformation of plasmid DNA in yeast}

For fast transformation of plasmid DNA in yeast, cells from an agar plate were resuspended in $300 \mu \mathrm{l} \mathrm{PEG}$ in Li-TE-buffer $(100 \mathrm{mM}$ lithium acetate; $10 \mathrm{mM}$ Tris; 1 mM EDTA, 40\% (v/v) PEG 3350; pH 8.0 with acetic acid). $5 \mu$ l herring-sperm DNA (10 mg / ml) and 1 - $5 \mu \mathrm{l}$ DNA were added and the samples were gently mixed and incubated as described in 3.2.3.1 High efficient transformation of yeast cells.

\subsubsection{E. coli cell culture}

\subsubsection{Growth of E. coli cultures}

E. coli liquid cultures were inoculated with cells from an agar plate or from a long term culture. Liquid cultures were incubated overnight at $220 \mathrm{rpm}, 37^{\circ} \mathrm{C}$ and then harvested (for example for plasmid isolations).

\subsubsection{E. coli long term storing}

To prepare a long term stock $500 \mu \mathrm{l} E$. coli overnight culture were mixed with $500 \mu \mathrm{l}$ $60 \%(\mathrm{v} / \mathrm{v})$ glycerol and stored at $-80^{\circ} \mathrm{C}$.

\subsubsection{Preparation of electro-competent $E$. coli cells}

Competent cells can take up DNA from the outside of the cell. To produce these competent cells a main-culture of $600 \mathrm{ml}$ LB-medium was inoculated $1: 100$ from an overnight pre-culture of $E$. coli strain $\mathrm{DH} 5 \alpha$. The cells were incubated at $37^{\circ} \mathrm{C}$ to an $\mathrm{OD}_{600}$ of $0.6-0.7$, chilled on ice for $10 \mathrm{~min}$ and harvested $\left(4^{\circ} \mathrm{C}, 6500 \mathrm{rpm}, 8 \mathrm{~min}\right)$. Three washing steps followed: The first with 1 I ice-cold $d_{d d} \mathrm{H}_{2} \mathrm{O}$, the second with $0.5 \mathrm{I}$ ice-cold $\mathrm{ddH}_{2} \mathrm{O}$ and the third with $20 \mathrm{ml} 4^{\circ} \mathrm{C}$ cold $10 \%(\mathrm{v} / \mathrm{v})$ glycerol $\left(4^{\circ} \mathrm{C}, 6500 \mathrm{rpm}\right.$, 
$8 \mathrm{~min})$. Finally the cells were resuspended in $2 \mathrm{ml}$ cold $10 \%(\mathrm{v} / \mathrm{v})$ glycerol, divided in $40 \mu \mathrm{l}$ aliquots and stored at $-80^{\circ} \mathrm{C}$.

\subsubsection{Transformation of $E$. coli cells}

In this study electroporation was used to transform E. coli cells. Electroporation is used to make the cell membrane more permeable to DNA by an electric impulse. Competent $E$. coli cells were thawn on ice and 1 - $2 \mu$ l of the transforming DNA was added. The sample was transferred to a pre-chilled electroporation cell and electroporated at $2500 \mathrm{~V} .900 \mu \mathrm{l} \mathrm{SOC}$-medium were immediately added to the cells and incubated for $1 \mathrm{~h}$ at $37^{\circ} \mathrm{C}, 220 \mathrm{rpm} .100-500 \mu \mathrm{l}$ of these cells were spread on LB-plates containing ampicillin and incubated overnight at $37^{\circ} \mathrm{C}$.

\subsubsection{Plasmid isolation from $E$. coli cells}

\subsubsection{Plasmid isolation from E. coli cells by alkaline lysis}

To isolate plasmids from $E$. coi cells, $1.5 \mathrm{ml}$ of an overnight culture was harvested (RT, $13000 \mathrm{rpm}, 1 \mathrm{~min}$ ) and the cells were resuspended in $100 \mu \mathrm{l}$ solution 1 (25 mM Tris/HCl pH 8.0; 50 mM D-glucose; 10 mM EDTA). After adding $200 \mu$ l of solution 2 (fresh mixed: $200 \mathrm{mM}$ sodium hydroxide; 1\% SDS (w/v)) and gently mixing, $150 \mu \mathrm{l}$ of solution 3 (3 M potassium acetate; $2 \mathrm{M}$ acetic acid) were added and mixed again. After centrifugation (RT, $13000 \mathrm{rpm}, 5 \mathrm{~min}$ ) the supernatant was transferred to a new reaction cup and the DNA was precipitated for 2 min with $900 \mu \mathrm{l}$ ethanol (100\%). The sample was centrifuged (RT, $13000 \mathrm{rpm}, 5 \mathrm{~min}$ ) and the DNA sediment was air dried. The plasmid DNA was resuspended in $50 \mu \mathrm{lddH_{2 }} \mathrm{O}$ incubated with $0.5 \mu \mathrm{RNAse} A$ $\left(10 \mathrm{mg} / \mathrm{ml}\right.$ ) for $30 \mathrm{~min}$ at room temperature. The DNA was stored at $-20^{\circ} \mathrm{C}$.

\subsubsection{Plasmid isolation from E. coli cells by Wizard Plus SV Kit}

To isolate small amounts of clean DNA the Wizard Plus SV Kit from Promega was used as described in the manufacturer's manual. 


\subsubsection{Plasmid isolation fom E. coli cells by Quiagen Maxi Kit}

To isolate huge amounts of clean DNA the Qiagen Plasmid Maxi Kit from Qiagen was used as described in the manufacturer's manual. The GFP-Osh1 plasmid was isolated using this kit.

\subsubsection{Restriction analysis of DNA}

DNA was digested with specific restriction enzymes to analyse and prepare DNA. For a $15 \mu \mathrm{l}$ digestion 1 - $5 \mu \mathrm{l}$ DNA, $1.5 \mu$ buffer ( $10 x$ concentrated), often $0.15 \mu \mathrm{l}$ BSA (100 x concentrated) and $2-10 \cup$ enzyme was used. The reaction was incubated for 1 - 2 hours at optimal enzyme temperature. All reactions were done following the manufacturers advice from NEB. $9 \mu \mathrm{l}$ of the reaction were mixed with $1 \mu \mathrm{l}$ of DNA sample buffer ( $1 \mathrm{M}$ Tris/ $\mathrm{HCl} \mathrm{H} 8.0 ; 50 \%(\mathrm{v} / \mathrm{v})$ glycerol; $0.1 \%(\mathrm{w} / \mathrm{v})$ bromphenolblue). The digest was tested using DNA agarose gel electrophoreses. For preparative digestions the standard reaction was scaled up.

\subsubsection{DNA agarose gel electrophoreses}

DNA fragments can be separated by size in an electric field using agarose gels. Dependent on the expected size of the fragments agarose gels between 0.8 and $1.5 \%(\mathrm{w} / \mathrm{v})$ agarose with $1 \mu \mathrm{g} / \mathrm{ml}$ ethidiumbromide in TAE buffer ( $40 \mathrm{mM}$ Tris/acetate $\mathrm{pH}$ 8.1; 2 mM EDTA; $0.114 \%$ acetic acid) were taken and used to separate DNA in an electrophoresis chamber in TAE buffer. The DNA samples were prepared with DNA sample buffer $(1 \mathrm{M}$ Tris/ $\mathrm{HCl} H \quad 8.0 ; 50 \% \quad(\mathrm{v} / \mathrm{v})$ glycerol; $0.1 \% \quad(\mathrm{w} / \mathrm{v})$ bromphenolblue) and separated for $25 \mathrm{~min}$ at $120 \mathrm{~V}$. Incorporation of ethidiumbromide allowed the detection of the DNA under UV-light $(\lambda=254 \mathrm{~nm})$.

\subsubsection{Gel extraction of DNA (Gel Extraction Kit)}

To purify DNA fragments from agarose gels the QIAEX II Gel Extraction Kit from Qiagen was used as described in the manufacturer's manual. 


\subsubsection{Sizing of DNA fragments}

To determine the size of linearized DNA fragments the Standard TriDye $1 \mathrm{~kb}$ DNA Ladder (NEB, Frankfurt) was used.

Tab. 11 Standard TriDye 1kb DNA Ladder

\begin{tabular}{l|c|c|c|c|c|c|c|c|c|c} 
Fragment & 1 & 2 & 3 & 4 & 5 & 6 & 7 & 8 & 9 & 10 \\
\hline Size (kb) & 10 & 8 & 6 & 5 & 4 & 3 & 2 & 1.5 & 1 & 0.5
\end{tabular}

\subsubsection{Ligation of DNA fragments}

To ligate DNA fragments 2 - $6 \mu \mathrm{l}$ insert DNA (prepared with restriction enzymes), 0.5 - $3 \mu \mathrm{l}$ vector DNA (prepared with corresponding restriction enzymes), $2.5 \mathrm{U}$ T4DNA-ligase and $1 \mathrm{x}$ ligation buffer ( $10 \mathrm{x}$ concentrated) were filled to $10 \mu \mathrm{l}$ with $\mathrm{ddH}_{2} \mathrm{O}$ and incubated overnight at $16^{\circ} \mathrm{C}$. The enzyme ligated the overhanging DNA sequences or the blunt end fragments. Afterwards $1-2 \mu \mathrm{l}$ of the sample were transformed into $E$. coli cells. Only circular plasmids enabled the $E$. coli cells to grow on selection plates.

\subsubsection{Polymerase chain reaction (PCR)}

The polymerase chain reaction allows the amplification of a DNA molecule using a DNA polymerase.

A $100 \mu$ PCR reaction contained $1 \times$ PCR buffer ( $10 \times$ concentrated), 100 pmol per oligonucleotide, $1 \mu \mathrm{l}$ template DNA, $1 \mu \mathrm{l}$ dNTP mix ( $25 \mathrm{mM}$ each dNTP), up to $2 \mu \mathrm{l}$ DMSO (for chromosomal DNA as template) and up to $5 \cup$ DNA polymerase. For small fragments Taq DNA polymerase (NEB) was used. To amplify longer DNA Fragments the proof reading polymerase Fideli Taq (USB) was used. This enzyme required special conditions (see manufacturers advice). Up to 30 cycles of DNA denaturation, oligonucleotide annealing and DNA synthesis followed. The program was specially designed for each experiment, depending on the oligonucleotides and the product size. The synthesized product could be analysed in an agarose gel electrophoresis. 


\subsubsection{DNA sequencing}

A sequencing reaction consisted of $1 \mu \mathrm{l}$ template DNA (preferably plasmid DNA from a Wizard Plus SV Kit purification), $1 \mu$ sequencing mix (polymerase; dNTP's with fluorescent dyes; $30 \mathrm{mM}$ magnesium chloride and buffer substances), $1 \mu \mathrm{l}$ oligonucleotide ( 1 : 100 diluted; compared to usual PCR), $1.5 \mu$ sequencing buffer and $6 \mu \mathrm{ldd} \mathrm{H}_{2} \mathrm{O}$. The PCR program consisted of 25 cycles with a $10 \mathrm{~s}$ denaturation step at $95^{\circ} \mathrm{C}$, an annealing step for $5 \mathrm{~s}$ at $50^{\circ} \mathrm{C}$ and an elongation step for $4 \mathrm{~min}$ at $60^{\circ} \mathrm{C}$. The PCR product was precipitated by adding $1 \mu \mathrm{l} 3 \mathrm{M}$ sodium acetate ( $\mathrm{pH}$ 5.2), $1 \mu \mathrm{l} 125 \mathrm{mM}$ EDTA and $50 \mu \mathrm{l}$ ethanol (100\%, RT). After centrifugation (RT, 13000 $\mathrm{rpm}, 10 \mathrm{~min}$ ) the sediment was washed with $70 \%$ ethanol and air-dried. $15 \mu \mathrm{l}$ formamide were added to stabilize the DNA. The reactions were analysed by the developmental biology of the Georg-August-Universität Göttingen.

\subsubsection{Gene deletion using homologue recombination}

The deletion of genes as described in Longtine et al. (1998) (Longtine, 1998) was used for the deletion of atg 4 , atg27 and vps 4 in different background strains. A DNA fragment was amplified using the primers listed in chapter 3.1.4 Oligonucleotides. The primers had a $20 \mathrm{bp}$ homologue region to the template (either a NAT cassette or a HIS3 cassette) and a 45 bp homologue region to the flanking regions of the gene origin. This PCR product was used in a high efficient transformation reaction as described in chapter 3.2.3.1. The yeast cells with the homologues integrated NAT or HIS3 cassette could be selected on medium containing nourseotricine (clonNAT) or lacking histidine. 


\subsubsection{Generating a CDC48.3 strain in WCG background}

\subsubsection{Crossing of haploid yeast strains}

To obtain diploid yeast cells two strains with corresponding mating type were mixed on a agar plate and incubated for $6 \mathrm{~h}$ at $30^{\circ} \mathrm{C}$.

Tab. 12 Strains for the generation of CDC48.3 in WCG background

\begin{tabular}{|c|c|c|}
\hline Strain & Genotype & Source \\
\hline cdc48-3 & $\begin{array}{l}\text { MATa pep4A::URA3 cdc48-3 } \\
\text { temperature sensitive at } 36^{\circ} \mathrm{C}\end{array}$ & F. Madeo \\
\hline WCG4 & $\begin{array}{l}\text { WCG4a MATa his3-11,15 } \\
\text { leu2-3,112 ura3 }\end{array}$ & $\begin{array}{l}\text { W. Heinemeyer, } \\
\text { Stuttgart }\end{array}$ \\
\hline
\end{tabular}

Then the cells were selected for diploids at $36.5^{\circ} \mathrm{C}$ on $\mathrm{CM}-\mathrm{HIS}$ selection plates for 2 days.

\subsubsection{Sporulation}

The diploid cells were shifted to fresh GNA agar plates $(100 \mathrm{ml}$ contain: $5 \mathrm{~g} \mathrm{D}$ glucose; $3 \mathrm{~g}$ Difco nutrient broth; $1 \mathrm{~g}$ Difco yeast extract and 2\% (w/v) agarose) for one day. Then the cells were transferred in $2 \mathrm{ml}$ supplemented liquid sporulation medium (200 ml contain: $20 \mathrm{ml}$ 10\% (w/v) potassium acetate stock; $2 \mathrm{ml} 0.5 \%(\mathrm{w} / \mathrm{v})$ zinc acetate stock; $2 \mathrm{ml}$ uracil solution $(0,2 \mathrm{mM}$ in $0.5 \%$ sodium hydrogen carbonate solution); $1 \mathrm{ml}$ L-histidine solution $(0.3 \mathrm{mM}) ; 3.3 \mathrm{ml}$ L-leucine solution $(1,7 \mathrm{mM}))$ for 5 days at $25^{\circ} \mathrm{C}$.

\subsubsection{Random spores}

$1 \times 10^{8}$ cells and asci of a sporulated culture were mixed with $180 \mu \mathrm{ddH}_{2} \mathrm{O}$ in a polypropylen tube. $20 \mu \mathrm{l}$ of $5 \mathrm{mg} / \mathrm{ml}$ Zymolyase 20T in ZL-buffer $(0.1 \mathrm{M}$ sodium phosphate $\mathrm{pH} 6.5 ; 1.2 \mathrm{M}$ sorbitol; $40 \%$ glycerol $(\mathrm{w} / \mathrm{v}))$ were added and the reaction was incubated for $30 \mathrm{~min}$ at $30^{\circ} \mathrm{C}$ while shaking. The cells were harvested (13000 rpm, $30 \mathrm{sec}$ ), washed once with water and resuspended in $100 \mu \mathrm{ddH}_{2} \mathrm{O}$. Afterwards they were gently mixed for 2 min and the supernatant was discarded. The 
reaction was washed two times with $\mathrm{ddH}_{2} \mathrm{O}$ and discarded again. $1 \mathrm{ml}$ of sterile $0.01 \%(\mathrm{v} / \mathrm{v}) \mathrm{NP}-40$ in $\mathrm{ddH}_{2} \mathrm{O}$ was added and the mixture was treated for 2 min with ultrasonic. The solution was diluted $(1: 10-1: 10000)$ and spread on YPD plates.

\subsubsection{Chromosomal N-terminal fusion of GFP-Atg8 using the cre recombinase system}

A PCR product for homologue recombination of GFP between Atg8 and its promoter was constructed (Fig. 13 upper part and text). As template the plasmid POM42 and as primers the primers cGFP-Atg8 $1 \mathrm{f}$ and cGFP-Atg8 $2 \mathrm{r}$ were used. After homologue recombination (see 3.2.15 Gene deletion using homologue recombination) the URA selection cassette was recombined out of the chromosome by the induction of a cre recombinase (using the Plasmid pSH65) as describen in Gauss R., Yeast 2005 (Gauss, 2005).

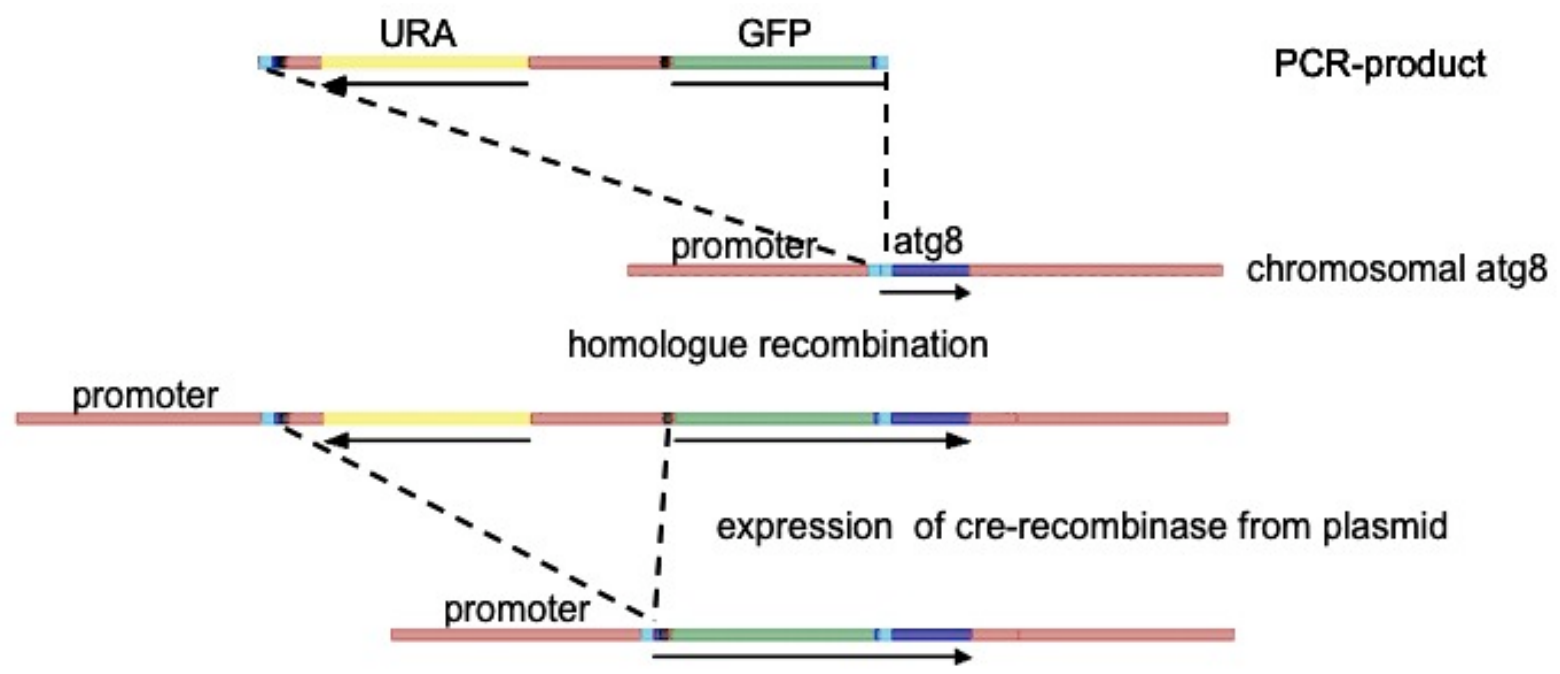

Fig. 13 Construction of the chromosomal $n$-terminal fusion protein GFP-Atg8

The construction took place in two steps. In the first step the homologue regions in light blue are required for recombination. They lie directly between the promoter region and atg8. In the second step a cre recombinase catalyses a homologue recombination between the two lox sites (in black). The arrows indicate open reading frames.

All steps were followed by PCR. 


\subsubsection{Southern blot}

Chromosomal DNA fragments were digested with restriction enzymes and separated by agarose gel electrophoresis. Then the DNA was transferred to a PVDF membrane and analysed with a labled single strand probe.

In a first step a specific DNA hybridisation probe was produced using the manufacturers advice (Gene Images ${ }^{\text {TM }}$ Random-Prime Labeling Module-Kit). $20 \mu \mathrm{g}$ chromosomal DNA was digested overnight with $10 \mathrm{U}$ of a restriction enzyme in a total volume of $50 \mu \mathrm{l}$ (chapter 3.2.8 Restriction digest). The fragments were separated in a $0.8 \%$ agarose gel for $1,5 \mathrm{~h}$ at $90 \mathrm{~V}$. Afterwards the gel was washed two times for $8 \mathrm{~min}$ in acid-nicking-buffer (250 $\mathrm{mM}$ hydrochloric acid), once for $15 \mathrm{~min}$ in denaturing buffer (1.5 M sodium chloride; $500 \mathrm{mM}$ sodium hydroxide) and for $1 \mathrm{~h}$ in neutralisation buffer $(500 \mathrm{mM}$ Tris/ $\mathrm{HCl} \mathrm{pH}$ 7.0; $3 \mathrm{M}$ sodium chloride). Then the DNA was transferred to a Hybond $\mathrm{N}+$-nylon-membrane using a diffusion blot overnight with $6 \times$ SSC buffer ( $90 \mathrm{mM}$ sodium citrate; $900 \mathrm{mM}$ sodium chloride; $\mathrm{pH}$ 7.0) (Fig. 14). After the transfer the DNA was cross-linked to the membrane using UV light ( 5 min on an UV table). The membrane could be stored at $4^{\circ} \mathrm{C}$ or used for hybridisation.

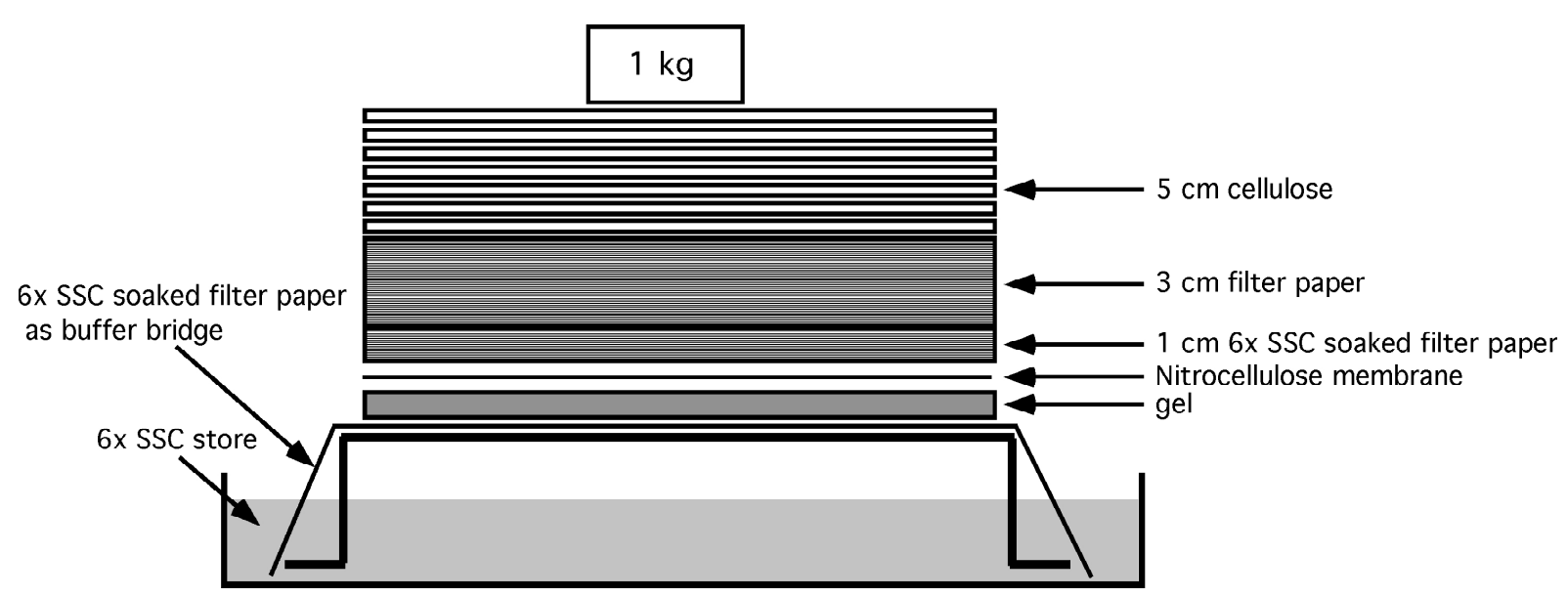

Fig. 14 Diffusion blot

The membrane was washed in hybridisation buffer ( $0.75 \mathrm{M}$ sodium chloride; $75 \mathrm{mM}$ sodium citrate; $0.1 \%(\mathrm{w} / \mathrm{v})$ SDS; $5 \%(\mathrm{w} / \mathrm{v})$ dextransulfate; $5 \%$ liquid block (from GE Healthcare)) which was preheated at $60^{\circ} \mathrm{C}$ for $3-5 \mathrm{~h}$ in a hybridisation oven at $60^{\circ} \mathrm{C}$. The DNA hybridisation probe was added, after boiling for $5 \mathrm{~min}$ and chilling on ice for $5 \mathrm{~min}$, to the membrane and incubated overnight. The probe could be reused several times. 
After hybridisation the membrane was washed for 15 min with wash buffer 1 (150 mM sodium chloride, $15 \mathrm{mM}$ sodium citrate, $0.1 \%(\mathrm{w} / \mathrm{v}) \mathrm{SDS}$ ) at $60^{\circ} \mathrm{C}$ and further washed for 15 min with wash buffer 2 (75 mM sodium chloride, $7.5 \mathrm{mM}$ sodium citrate, $0.1 \%(\mathrm{w} / \mathrm{v}) \mathrm{SDS}$ ) at $60^{\circ} \mathrm{C}$. The subsequent washing steps were performed with diluent buffer (300 mM sodium chloride, $100 \mathrm{mM}$ Tris/HCl, $\mathrm{pH}$ 9.5) for $5 \mathrm{~min}$, with $10 \%$ liquid block for $60 \mathrm{~min}$ and with diluent buffer for $5 \mathrm{~min}$ at room temperature. The AP-conjugate was diluted $1: 5000$ in diluent buffer with $0.5 \%(\mathrm{w} / \mathrm{v})$ BSA and incubated with the membrane for $1 \mathrm{~h}$ (shaking, RT). After three washing steps with diluent buffer for 15 min, the DNA was detected using the Gene Images CDP-Star Detection Reagent from Amersham (see manufacturers advice).

\subsubsection{Alkaline lysis of yeast cells}

For alkaline lysis $2 \mathrm{OD}_{600}$ of logarithmic, stationary or starved yeast cells were used. The cells were transferred to a reaction cup and sedimented at $3000 \mathrm{rpm}$ for $5 \mathrm{~min}$. The sediment was resuspended in $1 \mathrm{ml}$ of cold $\mathrm{ddH}_{2} \mathrm{O}$ and mixed with $150 \mu \mathrm{l}$ cold lysis-solution (fresh prepared: $1.85 \mathrm{M}$ sodium hydroxide; $7.5 \% \quad(\mathrm{v} / \mathrm{v})$ ßmercaptoethanol). The reaction was mixed every 2 min and kept on ice. After 10 min of incubation $150 \mu \mathrm{l} 50 \%$ trichloroacetic acid (w/v) were added and the reaction was incubated on ice for $10 \mathrm{~min}$. The precipitated proteins were sedimented $\left(4^{\circ} \mathrm{C}\right.$, $13000 \mathrm{rpm}, 10 \mathrm{~min}$ ), washed twice with acetone and dried for $5 \mathrm{~min}$ at $37^{\circ} \mathrm{C}$. The sediment was resuspended in $100 \mu \mathrm{l} 2$ x Lämmli-buffer $(116 \mathrm{mM}$ Tris $/ \mathrm{HCl} \mathrm{pH} 6.8$; $12 \%$ (w/v) glycerol; $3.42 \%$ SDS (w/v); a tip bromphenolblue; $1 \%$ ß-mercaptoethanol) by harsh vortexing for $30 \mathrm{~min}$ at $30^{\circ} \mathrm{C}$. Before loading the probe on a polyacrylamide gel the cell debris was centrifuged to the bottom of the cup (RT, $13000 \mathrm{rpm}, 5 \mathrm{~min}$ ).

\subsubsection{SDS-Polyacrylamid-Gel-Electrophoreses (PAGE)}

The discontinuous SDS-PAGE was used as described in Laemmli et al. (Laemmli, 1970) in a Mini-Protean III electrophoreses chamber from Biorad following the manufacturer advice. To separate the samples $8-12 \%$ acrylamide separating gels and $5 \%$ acrylamide collecting gels were used. 
Tab. 13 Composition of SDS Polyacrylamid gels

\begin{tabular}{l|c|c} 
& 10\%separating gel & $5 \%$ collecting gel \\
\hline $\mathrm{ddH}_{2} \mathrm{O}$ & $1.9 \mathrm{ml}$ & $3.0 \mathrm{ml}$ \\
$1.5 \mathrm{M}$ Tris, pH 8.8 & $1.25 \mathrm{ml}$ & - \\
$0.5 \mathrm{M}$ Tris PH 6.8 & - & $1.25 \mathrm{ml}$ \\
Protogel & $1.8 \mathrm{ml}$ & $0.7 \mathrm{ml}$ \\
$10 \%(\mathrm{w} / \mathrm{v})$ SDS & $50 \mu \mathrm{l}$ & $50 \mu \mathrm{l}$ \\
$10 \%(\mathrm{w} / \mathrm{v})$ APS & $50 \mu \mathrm{l}$ & $50 \mu \mathrm{l}$ \\
TEMED & $2.5 \mu \mathrm{l}$ & $5 \mu \mathrm{l}$
\end{tabular}

As molecular maker the "Precision Plus Protein All Blue Standards" marker from Biorad was used, consisting of the following molecular weights: $250 \mathrm{kDa}, 150 \mathrm{kDa}$, $100 \mathrm{kDa}, 75 \mathrm{kDa}, 50 \mathrm{kDa}, 37.5 \mathrm{kDa}, 25 \mathrm{kDa}, 15 \mathrm{kDa}, 10 \mathrm{kDa}$. After loading the gel $(10 \mu \mathrm{l} /$ probe) and filling the gel chamber with SDS-running buffer (200 mM glycerol, $25 \mathrm{mM}$ Tris, $0.1 \%$ SDS) the gel run was started with $100 \mathrm{~V}$. When the samples enter the collecting gel the voltage was raised to $150 \mathrm{~V}$. The gel run was stopped after the bromphenolblue band reached the end of the gel, the collecting gel was cut off and the rest of the gel was used for western blot analysis.

\subsubsection{Western blot analysis using a trans blot cell}

As standard for western blot analysis a Mini Trans-Blot Cell from Biorad was used to blot 2 Gels on PVDF membranes. In bigger approaches up to 8 gels could be blotted at the same time in a Trans blot cell from Biorad. The transfer assembly was built up in a gel holder cassette as follows:

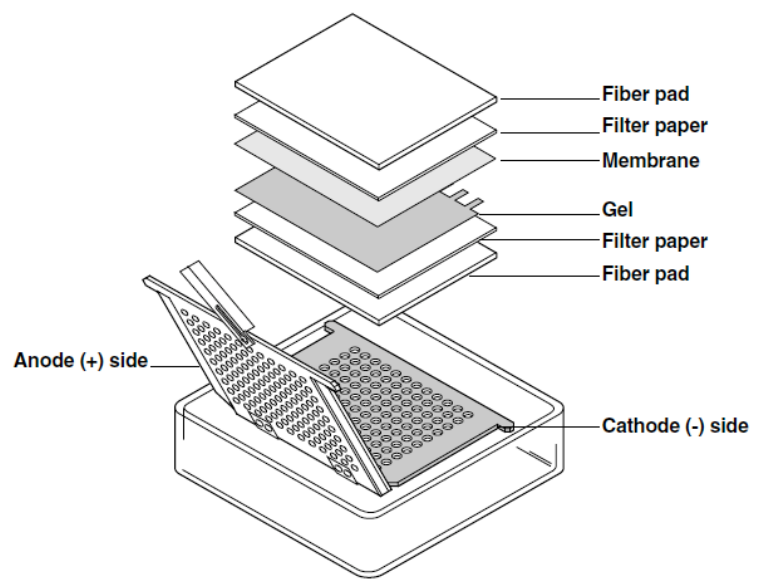

Fig. 15 Cartoon of a gel holder cassette

Two peaces of filter papers (GB 002) were aequilibrated in blotting buffer. The PVDF membrane was activated in methanole (100\%) before usage. (picture taken from the Biorad manual) 
This packed gel holder cassette was inserted into the buffer tank, which was filled with cold blotting buffer (192 mM glycerol; $25 \mathrm{mM}$ Tris; $20 \%$ methanole; $4^{\circ} \mathrm{C}$ cold). The transfer time was at least 4 hours or overnight at $90 \mathrm{~mA}$ per gel. After the blotting process the PVDF-membrane was blocked in TBST $(20 \mathrm{mM}$ Tris/HCl pH7.6; $137 \mathrm{mM}$ sodium chloride; $0.1 \%$ Tween $20(\mathrm{w} / \mathrm{v})$ ) containing 10\% (w/v) skim milk powder, to block up all unspecific binding sites on the membrane, for $1 \mathrm{~h}$ at room temperature or overnight at $4^{\circ} \mathrm{C}$. The immunoblot was washed three times with $25 \mathrm{ml}$ TBST for 5 min. In the next step the blot was incubated with the primary (first) antibody in TBST at room temperature for at least one hour or overnight at $4^{\circ} \mathrm{C}$. The immunoblot was washed three times with $25 \mathrm{ml} \mathrm{TSBT}$ for $5 \mathrm{~min}$ and then incubated with the second antibody (in TBST with 1\% skim milk powder (w/v)) for $1 \mathrm{~h}$. After six 5 min washing steps with TBST, the blot was developed with $\mathrm{ECL}^{\mathrm{TM}}$ Plus (Amersham) following the manufacturer's advice.

Afterwards the immunoblot was analysed using a LAS-3000 (Fujifilm). Quantitative statistics from blots were done using the AIDA Software, Version 4.06.116 (Raytest, 2005).

\subsubsection{Stripping of once immunodetected membranes}

To remove an antibody from an already used immunoblot the membrane was airdried for $5 \mathrm{~min}$. As first step the blot was washed with methanol and three times with TBST-buffer. Then the attached antibodies were denatured and washed of the membrane by a 10 min incubation with $10 \%$ acetic acid (v/v). The acetic acid was removed by washing five times using $25 \mathrm{ml}$ TBST for $5 \mathrm{~min}$. The method continued as described in chapter 3.2.21 with blocking in TBST containing 10\% (w/v) skim milk powder.

\subsubsection{Subcellular fractionation}

For subcellular fractionation $60 \mathrm{OD}_{600}$ of $4 \mathrm{~h} S \mathrm{SD}(-\mathrm{N})$ starved cells $\left(\mathrm{OD}_{600}\right.$ of 6 ) were harvested (2000 rpm, 5min) and incubated for $15 \mathrm{~min}$ in $30 \mathrm{ml}$ DTT-buffer $(10 \mathrm{mM}$ Tris sulfate $\mathrm{pH}$ 9.4; $10 \mathrm{mM}$ DTT). The cells were sedimented (RT ,2000 rpm, 5min), the supernatant discarded and the cells resuspended in $6 \mathrm{ml} \mathrm{SP-buffer} \mathrm{(1} \mathrm{M} \mathrm{sorbitol;}$ 
$20 \mathrm{mM}$ PIPES pH 6.8). $120 \mu \mathrm{l}$ of freshly solved Zymolyase T20 (10 mg / ml) in SPbuffer were added and the reaction was incubated in a water bath at $30^{\circ} \mathrm{C}$ and $20 \mathrm{rpm}$ for $25 \mathrm{~min}$. The spheroplasts were sedimented (RT, $3000 \mathrm{~g}, 15 \mathrm{~min}$ ) and resuspended with a glass stick in $6 \mathrm{ml}$ SP-buffer. After a second centrifugation (RT, $3000 \mathrm{~g}, 3 \mathrm{~min}$ ) the speroplasts were hypotonically lysed in lysis buffer ( $0.2 \mathrm{M}$ sorbitol; 20 mM PIPES pH 6.8; $5 \mathrm{mM} \mathrm{MgCl}_{2}$; 1x Complete protease inhibitor (Roche); $1 \mathrm{mM}$ PMSF and $1 \times$ protease inhibitor mix (1000 x concentrated stock $1 \mathrm{mg}$ Antipain, $1 \mathrm{mg}$ Aprotinin, $1 \mathrm{mg}$ Benzamidin, $1 \mathrm{mg}$ Pepstatin A, $1 \mathrm{mg}$ Leupeptin, $1 \mathrm{mg}$ Chymostatin in $1 \mathrm{ml} \mathrm{DMSO})$ ). Lysates were generated by centrifugation at $500 \mathrm{~g}$ for $10 \mathrm{~min}$. Lowspeed pellet P13 (13000 g pellet), high-speed pellet P100 (100000 g pellet) and high speed supernatants $\mathrm{S} 100$ (100000 g sup) were generated as described by Kirisako et al. (Kirisako, 2000). The sediments were resuspended in a corresponding volume of $2 \times$ Laemmli buffer and processed for immunoblots.

\subsubsection{Sucrose gradient}

For a sucrose gradient $600 \mathrm{OD}_{600}$ of $4 \mathrm{~h} \mathrm{SD}(-\mathrm{N})$ starved cells $\left(\mathrm{OD}_{600}\right.$ of 6$)$ were harvested $\left(500 \mathrm{~g}, 5 \mathrm{~min}, 4^{\circ} \mathrm{C}\right)$. Cells were washed with $30 \mathrm{ml}$ ice-cold $10 \mathrm{mM}$ sodium azide and centrifuged again $\left(500 \mathrm{~g}, 5 \mathrm{~min}, 4^{\circ} \mathrm{C}\right)$. The sediment was resuspended in $10 \mathrm{ml}$ spheroplasting (SP) buffer (50 mM potassium dihydrogen phosphate $\mathrm{pH} 7.5$; $10 \mathrm{mM}$ sodium azide; $40 \mathrm{mM}$ ß-mercaptoethanol) containing $3 \mathrm{mg}$ Zymolyase T100 and incubated for $30-45 \mathrm{~min}$ at $30^{\circ} \mathrm{C}$. All following steps were done at $4^{\circ} \mathrm{C}$. The spheroplasts were centrifuged $\left(500 \mathrm{~g}, 10 \mathrm{~min}, 4^{\circ} \mathrm{C}\right)$ and the sediment was resuspended with a glass stick in $10 \mathrm{ml} \mathrm{SP-buffer}$. After a centrifugation (500 g, $\left.10 \mathrm{~min}, 4^{\circ} \mathrm{C}\right)$ the sediment was resuspended in lysis buffer $(0.8 \mathrm{M}$ sorbitol; $10 \mathrm{mM}$ MOPS pH 7.2; 1 mM EDTA; PMSF and 1x protease inhibitor mix (1000x concentrated stock $1 \mathrm{mg}$ Antipain, $1 \mathrm{mg}$ Aprotinin, $1 \mathrm{mg}$ Benzamidin, $1 \mathrm{mg}$ Pepstatin A, $1 \mathrm{mg}$ Leupeptin, $1 \mathrm{mg}$ Chymostatin in $1 \mathrm{ml}$ DMSO)) and homogenized with 40 beats of a douncer. After preclearing $\left(5000 \mathrm{rpm}, 10 \mathrm{~min}, 4^{\circ} \mathrm{C}\right)$ the supernatant was applied on the top of a sucrose gradient (per step $1 \mathrm{ml}$ of 18, 22, 26, 30, 34, 38, 42, $46,50,54 \%$ sucrose $(\mathrm{w} / \mathrm{v})$ ). After $3 \mathrm{~h}$ of ultracentrifugation (Beckman ultracentrifuge, SW41 rotor, $34000 \mathrm{rpm}) 18$ fractions each $610 \mu$ l were collected and precipitated with trichloroacetic acid. The sediments were washed two times with acetone and resuspended in $75 \mu \mathrm{l}$ of $2 \times$ Lämmli-buffer $(116 \mathrm{mM} \mathrm{Tris/HCl} \mathrm{pH} \mathrm{6.8;12 \%} \mathrm{(w/v)}$ 
glycerol; $3.42 \%$ SDS (w/v); a tip bromphenolblue; $1 \%$ ß-mercaptoethanol) and processed for immunoblots.

\subsubsection{Measuring the breakdown of GFP fused proteins}

\subsubsection{Measurement of the breakdown of GFP-Osh1p}

All deletion strains were transformed with pRS416-GFP-Osh1. These transformed cells were used for a pre-culture in selective medium (usually CM -URA) overnight at $30^{\circ} \mathrm{C}$ at $220 \mathrm{rpm}$ agitation. After $26 \mathrm{~h}$ of incubation the pre-culture was diluted $1: 100$ as main-culture in the same selective medium and grown overnight at $30^{\circ} \mathrm{C}$ at $220 \mathrm{rpm}$. The next morning the cells were harvested at an $\mathrm{OD}_{600}$ of $5-9.20 \mathrm{OD}_{600}$ cells were washed with $\mathrm{SD}(-\mathrm{N})$ starvation medium, resuspended in $2 \mathrm{ml} S \mathrm{SD}(-\mathrm{N})$ medium and incubated at $30^{\circ} \mathrm{C}$ at $220 \mathrm{rpm} .200 \mu \mathrm{l}$ samples $\left(2 \mathrm{OD}_{600}\right.$ cells) were taken at the given time points (usually 0, 2, 4, 6 and $8 \mathrm{~h}$ ) and alkaline lysed (see chapter 3.2.19 Alkaline lysis of yeast cells). These samples were applied on $10 \%$ acrylamide gels containing $6 \mathrm{M}$ urea, analysed with western blots using a trans blot cell (see chapter 3.2.21) and detected with $\mathrm{ECL}^{\mathrm{TM}}$ Plus (Amersham). After rapamycine-induced starvation the same washing steps were done with fresh $\mathrm{CM}$ medium containing rapamycine $(0.2 \mu \mathrm{g} \mathrm{/} \mathrm{ml}$ end concentration from a stock solution $1 \mathrm{mg} / \mathrm{ml}$ rapamycine in DMSO). When using potassium acetate as starvation medium the cells were washed with $1 \%$ potassium acetate $(\mathrm{w} / \mathrm{v})$ or $1 \%$ potassium acetate $(\mathrm{w} / \mathrm{v})$ and $2 \%$ glucose.

\subsubsection{Measurement of the breakdown of GFP-Osh1p or GFP-Atg8 in temperature sensitive strains}

To measure the breakdown of GFP-Osh1 or GFP-Atg8 in temperature sensitive strains, the cells were transformed with the pRS416-GFP-Osh1 or GFP-Atg8 plasmid. Transformed cells were taken from agar plates, inoculated as a pre-culture in liquid selection medium (usually $\mathrm{CM}-\mathrm{URA}$ ) and grown overnight at $23^{\circ} \mathrm{C}$ (permissive temperature) at $220 \mathrm{rpm}$. Once the cells reached a stationary culture $\left(\mathrm{OD}_{600}=6-10\right)$, a $20 \mathrm{ml}$ main-culture was started with a dilution of about $1: 80$ which was incubated overnight at $23^{\circ} \mathrm{C}$ at $220 \mathrm{rpm}$. The next morning the $\mathrm{OD}_{600}$ of the 
cultures usually were between 4 and $8.50 \mathrm{OD}_{600}$ cells were taken, washed two times with $10 \mathrm{ml} \mathrm{SD}(-\mathrm{N})$-medium and then resuspended again in $10 \mathrm{ml} \mathrm{SD}(-\mathrm{N})$-medium. The sample was then divided in two equal parts. One was transferred to a water bath at $23^{\circ} \mathrm{C}$ (permissive temperature), $110 \mathrm{rpm}$ and the other to a water bath at $34^{\circ} \mathrm{C}$, $36^{\circ} \mathrm{C}$ or $38^{\circ} \mathrm{C}$ (restrictive temperature), $110 \mathrm{rpm} .400 \mu$ samples $\left(2 \mathrm{OD}_{600}\right.$ cells) were taken at the given time points $(0,1,2,3$ and $4 \mathrm{~h})$ and alkaline lysed (see chapter 3.2.19 Alkaline lysis of yeast cells). These samples were applied on $10 \%$ acrylamide Geld containing $6 \mathrm{M}$ urea, analysed with western blots using a trans blot cell (see chapter 3.2.21) and detected with $E C L^{\mathrm{TM}}$ Plus (Amersham).

\subsubsection{Microscopy}

\subsubsection{Fluorescence microscopy}

Most of the fluorescence microscopy was done using a Zeiss Axioskope 2. The pictures were taken with a digital camera (AxioCam MRm) and the AxioVision software (release 4.5, Zeiss). The images were converted and processed with Adobe Photoshop CS3 or Canvas X. Fluorescent pictures were taken with corresponding filter sets: GFP, RFP / Cy3 and DAPI.

$5 \mu \mathrm{l}$ of yeast cells were taken at the indicated time points, dropped on a glass slide and covered with a cover slip.

\subsubsection{Laser scanning microscopy}

To visualize two fluorescent dyes simultaneously a Leica TCS SP2 AOBS confocal laser scanning microscope was used.

\subsubsection{Endosome and vacuole staining using the dye FM4-64}

Yeast cells were grown overnight to an $\mathrm{OD}_{600}$ of $0.5-6.0 .20 \mathrm{OD}_{600}$ cells were sedimented (RT, $5 \mathrm{~min}, 2000 \mathrm{rpm}$ ) and resuspended in $1 \mathrm{ml}$ YPD-medium containing $2 \mu \mathrm{l}$ of a FM4-64 solution (1 mg FM4-64 in $100 \mu \mathrm{l}$ DMSO). The cells were incubated $30 \mathrm{~min}$ at $30^{\circ} \mathrm{C}$ at $220 \mathrm{rpm}$ shaking then transferred to fresh YPD-medium and 
directly visualized in the microscope or shifted to starvation medium (SD-(N)) for up to 4 hours. For the visualisation a Cy-3 filter set was used.

\subsubsection{Vacuole staining of Cell tracker blue (CMAC)}

To visualize the vacuole the Cell tracker blue (CMAC) was used. $20 \mathrm{OD}_{600}$ of yeast cells were harvested and resuspended in $1 \mathrm{ml}$ YPD. $2 \mu \mathrm{l}$ of a $10 \mathrm{mM}$ Cell tracker blue CMAC solution (Invitrogen) were added and the cells were incubated for $30 \mathrm{~min}$ at $30^{\circ} \mathrm{C}$ at $220 \mathrm{rpm}$. The cells were then starved for up to 4 hours and analysed with a DAPI blue filter set. 


\section{Results}

\subsection{Where are the autophagic membranes coming from?}

Double membrane layered vesicles are formed out of the pre-autophagosomal structure (PAS). Where these membranes come from has been addressed for a long time but not answered yet. Different cell components have been discussed as potential membrane sources (Reggiori, 2004) (Reggiori, 2005) (Young, 2006) (Obara, 2008a). Probably more than one membrane source is required: one for the constitutive Cvt-pathway and an additional one under nutrient limitation for the larger autophagosomes.

Only two transmembrane proteins are known to locate at the PAS. These proteins are Atg27 that has been described to locate at the PAS, the mitochondria and the Golgi complex (Yen, 2007) and Atg9 that has been proposed to cycle between the PAS and mitochondria (Reggiori, 2005) dependent on Atg27. This cycling of Atg9 could deliver lipids to the PAS and thus facilitate the formation of Cvt vesicles and autophagosomes. In $\operatorname{atg} 1 \Delta \operatorname{atg} 27 \Delta$ double deletion cells the localization of Atg9 to its peripheral pool, which corresponds in part to mitochondria, is increased (Yen, 2007).

\subsubsection{Analysis of the peripheral Atg9 pool}

To enrich the peripheral pool of Atg9 several knockout strains in the WCG4a background were generated as described in chapter 3.2.15. All knockout strains were analyzed using southern blot analysis as described in 3.2.18 (data not shown).

The resident vacuolar hydrolases, aminopeptidase I (Ape1) is synthesized as pro form (pApe1) in the cytosol and transported either constitutively via the Cvt pathway or via the starvation induced macroautophagy pathway to the vacuole. The protein is matured (mApe1) by proteinase A (pep4), which can be monitored by western blot. As additional control of the correct knockout strains were harvested at stationary phase and after $4 \mathrm{~h}$ starvation in $\mathrm{SD}(-\mathrm{N})$-medium, alkaline lysed and prepared for immunoblots (Fig. 16 (A.)). A rabbit polyclonal Ape1 antibody was used for detection.

One aim of this study was to review the actual localization of Atg9, since 
mitochondria seem unlikely as a membrane source for the PAS.

$\operatorname{Atg} 9 \Delta, \operatorname{atg} 1 \Delta, \operatorname{atg} 1 \Delta \operatorname{atg} 27 \Delta$ and $\operatorname{atg} 4 \Delta \operatorname{atg} 27 \Delta$ cells were transformed with GFP-Atg 9 and the PAS marker Ape1-RFP (Fig. 16 (B.)).

A.

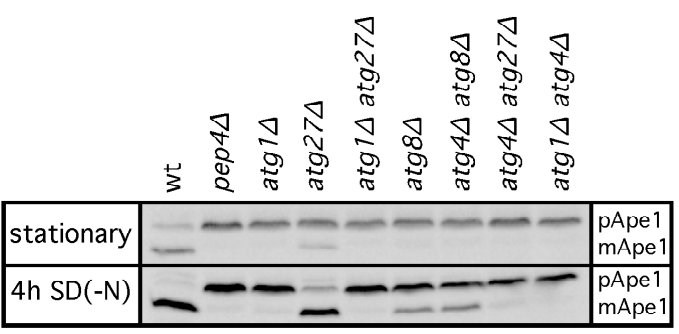

B.

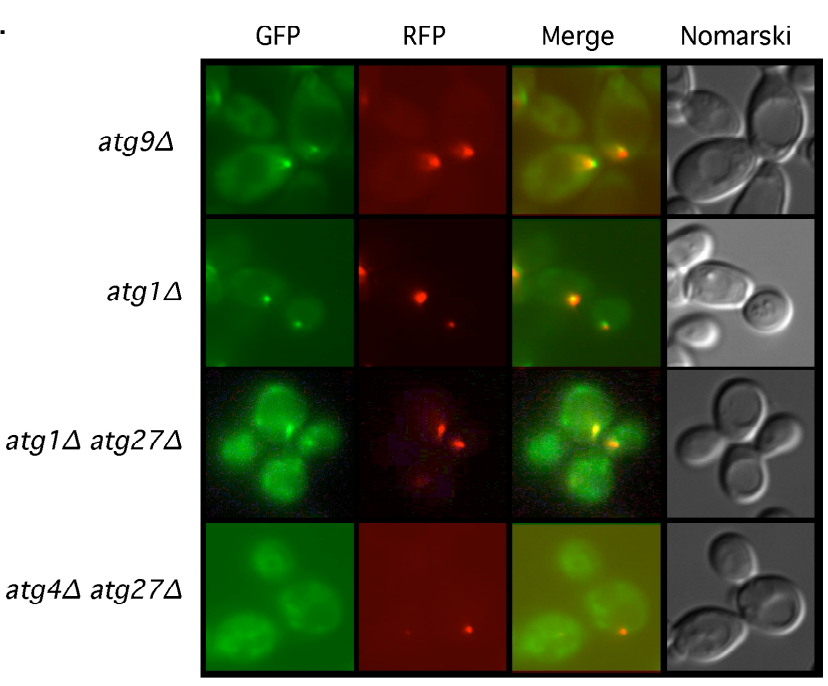

Fig. 16 Verification of the autophagic phenotype of the $\operatorname{atg} 27 \Delta, \operatorname{atg} 4 \operatorname{atg} 27 \Delta$ and $\operatorname{atg} 1 \Delta \operatorname{atg} 27 \Delta$ strains using Ape1 (A.) or GFP-Atg9 (B.) as a marker.

All strains in WCG background. (A.) Western blot of stationary and 4 hours $\mathrm{SD}(-\mathrm{N})$ starved alkaline lysed yeast cells. The full length (pApe1) and the matured form (mApe1) were detected using a polyclonal rabbit Ape1 antibody. (B.) Microscopy of stationary grown yeast cells carrying methionine inducible GFP-Atg9 (URA) and Ape1-RFP (LEU); medium: CM -URA -LEU +0,3mM MET.

In wild type cells Ape1 was matured. The vacuolar proteinase $A$ is required for the maturation of Ape1 in the vacuole and Atg1 for the formation of its transport vesicles, independent on the growth conditions.

Atg27 cells showed only a small amount of mature Ape1 at stationary phase, but complete maturation after starvation. In atg $8 \Delta$ cells the pro form accumulated but after $4 \mathrm{~h}$ starvation $20 \%$ of Ape1 was matured (Fig. 16 (A.)).

The plasmid expressed GFP-Atg9 complemented the atg9 $\Delta$ phenotype (after $4 \mathrm{~h}$ starvation the Ape1 signal was vacuolar; data not shown). In atg1 cells GFP-Atg9

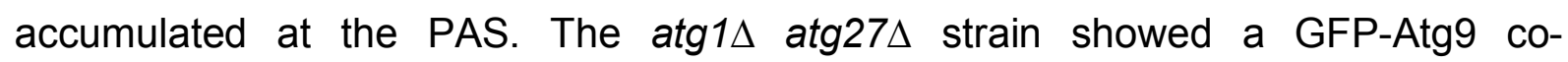
localization with the PAS marker Ape1 but had additional peripheral dots. This additional pool only existed in some cells and was not stable in further experiments. The $\operatorname{atg} 4 \Delta \operatorname{atg} 27 \Delta$ strain lost the clear peripheral GFP-Atg9 pool (Fig. 16 (B.)). 


\subsubsection{Identifying a peripheral Atg8 pool}

Problems with the stability of the peripheral GFP-Atg9 pool and the finding that the Atg8 protease Atg4 plays a role in the Atg9 cycling, led to the analysis of Atg8. Yeast cells were transformed with GFP-Atg8 and Ape1-RFP and analyzed after $4 \mathrm{~h}$ starvation in SD(-N)-medium (Fig. 17).

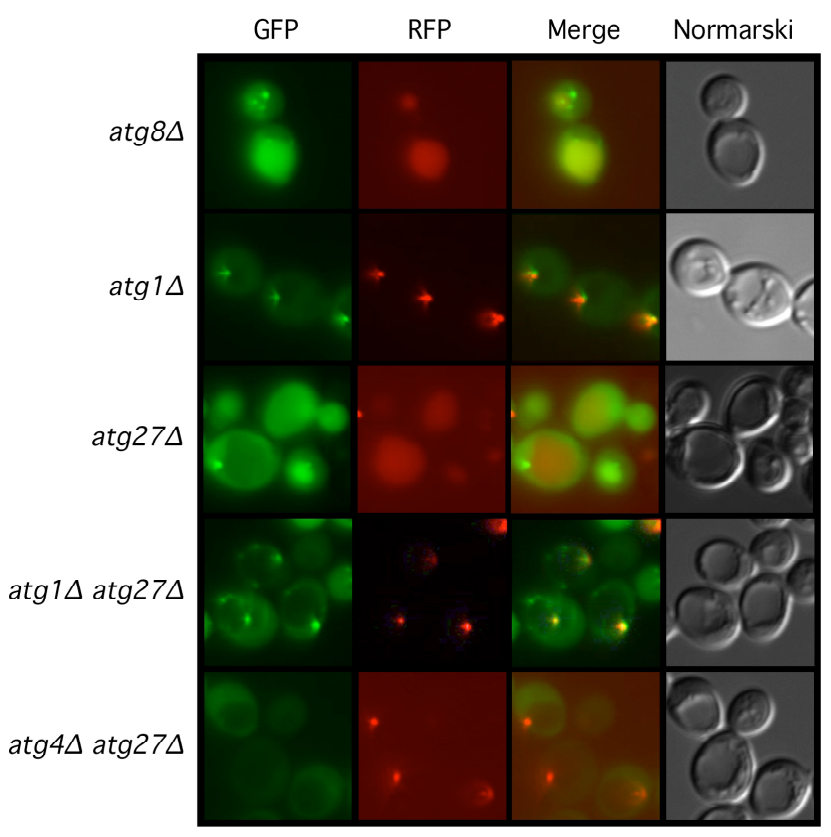

Fig. 17 Identifying a peripheral pool of Atg8 in atg1 $\Delta$ atg $27 \Delta$ cells

All strains in WCG background. Microscopic analysis of the localization of GFP-Atg8 in different knockout strains. Stationary grown yeast cells carrying GFP-Atg8 and Ape1-RFP were starved in $\mathrm{SD}(-\mathrm{N})$ for $4 \mathrm{~h}$ before visualization.

The plasmid expressed GFP-Atg8 complemented the atg8 $\Delta$ phenotype. As control, the $\operatorname{atg} 1 \Delta$ strain was used that restricted Atg 8 to the PAS shown by its colocalization with the PAS marker Ape1-RFP. In the $\operatorname{atg} 1 \Delta \operatorname{atg} 27 \Delta$ strain GFP-Atg8 partially colocalized with the PAS and showed an additional peripheral pool. In contrast GFPAtg8 gave a diffuse and often vacuolar signal in $\operatorname{atg} 27 \Delta$ cells. Atg $4 \Delta \operatorname{atg} 27 \Delta$ cells only showed a diffuse cytosolic signal. 


\subsubsection{Lipidation of Atg8 is essential for its peripheral pool}

To analyze the lipidation state of Atg8 at its peripheral pool and the requirement of the modification machinery for this localization, two different GFP-Atg8 plasmids were used. A full length GFP-Atg8 and an additional GFP-Atg8*, lacking the Cterminal arginine. This arginine is in vivo cleaved of by Atg4 before it is coupled to phosphatidylethanolamine (PE) in an ubiquitin like reaction with E1 / Atg3 and E2 / Atg7 (chapter 2.5.6.1). The maturation of Ape1p was tested under stationary and starvation conditions (Fig. 18 (A.)).

The localization of GFP-Atg8 and GFP-Atg8* in $\operatorname{atg} 4 \Delta \operatorname{atg} 8 \Delta$ cells was examined. Cells were cotransformed with GFP-Atg8 or GFP-Atg8* and Ape1-RFP (Fig. 18 (B.) upper part) or stained using FM4-64 as described in chapter 3.2.26.4 (Fig. 18 (B.) lower part). Cells were imaged after $4 \mathrm{~h}$ starvation in $\mathrm{SD}(-\mathrm{N})$-medium.

A.

\begin{tabular}{|c|c|c|c|c|c|}
\hline GFP-Atg8 & + & + & & + & + \\
\hline GFP-Atg8* & + & + & & + & + \\
\hline $\begin{array}{c}\text { pApe 1-1 } \\
\text { mApe1- }\end{array}$ & -1 & -1 & - & - - & - \\
\hline & $\operatorname{atg} 8 \Delta$ & $\begin{array}{l}\operatorname{atg} 4 \Delta \\
\operatorname{atg} 8 \Delta\end{array}$ & $\begin{array}{l}3 \frac{7}{7} \\
0 \\
8 \\
0\end{array}$ & $\operatorname{atg} 8 \Delta$ & $\begin{array}{l}\operatorname{atg} 4 \Delta \\
\operatorname{atg} 8 \Delta\end{array}$ \\
\hline & \multicolumn{2}{|c|}{ stationary } & \multicolumn{3}{|c|}{ 4h starved } \\
\hline
\end{tabular}

B.

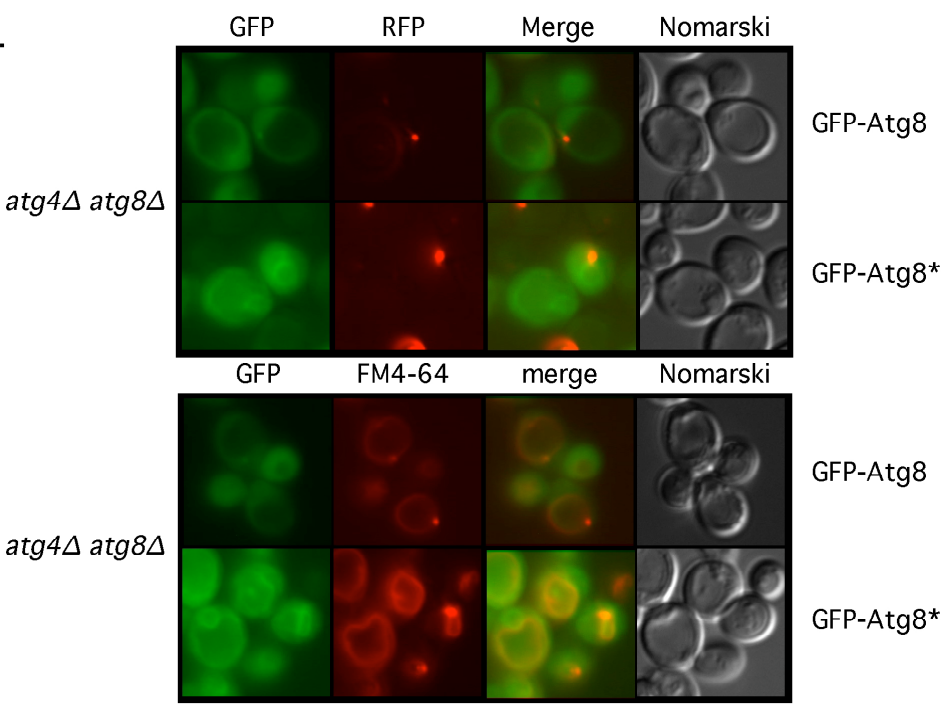

GFP-Atg8

$\operatorname{atg} 4 \Delta \operatorname{atg} 8 \Delta$

Fig. 18 Analysis of GFP-Atg8 and a GFP-Atg8 mutant lacking the C-terminal arginine (GFPAtg $8^{*}$ )

All strains in WCG background. (A.) Complementation study of GFP-Atg8 and GFP-Atg8* using a polyclonal rabbit Ape1 antibody. (B.) Microscopic analysis of the localization of GFP-Atg8 and GFPAtg $8^{*}$ in the $\operatorname{atg} 4 \Delta$ atg8 8 strain using the PAS marker Ape1-RFP (upper part) and the endosomal / vacuolar membrane marker FM4-64 (lower part). Cells were starved $4 \mathrm{~h}$ in SD(-N)-medium. 
Both GFP-Atg8 constructs rescued the Ape 1 maturation phenotype of atg $8 \Delta$ cells but in $\operatorname{atg} 4 \Delta \operatorname{atg} 8 \Delta$ cells only the GFP-Atg8* construct complemented the knockout phenotype (Fig. 18 (A.)).

The plasmid carrying wild type GFP-Atg8 had a weak GFP signal but colocalized with the PAS maker Ape1-RFP. The mutant GFP-Atg8* accumulated at a ring around the vacuole. This ring signal colocalized with FM4-64, an endosomal / vacuolar membrane marker (Fig. 18 (B.)).

A plasmid expressing a GFP-Atg8-cherry protein was constructed by insertion of the cherry sequence into the GFP-Atg8 plasmid. The cherry sequence was amplified in a $P C R$ reaction using a plasmid containing NLS-mcherry as template and the primers GFP-Atg8-cherry $1 \mathrm{f} /$ GFP-Atg8-cherry $2 \mathrm{r}$ (chapter 3.2.13). The resulting PCR product was cotransformed with the linearized GFP-Atg8 plasmid into atg $8 \Delta$ yeast cells for homologous recombination. The plasmid was rescued and sequenced.

Atg8 is coupled by its C-terminus to the inside and outside of autophagosomal membranes and its internal part reaches the vacuole. Because of the stability of GFP in the vacuole, the degradation of GFP-Atg8 can be visualised by immunoblots. The GFP-Atg8-cherry plasmid was constructed to differentiate between uncoupled (GFP and cherry signal colocalizing) and PE-coupled Atg8 (cherry is cleaved of Atg8; no colocalization of GFP and cherry).

The GFP-Atg8-cherry plasmid was transformed in wt, $\operatorname{atg} 8 \Delta, \operatorname{atg} 1 \Delta, \operatorname{atg} 1 \Delta \operatorname{atg} 27 \Delta$ and $\operatorname{atg} 1 \Delta \operatorname{atg} 4 \Delta \operatorname{atg} 27 \Delta$ cells. The cells were starved, alkaline lysed at the indicated time points and prepared for immunoblots. The membranes were probed with monoclonal GFP antibody (Fig. 19 (A.)). The same cells were analysed in a microscope after $4 \mathrm{~h}$ starvation in SD(-N)-medium using a Cy3 and a GFP filter set (Fig. 19 (B.)). 
A.

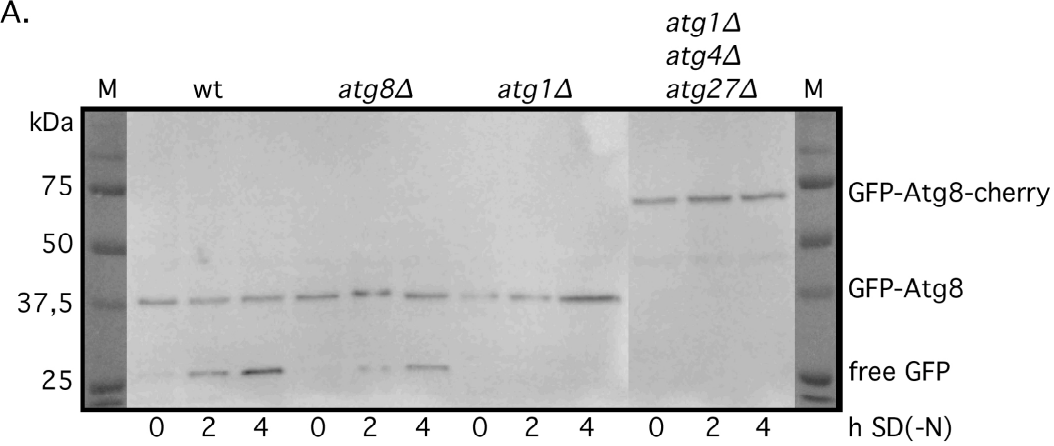

B.

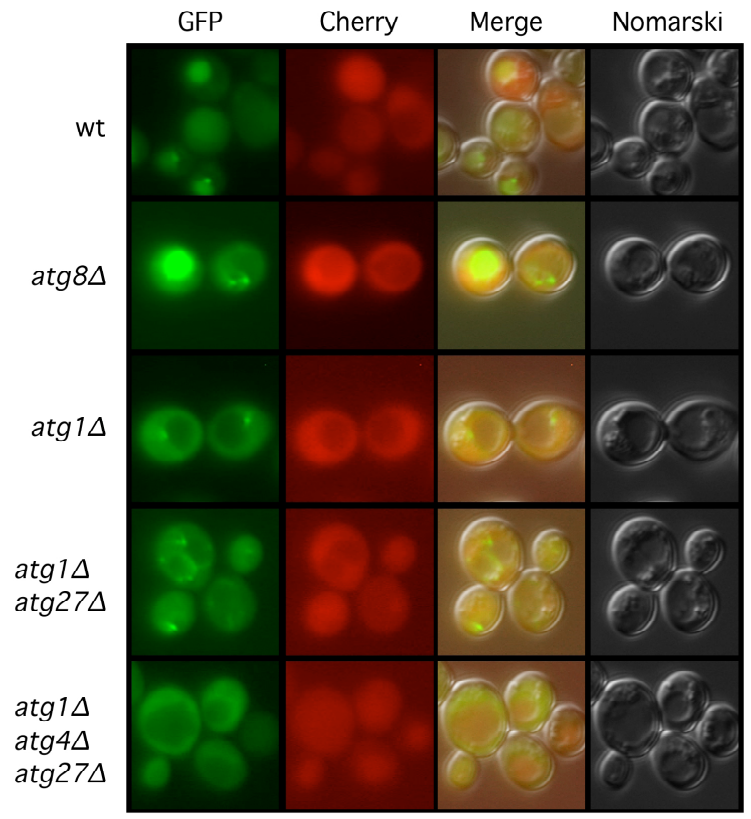

Fig. 19 Lipidation of Atg8 is essential for the peripheral pool

All strains in WCG background. (A.) Western blot of stationary $(0 \mathrm{~h})$ and $\mathrm{SD}(-\mathrm{N})$ starved $(2-4 \mathrm{~h})$ alkaline lysed yeast cells. The plasmid GFP-Atg8-cherry was detected using a mouse monoclonal GFP Antibody. Size of proteins: GFP $=240$ aa $=26$ kDa; GFP-Atg8 $=365$ aa $=40$ kDa; GFP-Atg8cherry $=594$ aa $=65 \mathrm{kDa}$; (B.) Microscopy of stationary yeast cells starved for $4 \mathrm{~h}$ in $\mathrm{SD}(-\mathrm{N})$ also carrying the GFP-Atg8-cherry plasmid.

The GFP-Atg8-cherry plasmid showed free GFP, thus the plasmid complemented the atg8s phenotype in western blot analysis. Microscopy provided this by GFP accumulating in the vacuole in those cells. The construct only showed a diffuse microscopic cherry signal in all strains. In atg1 $\Delta$ atg27 cells a peripheral GFP pool was visible. The peripheral pool vanished in the $\operatorname{atg} 1 \Delta \operatorname{atg} 4 \Delta \operatorname{atg} 27 \Delta$ cells, where cherry was not cleaved of by Atg4 and was full length. Antibodies against the cherry protein were not specific and showed only cross reactions with high molecule weight in immunoblots (data not shown). 


\subsubsection{The peripheral pool of Atg8 localizes to a PI3P containing ring around the vacuole}

The $\operatorname{atg} 8 \Delta, \operatorname{atg} 1 \Delta$ and $\operatorname{atg} 1 \Delta \operatorname{atg} 27 \Delta$ strains were transformed with the pGFP-Atg8 plasmid. The cells were stained with the endosomal / vacuolar membrane marker FM4-64 as described in chapter 3.2.26.3 (Fig. 20 (A.)).

In Fig. 20 (B.) the cells were cotransformed with GFP-Atg8 and a plasmid expressing a RFP-FYVE fusion protein. The FYVE domain binds to PI3P (Stenmark, 2002). The vacuole was additionally visualized using the vacuolar marker Cell tracker blue CMAC as described in chapter 3.2.26.4.

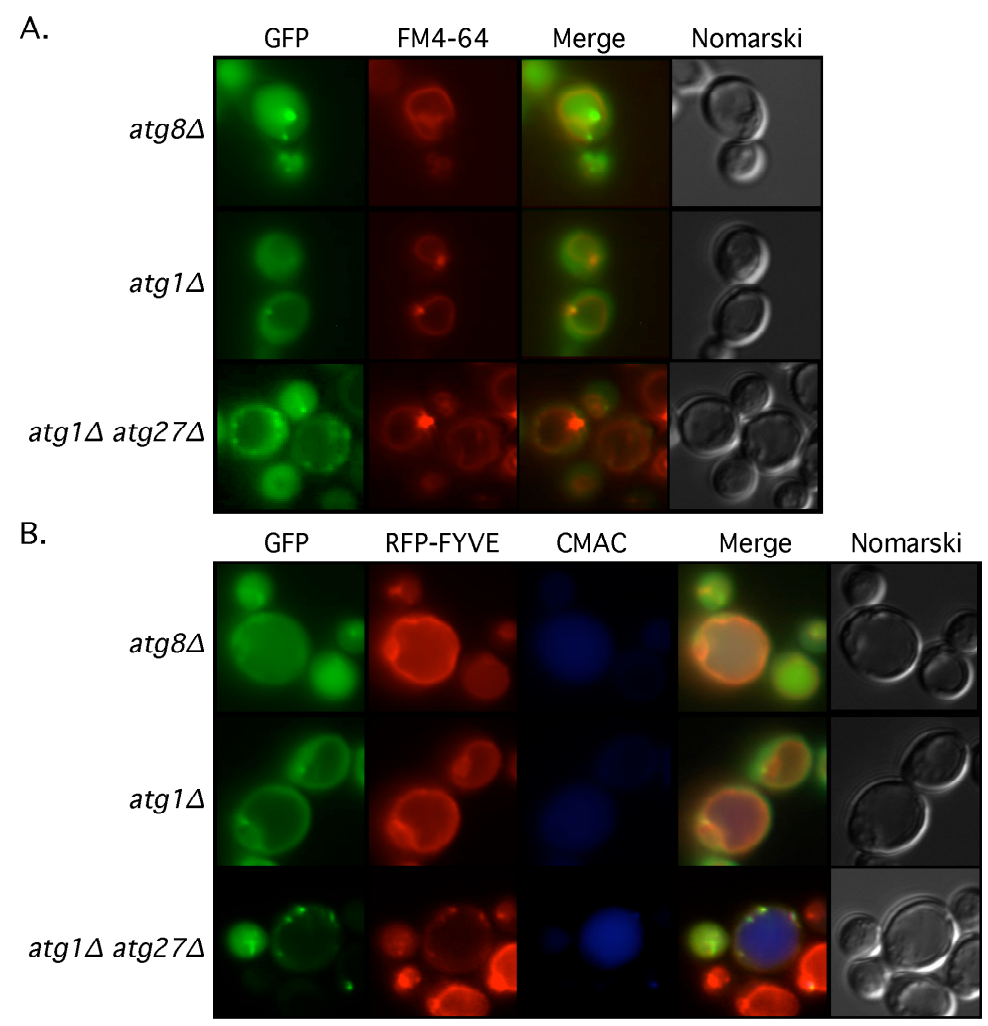

Fig. 20 The peripheral pool of Atg8 localizes to a PI3P containing ring around the vacuole All strains in WCG background. (A.) Microscopic analysis of the localization of GFP-Atg8 in different knockout strains after $4 \mathrm{~h}$ starvation in $\mathrm{SD}(-\mathrm{N})$-medium using the endosomal / vacuolar membrane marker FM4-64 and (B.) a combination of the RFP-tagged PI3P binding domain FYVE and the vacuolar marker Cell tracker blue CMAC.

The GFP-Atg8 plasmid complemented the atg8 8 phenotype. As a control the atg1 $\Delta$ strain was used that restricted Atg8 to the PAS. In the $\operatorname{atg} 1 \Delta$ atg27 $\Delta$ strain GFP-Atg8 partially colocalized with the PAS and showed an additional peripheral pool that colocalized with FM4-64 (Fig. 20 (A.)) and RFP-FYVE (Fig. 20 (B.)). 


\subsubsection{The peripheral pool of Atg8 localizes to endosomes}

Vps4 is an AAA $^{+}$ATPase (Babst, 1997). It plays a critical role in the MVB sorting pathway by catalyzing the dissociation of all three ESCRT complexes from the endosome (Katzmann, 2001). Inactivation of Vps4 results in the accumulation of the ESCRT machinery on the endosomal surface leading to enlarged endosomal structures (Hurley and Emr, 2006).

In the WCG4a $\operatorname{atg} 1 \Delta \operatorname{atg} 27 \Delta$ strain the vps 4 gene was deleted. A PCR reaction using the primers (Primer 1 vps4 ko NAT and Primer 2 vps4 ko NAT) and the pFA6-natNT2 plasmid as template was performed. The resulting deletion cassette was used for homologues recombination in the WCG4a $\operatorname{atg} 1 \Delta \operatorname{atg} 27 \Delta$ strain (chapter 3.2.15). The cells were grown on nourseotricin (clonNAT) and tested for correct integration using southern blot (chapter 3.2.18) (data not shown).

The $\operatorname{atg} 1 \Delta \operatorname{atg} 27 \Delta$ strain was used as a control for the normal size of the peripheral GFP-Atg8 dots. Together with $\operatorname{atg} 1 \Delta \operatorname{atg} 27 \Delta v p s 4 \Delta$ cells they were cotransformed with GFP-Atg8 and Ape1-RFP and imaged (Fig. 21 (A.)).

Snf7 is one of two major components of ESCRT-III that localizes to endosomal membranes (Hurley and Emr, 2006) and can therefore be used as an endosomal marker.

Two strains atg1 $1 \Delta$ atg27 (WCG4a MAT $\alpha$ atg1 $1:$ KAN $\operatorname{atg} 27 \Delta::$ HIS3) and Snf7-RFP (S288C MATa Snf7-RFP::KAN), carrying a pRS315 (LEU) plasmid, were crossed. The diploid cells were selected on CM -HIS -LEU and transferred to $1 \%$ potassium acetate for 5 days. The sporulated cells were used for random spores treatment as described in chapter 3.2.16.3 and then selected on CM -HIS -LEU +KAN to receive a haploid $\operatorname{atg} 1 \Delta$ atg27 $\Delta$ Snf-RFP strain. The cells were tested by western blot analysis for maturation of Ape1 after $4 \mathrm{~h} \mathrm{SD}(-\mathrm{N})$ starvation and their RFP signal in microscopy (data not shown).

Atg1 $\Delta \operatorname{atg} 27 \Delta$ and $\operatorname{atg} 1 \Delta \operatorname{atg} 27 \Delta$ SNF7-RFP cells were transformed with GFP-Atg8 and imaged after $4 \mathrm{~h}$ starvation in SD(-N) (Fig. 21 (B.)) 
A.

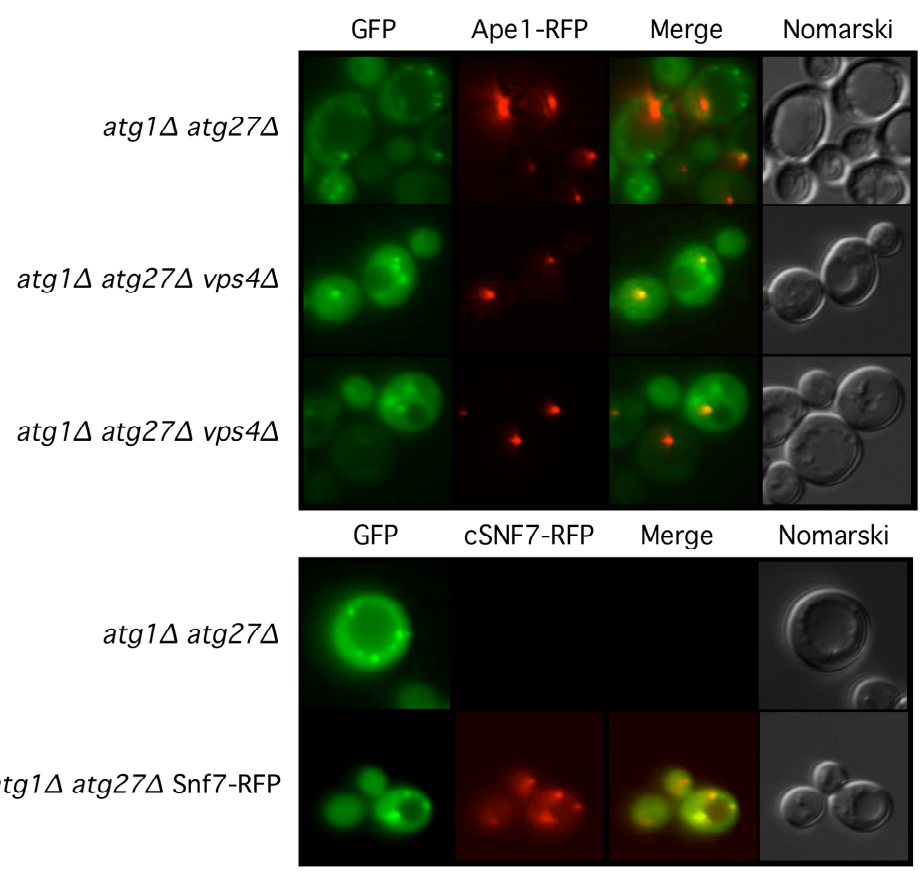

Fig. 21 Accumulation of the peripheral Atg8 pool in vps4 $\Delta$ cells and colocalization with the endosomal protein SNF7.

(A.) Microscopic analysis of the localization of GFP-Atg8 in different knockout strains using the PAS marker Ape1-RFP. The upper row of pictures shows atg1 $\Delta$ atg27 $\Delta$ cells, the lower two rows of pictures show $\operatorname{atg} 1 \Delta \operatorname{atg} 27 \Delta v p s 4 \Delta$ cells. (B.) Microscopic analysis of GFP-Atg8 in an $\operatorname{atg} 1 \Delta \operatorname{atg} 27 \Delta$ chromosomally Snf7-RFP tagged strain.

The $\operatorname{atg} 1 \Delta \operatorname{atg} 27 \Delta$ vps $4 \Delta$ strain showed a clear accumulation of GFP-Atg8 at the peripheral dots compared to the $\operatorname{atg} 1 \Delta \operatorname{atg} 27 \Delta$ strain (Fig. 21 (A.)).

The chromosomal integrated Snf7-RFP colocalized with the GFP-Atg8 in the $\operatorname{atg} 1 \Delta$ $\operatorname{atg} 27 \Delta$ yeast (Fig. 21 (B.)). 


\subsubsection{Quantification of the Atg8 peripheral pool in different deletion strains}

GFP-Atg8 was transformed into $\operatorname{atg} 1 \Delta$, $\operatorname{atg} 1 \Delta \operatorname{atg} 27 \Delta$ double mutant and $\operatorname{atg} 1 \Delta$ $\operatorname{atg} 27 \Delta$ vps $4 \Delta$ triple mutant cells.

At least three independent experiments were quantified. Cells with clear GFP-Atg8 dots were sorted into one of the following categories: one GFP-dot; two GFP-dots; more than two GFP-dots.

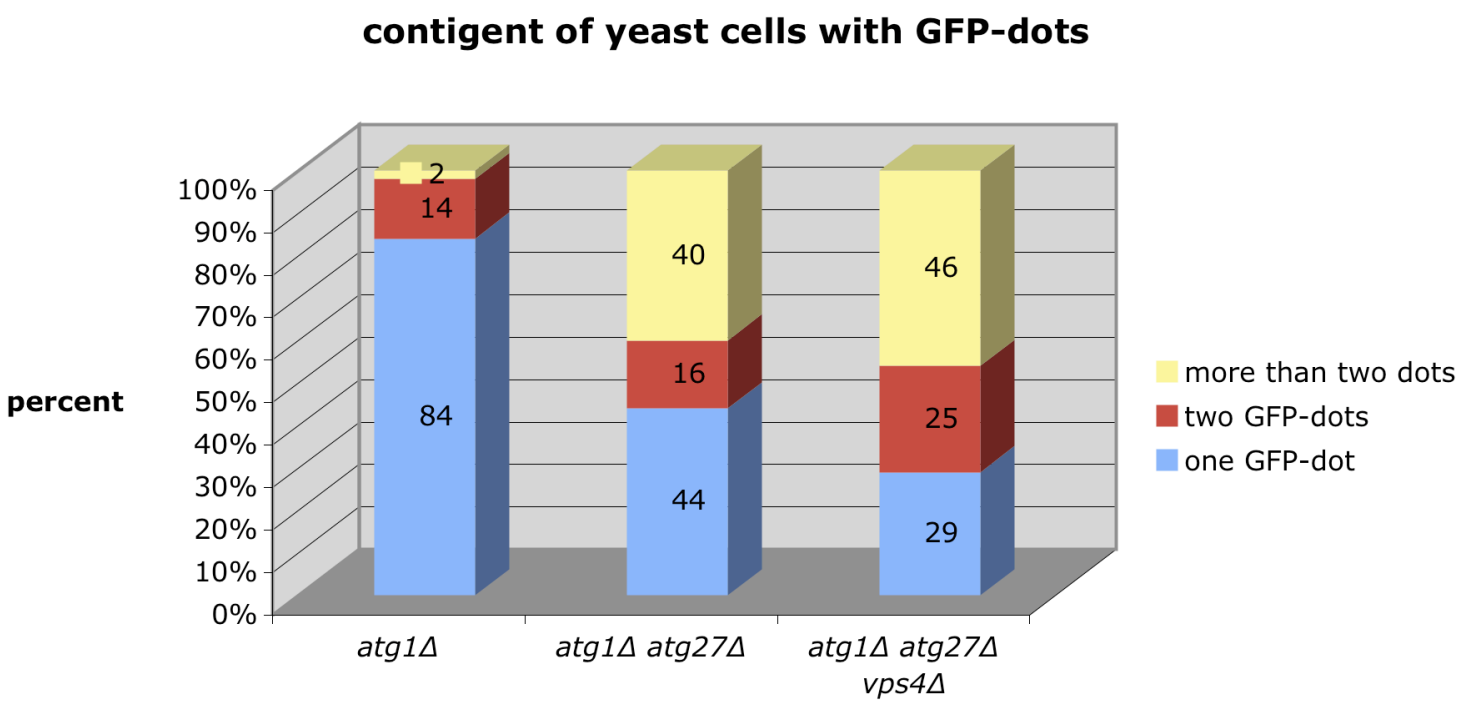

Fig. 22 Quantification of the Atg8 peripheral pool in different deletion strains

Data from at least three independent experiments $(\operatorname{atg} 1 \Delta n=193 ; \operatorname{atg} 1 \Delta \operatorname{atg} 27 \Delta n=314 ; \operatorname{atg} 1 \Delta \operatorname{atg} 27 \Delta$ $v p s 4 \Delta \mathrm{n}=145)$

$84 \%$ of atg $1 \Delta$ cells had one GFP-Atg 8 dot. Only $2 \%$ showed more than two dots. But $40 \%$ of atg $1 \Delta$ atg $27 \Delta$ cells and even $46 \%$ of $\operatorname{atg} 1 \Delta$ atg $27 \Delta$ vps $4 \Delta$ cells had more than two GFP-Atg 8 dots. The amount of cells with more than one GFP-dot increased in cells lacking Atg1 Atg27 and additionally Vps4.

\subsubsection{Characterization of the Atg8 peripheral pool}

Kirisako et al. showed a shift in the distribution of GFP-Atg8* compared to wildtype

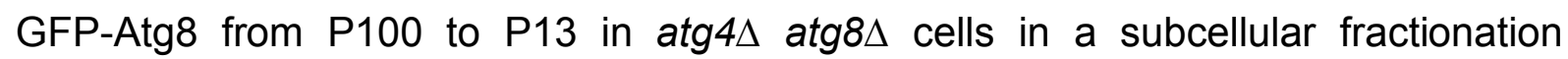
experiment (Fig. 23 (A.)) (Kirisako, 2000). This shift represented the different localizations of wild type and mutant GFP-Atg8* in microscopy (Fig. 18 (B.)). The fractionation experiment was extended to analyze the peripheral pool in $\operatorname{atg} 1 \Delta$ 


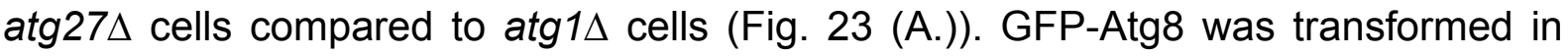
$\operatorname{atg} 1 \Delta, \operatorname{atg} 1 \Delta \operatorname{atg} 27 \Delta$ and $\operatorname{atg} 4 \Delta \operatorname{atg} 8 \Delta$ cells. As a control for experimental procedure $\operatorname{atg} 4 \Delta \operatorname{atg} 8 \Delta$ cells were also transformed with GFP-Atg8*. In Fig. 23 (A.) stationary cells were harvested, converted to spheroplasts and hypotonically lysed. Lysates were cleared by centrifugation at $500 \mathrm{~g}$ for $10 \mathrm{~min}$. Low-speed pellet P13 (13000 g pellet), high-speed pellet P100 (100000 g pellet) and high-speed supernatant S100 (100000 g sup.) were generated as described by Kirisako et al. (Kirisako, 2000). The pellets were dissolved in corresponding volume of Laemmli buffer and processed for immunoblots (chapter 3.2.23).

In Fig. 23 (B.) SD(-N) starved cells were harvested. Cells were converted to spheroplasts, solubilized in lysisbuffer and homogenized with 40 beats of a douncer. After preclearing, supernatant was applied on the top of a sucrose gradient (18\%$54 \%$ sucrose). After $3 \mathrm{~h}$ of ultracentrifugation 18 fractions were collected and precipitated. The pellets were dissolved in Laemmli buffer and processed for immunoblots (chapter 3.2.24).

A.

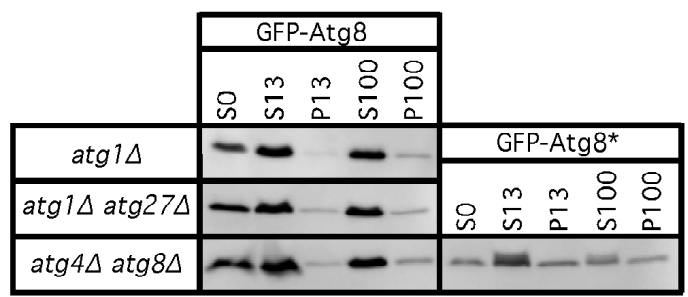

B. fraction $\mid$\begin{tabular}{llllllllllllllllllll|}
\hline & 2 & 3 & 4 & 5 & 6 & 7 & 8 & 9 & 10 & 11 & 12 & 13 & 14 & 15 & 16 & 17 & 18 \\
\hline
\end{tabular}

\begin{tabular}{|c|c|}
\hline$---\cdots-\cdots$ & $\operatorname{atg} 1 \Delta+$ GFP-Atg8 \\
\hline$-\ldots-\cdots-\cdots$ & $\operatorname{atg} 1 \Delta \operatorname{atg} 27 \Delta+$ GFP-Atg8 \\
\hline$--\cdots-\cdots$ & atg $4 \triangle$ atg $8 \Delta+$ GFP-Atg8 \\
\hline$-\cdots-$ & $\operatorname{atg} 4 \Delta \operatorname{atg} 8 \Delta+$ GFP-Atg8 $*$ \\
\hline
\end{tabular}

Fig. 23 Characterization of the Atg8 peripheral pool.

All strains in WCG background. Cells expressing GFP-Atg8 from a plasmid were treated as described in chapter 3.2.23 (A.) Subcellular fractionation and 3.2.24 (B.) Sucrose gradient analyzed by western blot using a monoclonal GFP mouse antibody.

In the subcellular fractionation experiment (Fig. 23 (A.)), no shift of plasmid expressed wild type GFP-Atg8 could be detected in the distribution pattern of $\operatorname{atg} 1 \Delta$ compared to the double deletion $\operatorname{atg} 1 \Delta \operatorname{atg} 27 \Delta$.

In the sucrose gradient (Fig. 23 (B.)) also no shift in the distribution of Atg8 in atg1 $1 \Delta$ $\operatorname{atg} 27 \Delta$ cells compared to $\operatorname{atg} 1 \Delta$ could be detected. The quality of the sucrose 
gradient was tested using the endosomal marker Pep12 that was mainly located in fraction 5 and 6 in all four gradients (data not shown).

In the subcellular fractionation as well as the sucrose gradient, a shift could be seen in atg $4 \Delta$ atg $8 \Delta$ cells expressing GFP-Atg8 and GFP-Atg8* used as a control for the successful experiment.

\subsubsection{Chromosomal integration of GFP-Atg8}

GFP-Atg8 was chromosomally integrated behind the endogenous Atg8 promoter using a Cre-Lox recombination strategy (chapter 3.2.17). The integration was done in

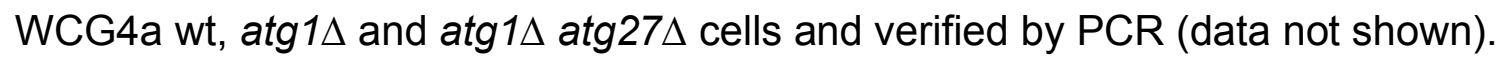

All three strains were grown to stationary phase and shifted to $\mathrm{SD}(-\mathrm{N})$-medium for $4 \mathrm{~h}$ before imaging.

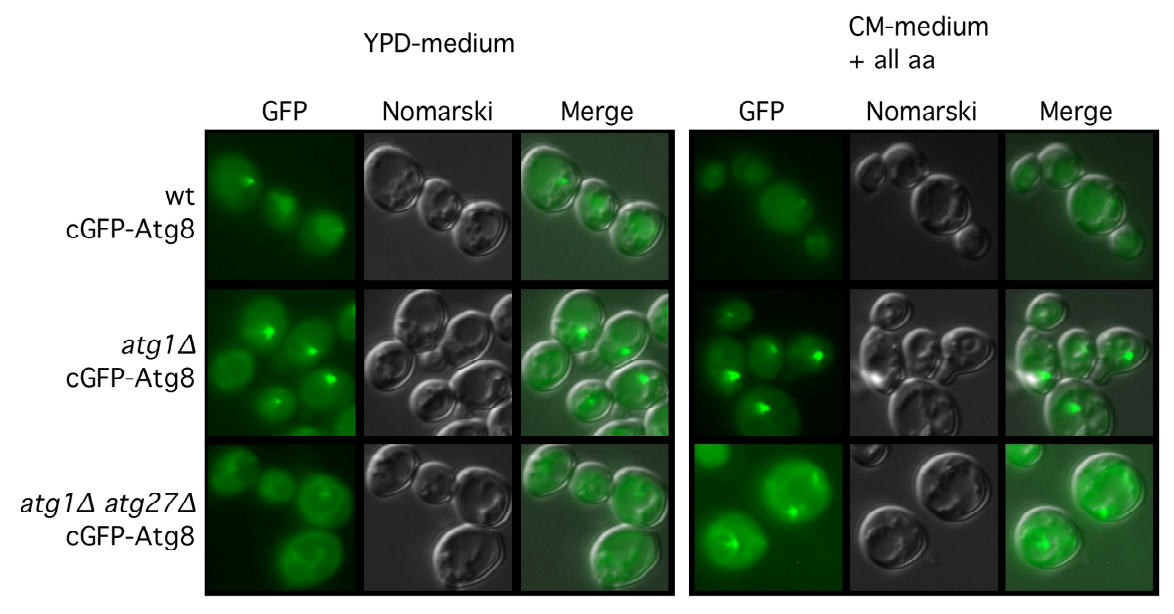

Fig. 24 Chromosomal integrated cGFP-Atg8

YPD-medium (left) and CM-medium containing all amino acids (right) were used as growth medium. At stationary phase $\left(\mathrm{OD}_{600}=6\right)$ cells were starved for $4 \mathrm{~h}$ in $\mathrm{SD}(-\mathrm{N})$ and photos were taken.

GFP-Atg8 accumulated in the vacuole of wild type cells. Some cells showed one GFP-Atg8 dot. The majority of atg1 $1 \Delta$ cells the GFP signal was restricted to a single dot. Atg1 $1 \Delta \operatorname{atg} 27 \Delta$ cells often showed membranous GFP structures but rarely dots. 


\subsubsection{Comparison of plasmid GFP-Atg8 and chromosomal GFP-Atg8}

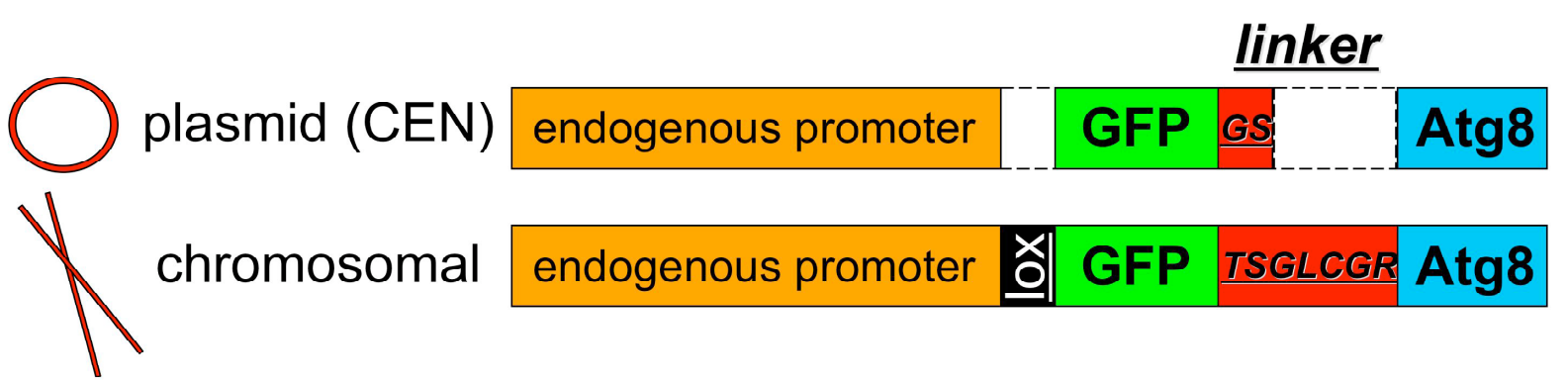

Fig. 25 Comparison of plasmid and chromosomal GFP-Atg8

The proportions in this figure are not correct. The letters between GFP and Atg8 represent amino acids in single letter code. The lox site derives from the cre recombination (chapter 3.2.17), it is $69 \mathrm{bp}$ long and leads to 23 additional amino acids in front of GFP.

The two GFP-Atg8 differ in three points: the expression level, the remaining lox site between promoter and GFP and the linker connecting the GFP with Atg8. 


\subsection{Piecemeal microautophagy of the nucleus (PMN / micronucleophagy)}

In the yeast $S$. cerevisiae autophagy selective degradation of nearly all compartments by autophagy has been described. Even the nucleus is degraded in a microphagic process, which has been called piecemeal microautophagy of the nucleus (PMN), and is induced by nitrogen starvation (Roberts, 2003). PMN occurs at contact sites between the nucleus and the vacuole, the so called vacuolar junctions (NV-junctions) and are formed by a set of proteins. Nvj1 is anchored in the inner and outer nuclear membrane, spans the whole contact site and interacts on the vacuolar membrane with Vac8 (Fig. 9) (Millen, 2008). In vac8s cells, Nvj1 fails to concentrate into NV-junctions and instead encircled the nucleus. NV-junctions are absent in both $n v j 1 \Delta$ and vac8s cells (Pan, 2000). Therefore vac8s cells were used as negative-control for all PMN experiments in this study. Under starvation conditions Nvj1 enhances the recruitment of Tsc13 and Osh1. Both proteins are involved in the lipid metabolism of the cell (Kvam and Goldfarb, 2007). GFP-Osh1 has been shown to be a reliable molecular marker to follow nuclear degradation by PMN (Krick, 2008b).

The formation of PMN vesicles depends on these NV-junction proteins and more recently the autophagic machinery has been described to be involved in the PMN process (Krick, 2008b).

\subsubsection{Detection of intravacuolar free-floating PMN vesicles}

Studies concerning PMN were mainly focused on NV-junction proteins. Their degradation was followed using immunoblots and EM and microscopy.

The nuclear content of PMN vesicles was traced using a NLS-mcherry fusion protein consisting of the nuclear localization sequence of Nab2 and a tandem repeat of the fluorescent mcherry protein. The lipase-like Atg15 protein is required for intravacuolar lysis of autophagic bodies and PMN vesicles. Atg1 is a core autophagic protein required for all known autophagic processes in S. cerevisiae (chapter 2.5.5).

Atg15 $\Delta$ and $\operatorname{atg} 1 \Delta$ atg15 $\Delta$ cells expressing NLS-mcherry were starved for $4 \mathrm{~h}$ in SD($\mathrm{N}$ ) and examined using videomicroscopy (Fig. 26 (A.)). 
Atg15 cells expressing NLS-mcherry and the autophagosomal marker GFP-Atg8 (Fig. 26 (B.)) or the cytosolic marker 3-phosphoglycerate kinase (PGK) (Fig. 26 (C.)) were starved for $4 \mathrm{~h}$ in SD-(N). Both images (shown in Fig. 26 (B) and Fig. 26 (C)) were taken simultaneously with a Leica TCS SP2 AOBS confocal laser scan microscope.

A.

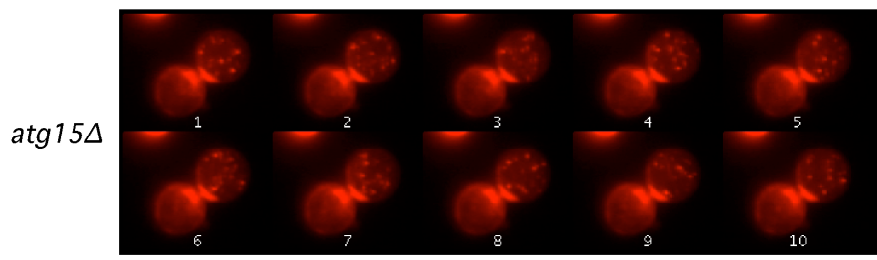

$\operatorname{atg} 1 \Delta \operatorname{atg} 15 \Delta$

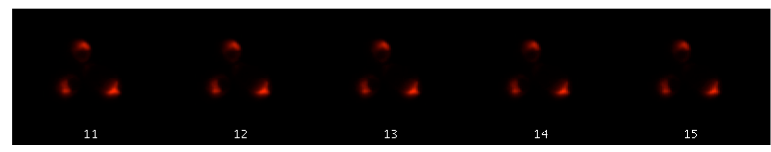

B.

NLS-mcherry GFP-Atg8 merge

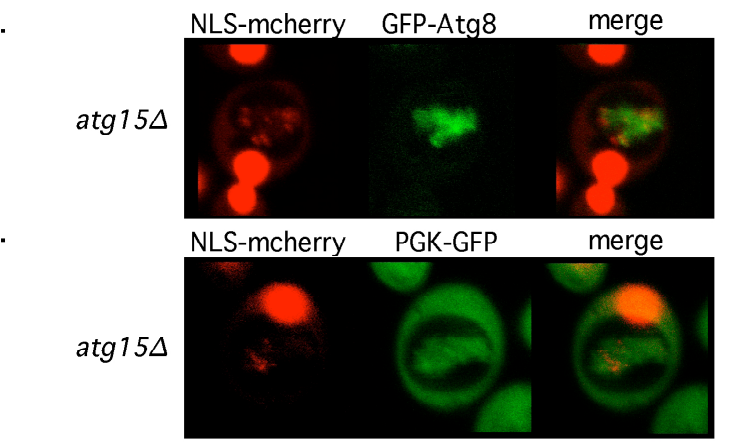

Fig. 26 Detection of intravacuolar free-floating PMN vesicles by fluorescence microscopy.

(A.) Videomicroscopy of atg15 cells expressing NLS-2mcherry. Cells were starved for $4 \mathrm{~h}$ in SD(-N). The imaging of picture $1-10$ took about $2 \mathrm{sec}$ and pictures $11-15$ about $1 \mathrm{sec}$. Atg15 $\Delta$ cells expressing NLS-mcherry and GFP-Atg8 (B.) or PGK-GFP (C.) were starved for $4 \mathrm{~h}$ in SD-(N) and imaged using a confocal laser scan microscope.

In atg15 cells free floating red vesicles accumulated in the vacuole. The red fluorescent vesicles were absent in $\operatorname{atg} 1 \Delta$ atg15 cells (Fig. 26 (A.)).

Fig. 26 (B.) and Fig. 26 (C.) showed significantly more green than red fluorescent intravacuolar vesicles. The red and green vesicles did not overlap.

\subsubsection{PMN depends on the autophagic core machinery}

Krick et al. showed, using western blot analysis, that the degradation of GFP-Osh1 depends on the core autophagic machinery (Krick, 2008b).

PMN can also be visualized microscopically by NLS-mcherry (Fig. 26). Cells expressing NLS-mcherry and the autophagosome marker GFP-Atg8 were starved for $4 \mathrm{~h}$ in $\mathrm{SD}(-\mathrm{N})$ medium in the presence of $1 \mathrm{mM}$ proteinase $\mathrm{B}$ inhibitor PMSF. 


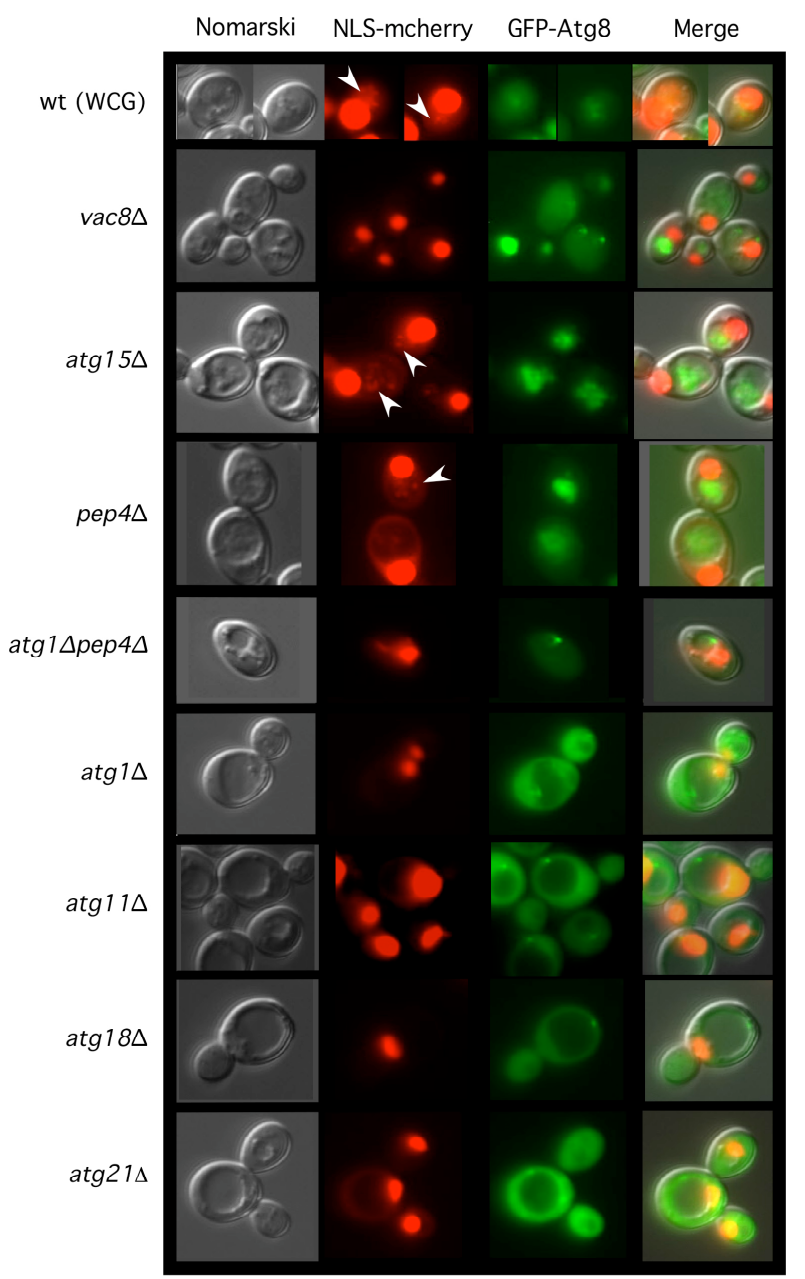

Fig. 27 PMN depends on the autophagic core machinery

The indicated mutant cells coexpressing NLS-mcherry and the autophagic marker GFP-Atg8 were starved for $4 \mathrm{~h}$ in SD(-N)-medium in the presence of $1 \mathrm{mM} \mathrm{PMSF}$. White arrowheads indicate vesicles.

In wild type, $\operatorname{atg} 15 \Delta$ and pep $4 \Delta$ cells red and green fluorescent vesicles accumulated in the vacuole. The vac8 8 cells showed green but no red vesicles in the vacuole. All other knockouts neither had a GFP nor a RFP signal in the vacuole, which is in accordance with the western blot analysis of PMN (shown in (Krick, 2008b) (Krick, 2008a)).

\subsubsection{Quantification of PMN induction}

To find out the best stimulus for PMN induction different starvation media were tested. Stationary $\left(\mathrm{OD}_{600}=6\right)$ wild type and vac8 $\Delta$ cells expressing GFP-Osh1 were shifted to different starvation conditions: $\mathrm{SD}(-\mathrm{N})$-media, $1 \% \mathrm{KAc}$ (potassium acetate), $1 \% \mathrm{KAc}+2 \%$ glucose and $\mathrm{CM}$-medium containing rapamycin $(0.2 \mu \mathrm{g} / \mathrm{ml})$, a TOR (target of rapamycin) inhibitor leading to autophagy induction (chapter 2.5.5). 

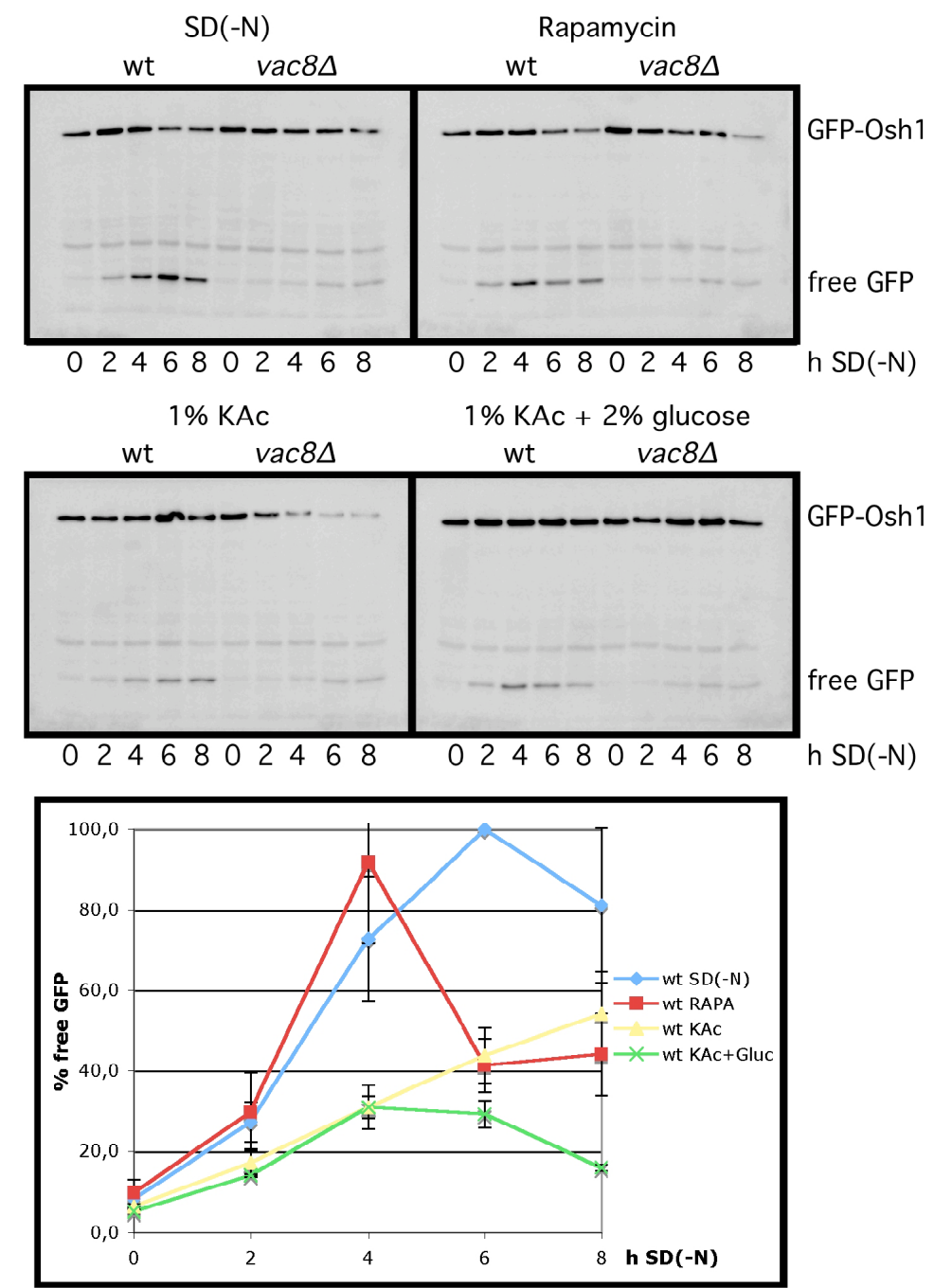

Fig. 28 Quantification of PMN induction

All strains in WCG background. Upper part: Cells expressing GFP-Osh1 were shifted to different starvation conditions, were alkaline lysed at the indicated time points and analyzed by western blot analysis using a monoclonal GFP mouse antibody. Lower part: The free GFP-band of three independent experiments were quantified using the aida software. The $6 \mathrm{~h}$ value of the wild type strain in $\mathrm{SD}(-\mathrm{N})$ of each experiment was set to $100 \%$. Values are shown with SED.

$\mathrm{SD}(-\mathrm{N})$ caused the brightest free GFP signal. Until $4 \mathrm{~h}$ induction rapamycin treatment resulted in the same amount of free GFP. Then the GFP signal decreased drastically to $40 \%$. In $1 \%$ potassium acetate the results showed a slower increase in free GFP compared to $\mathrm{SD}(-\mathrm{N})$ starvation. Addition of $2 \%$ glucose decreased the free GFP rate. 


\subsubsection{Cdc48.3}

Cdc48 belongs to the family of $\mathrm{AAA}^{+}$ATPases. It is involved in many cellular processes like membrane fusion (chapter 2.6.1). The human homologue of Cdc48 is believed to extract ubiquitin conjugated fusion inhibitors out of complexes or lipid membranes and thus mediate fusion events (Schuberth and Buchberger, 2008).

Therefore the involvement of Cdc48 in PMN membrane fusion events was tested. Crossing of the cdc48-3 and WCG4 (wild type in the lab) strain generated the Cdc48.3 temperature sensitive strain in WCG background as described in chapter 3.2.16. The strain did not grow at $38^{\circ} \mathrm{C}$ which was set as restrictive temperature. The viability at this temperature in $\mathrm{SD}(-\mathrm{N})$-medium for $4 \mathrm{~h}$ was not altered compared to wild type cells (data not shown).

In the BY4741 background the Cdc 48.3 strain showed a growth defects at $36^{\circ} \mathrm{C}$. The restrictive temperature for $\mathrm{W} 303$ was $34^{\circ} \mathrm{C}$.

The experiments were conducted as described in chapter 3.2.25.2 in these three different backgrounds (WCG (I.); BY4741 (II.); W303 (III.)). The blots were reprobed with antibodies to 3-phosphoglycerate kinase (PGK) as loading control. The samples were loaded again, blotted and the maturation of Ape1 was tested using polyclonal Ape1 antibodies. 
I. A.

WCG background GFP-Osh1
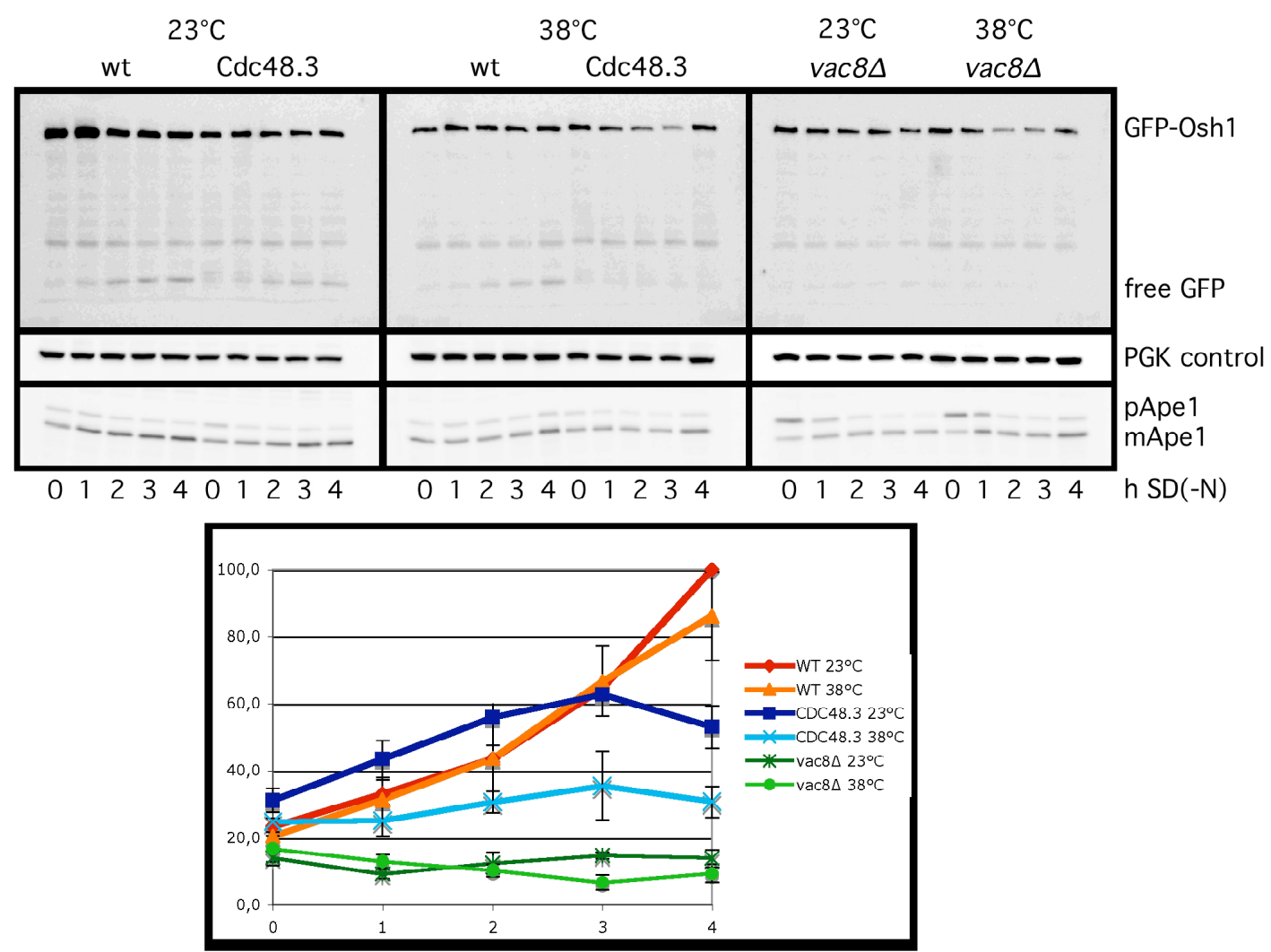

I. B.

WCG background GFP-Atg 8
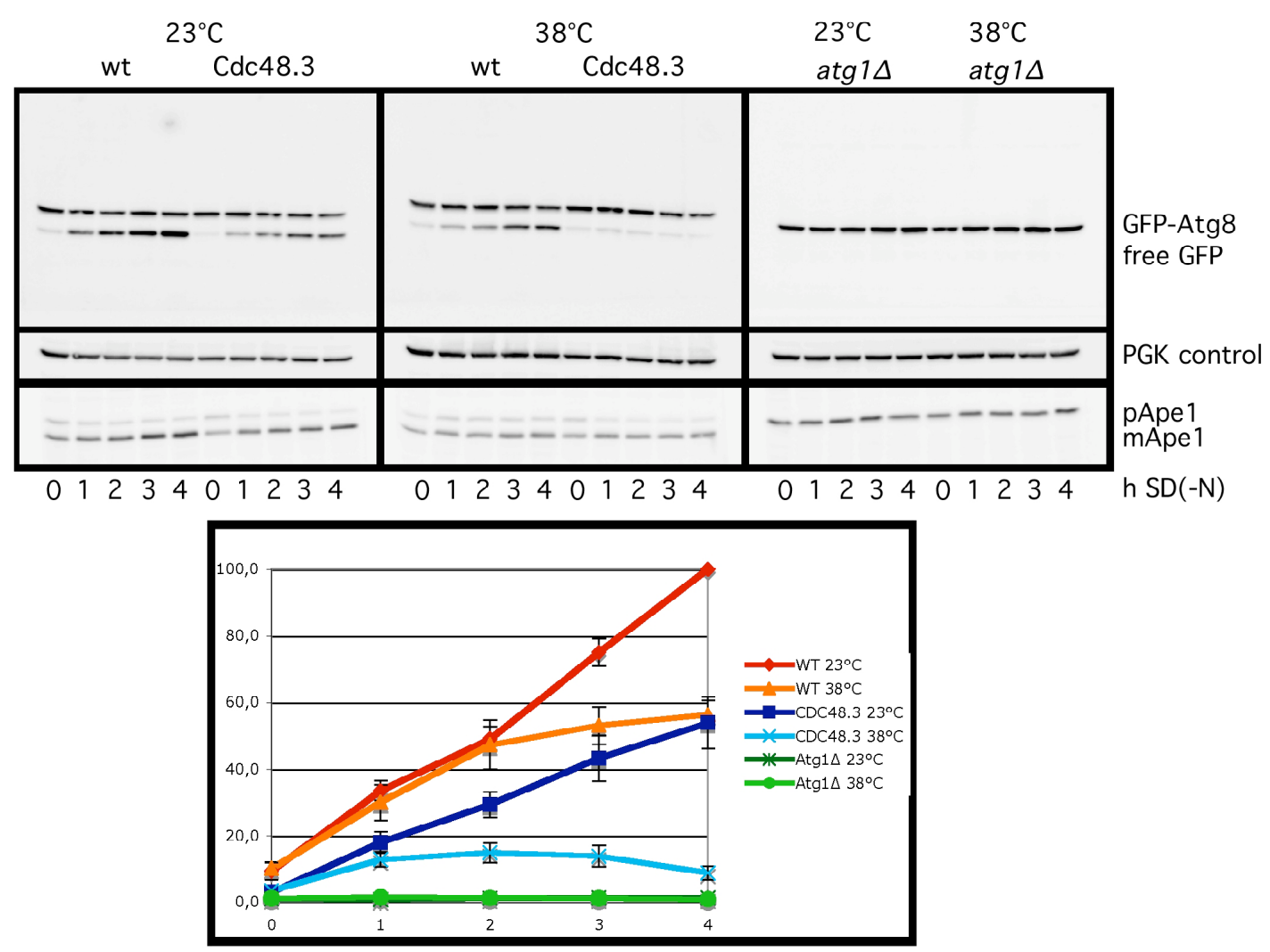

Fig. 29 (cont.) 
II. A.

BY4741 background GFP-Osh1
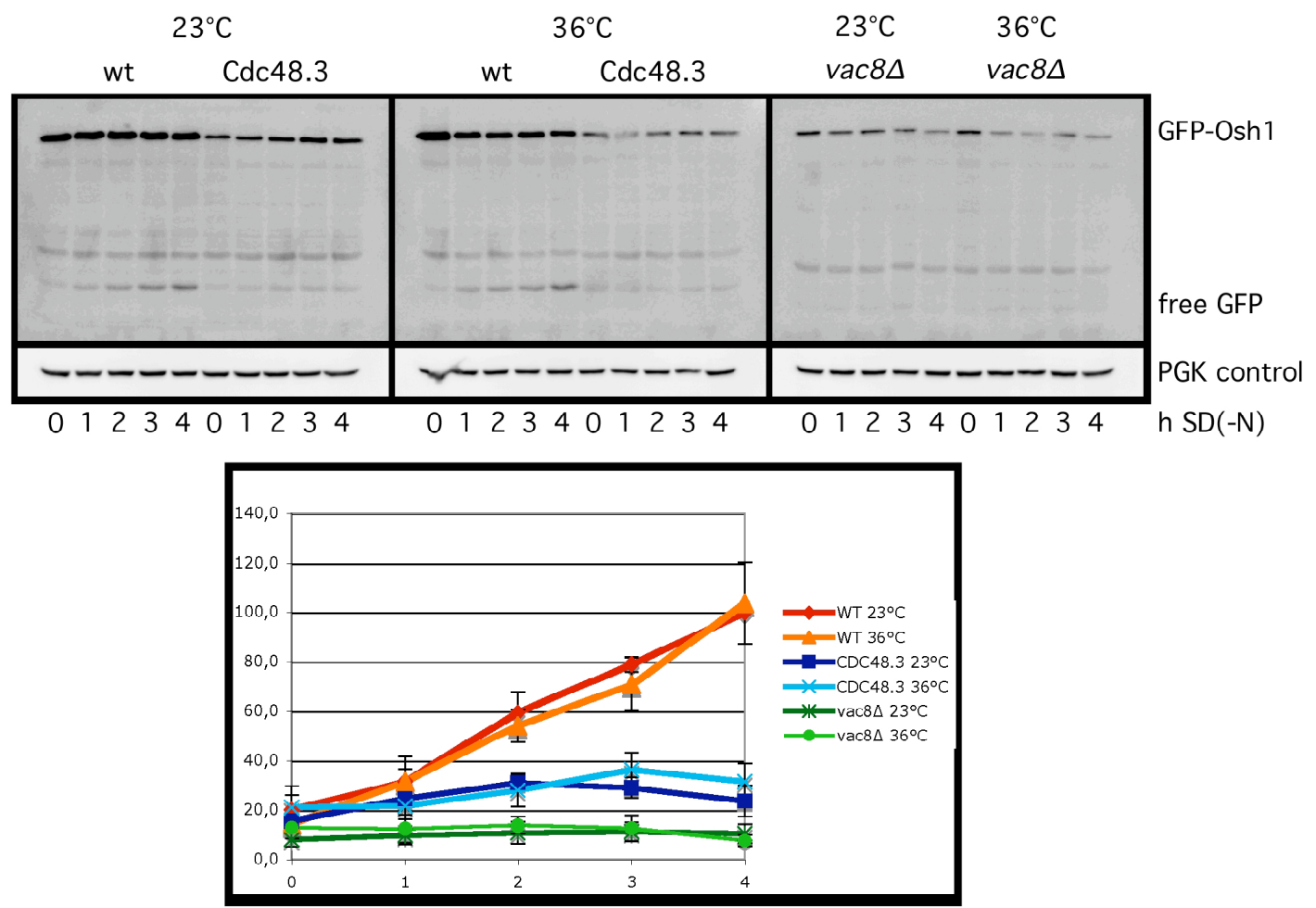

II. B.

BY4741 background GFP-Atg8
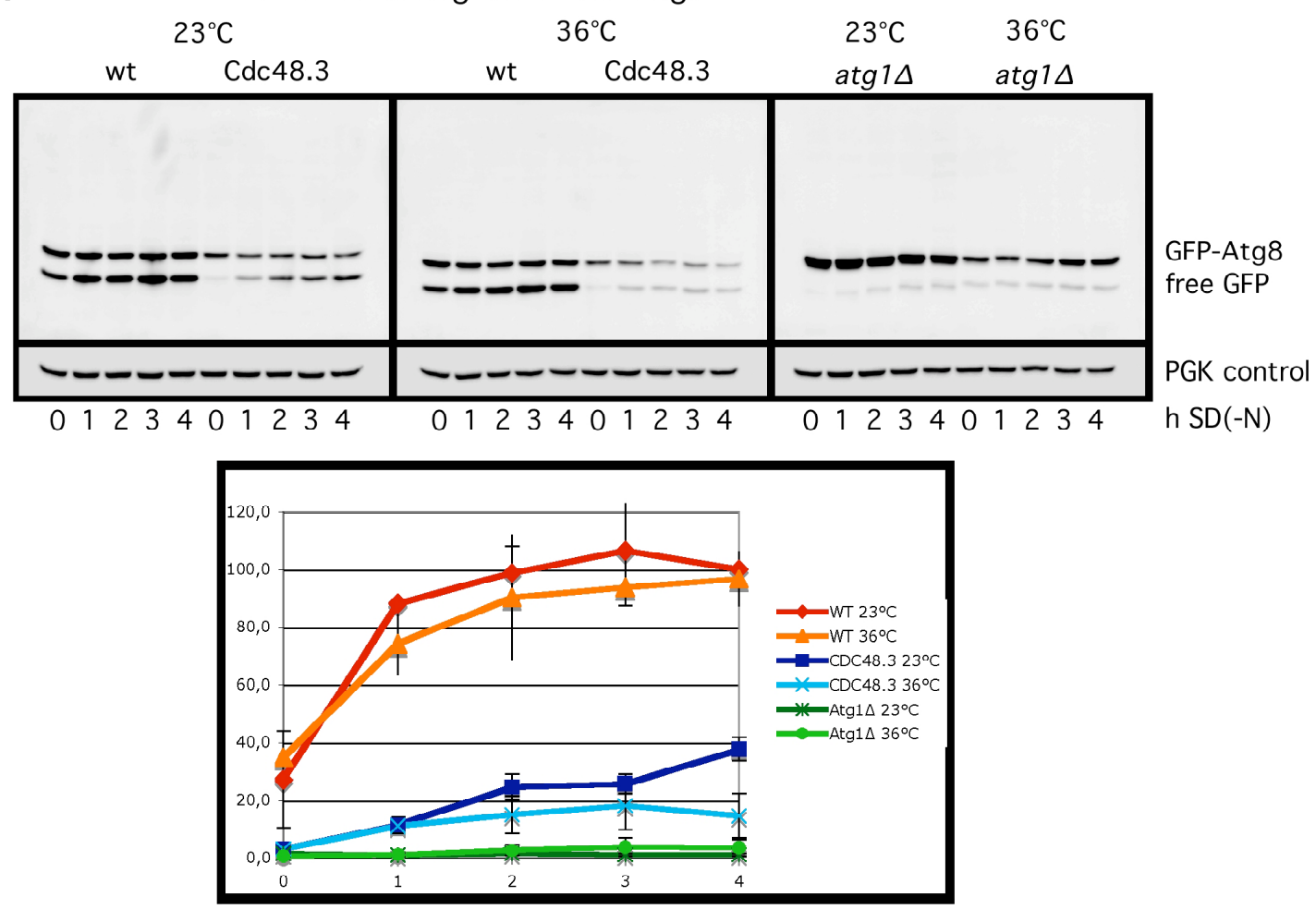

Fig. 29 (cont.) 
III. A. W303 background GFP-Osh1

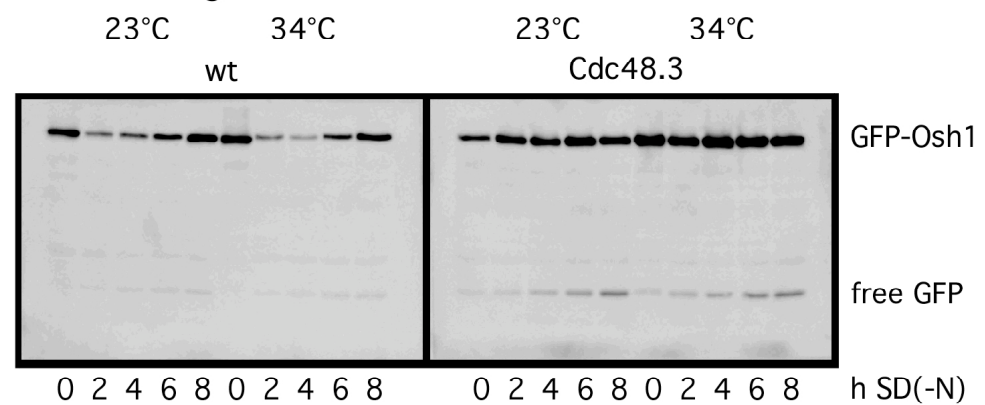

III. B. W303 background GFP-Atg8
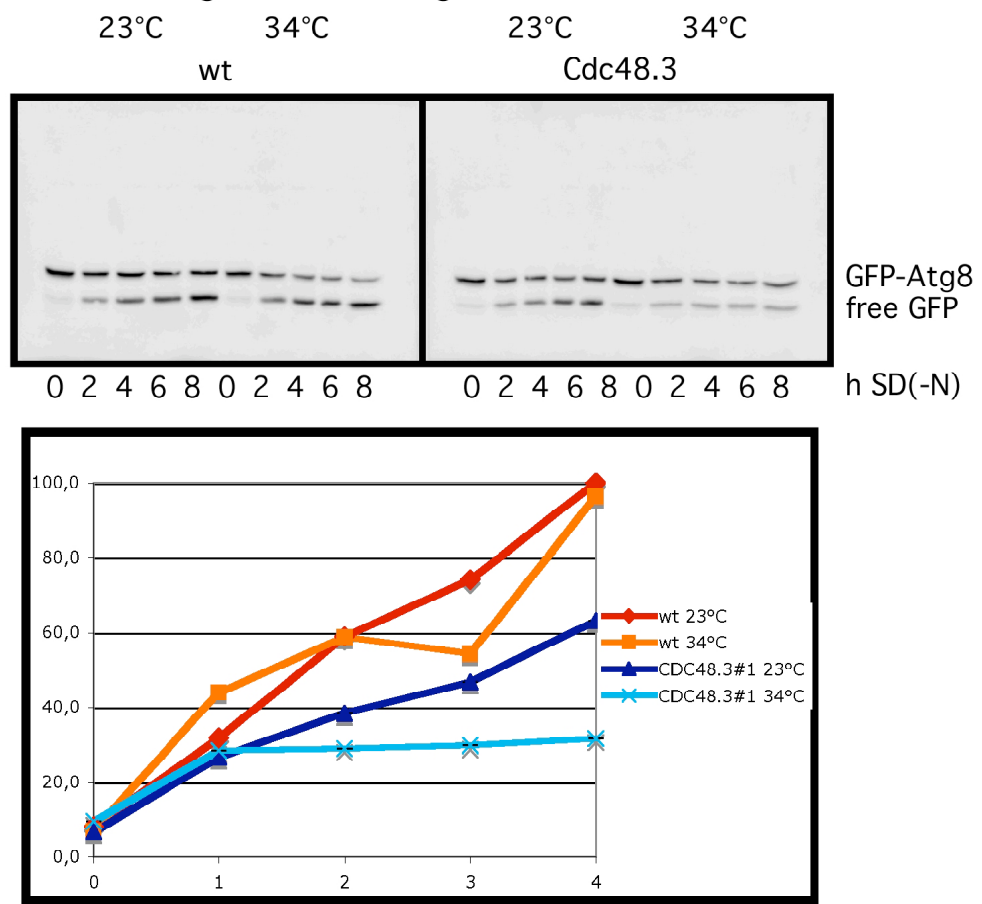

Fig. 29 Cdc48.3 (I.) WCG, (II.) BY4741 and (III.) W303 background

(I.) All strains in WCG background. (II.) All strains in BY4741 background. (III.) All strains in W303 background. Cells expressing GFP-Osh1 (A.) or GFP-Atg8 (B.). Cells were pre-cultured at $23^{\circ} \mathrm{C}$, shifted to $\mathrm{SD}(-\mathrm{N})$-medium, divided in two equal parts and incubated at 23 or $34^{\circ} \mathrm{C}(\mathrm{W} 303), 36^{\circ} \mathrm{C}$ (BY4741) or $38^{\circ} \mathrm{C}$ (WCG). Western blot analysis of alkaline lysed cells at indicated time points. Blots were probed using a GFP monoclonal antibody and reprobed using a monoclonal PGK antibody (I. and II.). In WCG background (I.) the maturation of Ape1p was detected with a polyclonal rabbit Ape1 antibody.

Quantification: The free GFP-signal was quantified: Quantificatin by aida software: (I.) three (A) or four (B) independent experiments; (II.) three (A) or two (B) independent experiments; (III.) one experiment (B) was quantified.The $4 \mathrm{~h}$ value of the wt cells at $23^{\circ} \mathrm{C}$ was set to $100 \%$ in each experiment. Values are shown with SED.

\section{(I.) WCG background:}

The degradation of GFP-Osh1 was normal in Cdc48.3 cells at the permissive temperature but a $50 \%$ reduction of free GFP was detectable at the restrictive temperature.

The degradation of GFP-Atg8 was slightly reduced at the permissive temperature. This effect was drastically increased at $38^{\circ} \mathrm{C}$. 
Ape1 maturation was independent on the temperature. Wild type cells produced matured Ape1 and atg1 $1 \Delta$ cells showed no maturation of Ape1. The PGK loading controls showed no significant difference between samples.

(II.) BY4741 background:

After PMN induction Cdc48.3 cells expressing GFP-Osh1 showed only small amounts of free GFP independent on the temperature. There was no difference in free GFP between $23^{\circ} \mathrm{C}$ and $38^{\circ} \mathrm{C}$, but a significant decrease in free GFP compared to wild type.

GFP-Atg8 degradation was low in Cdc48.3 cells even at the permissive temperature. An increase to the restrictive temperature reduced the free GFP. The PGK controls showed no significant difference between samples.

(III.) W303 background:

GFP-Osh1 showed no free GFP-signal in wild type. Cdc48.3 had a free GFP signal, which did not change between permissive and restrictive temperature. GFP-Atg8 showed a reduction in free GFP at the restrictive temperature. 


\subsubsection{Cdc48 cofactors}

\subsubsection{The substrate recruiting adaptor Shp1 is required for PMN and macroautophagy}

UBX proteins in general are cofactors for Cdc48 / p97 (chapter 3.6.1). In humans the homologues of the substrate recruiting adaptor Shp1 (p47) and Cdc48 (p97) control the fusion of homotypic Golgi membranes (Kondo, 1997). Ubx2 and Ubx5 are described as additional substrate recruiting factors for Cdc48 (Tab. 1) (Schuberth, 2004) (Schuberth and Buchberger, 2008).

Cells were transformed with GFP-Osh1 (Fig. 30 (A.) upper part and (Fig. 30 (B.)) or GFP-Atg8 (Fig. 30 (A.) lower part), grown to stationary phase and starved for up to 8 h. Samples were taken at the indicated time points, alkaline lysed and prepared for immunoblots (chapter 3.2.25.1).

A.

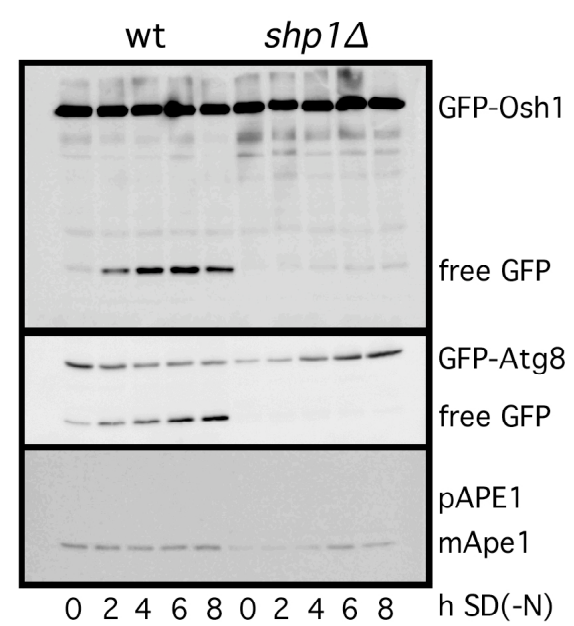

B.

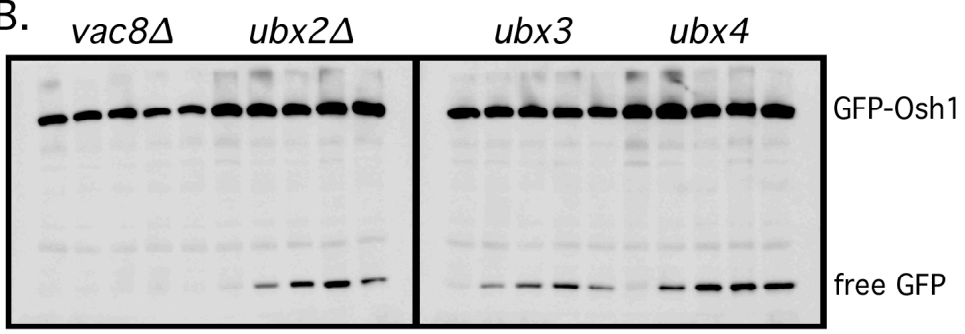

02246680024668 o $\begin{array}{llll}u b \times 5 & u b \times 6 & u b \times 7 & \text { wt }\end{array}$

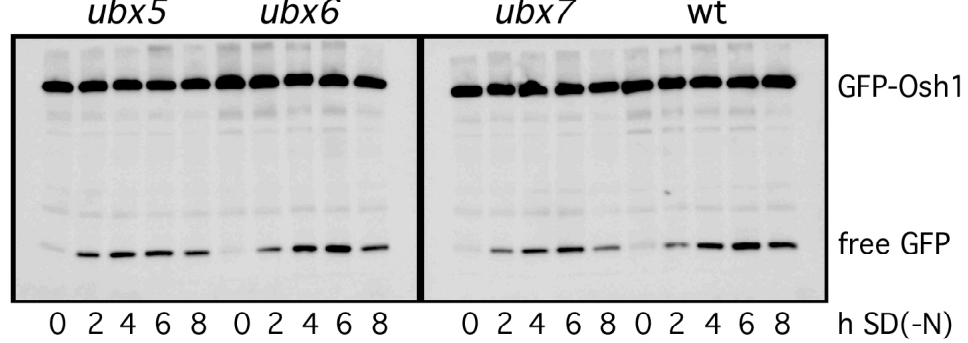

Fig. 30 The Cdc48 substrate adaptor Shp1 is required for PMN and autophagy (A.), but non of the other ubx protein family members (B.)

All strains were BY4741 background. Cells were transformed with GFP-Osh1 (A) upper blot and (B) or GFP-Atg8 (A.) lower two blots. Western blot of alkaline lysed stationary $(0 \mathrm{~h})$ and starved $(2-8 \mathrm{~h})$ $\mathrm{SD}(-\mathrm{N})$ ) yeast cells. GFP-Osh1, GFP-Atg8 and free GFP were detected using a mouse monoclonal GFP antibody. The maturation of Ape1p was detected with a polyclonal rabbit Ape1 antibody. Three independent experiments showed comparable results.

$U b \times 2 \Delta, u b x 3 \Delta, u b x 4 \Delta, u b \times 5 \Delta, u b \times 6 \Delta$ and $u b x 7 \Delta$ showed the same amount of free GFP as the corresponding wild type cells expressing GFP-Osh1. The free GFP was drastically reduced in shp1D cells expressing GFP-Osh1 or GFP-Atg8. Ape1 was matured in shp1 $1 \Delta$ cells. 


\subsubsection{Other known complex partners and processing factors of Cdc48}

Despite the UBX family there are other known complex partners and processing factors of Cdc48. Der1 and Dfm1 are homologue proteins (Hitt and Wolf, 2004). They both interact with Cdc48 but are part of distinct complexes (Goder, 2008) involved in ER-associated protein degradation (ERAD). The trimeric Cdc48-Ufd1-Npl4 complex is the core component in the export of misfolded ER substrates (ERAD) (Raasi and Wolf, 2007). Ufd 1 and Npl4 deletion strains are inviable, therefore a ufd1.1 point mutant lacking the ERAD function was analyzed (Jarosch, 2002). This mutant was also mutated in prc1 (prc1.1) that codes for the carboxypeptidase Y (CPY; proteinase C). Ufd2 and Ufd 3 bind Cdc48 via the same region and compete for Cdc48 binding (Rumpf and Jentsch, 2006). Ufd2 promotes Cdc48 dependent degradation of ubiquitylated substrates whereas Ufd3 stabilizes substrates. The human UBX(-like) protein VCIP135 has been described as the only cofactor that cooperates with the p97-p47 complex in membrane fusion events (Uchiyama, 2002) (Kano, 2005). In contrast to VCIP135, the yeast homologue Otu1 has been characterized in Cdc48 Ufd1-Npl4-dependent degradation processes (Rumpf and Jentsch, 2006), where it participates in the antagonistic interplay of Ufd2 and Ufd3.

Cells were transformed with GFP-Osh1 (Fig. 31 (A.)) or GFP-Atg8 (Fig. 31 (B.)), grown to stationary phase and starved for up to $8 \mathrm{~h}$. Samples were taken at the indicated time points, alkaline lysed and prepared for immunoblots (chapter 3.2.25.1). 
A

A. $\quad$ wt to ufd1.1

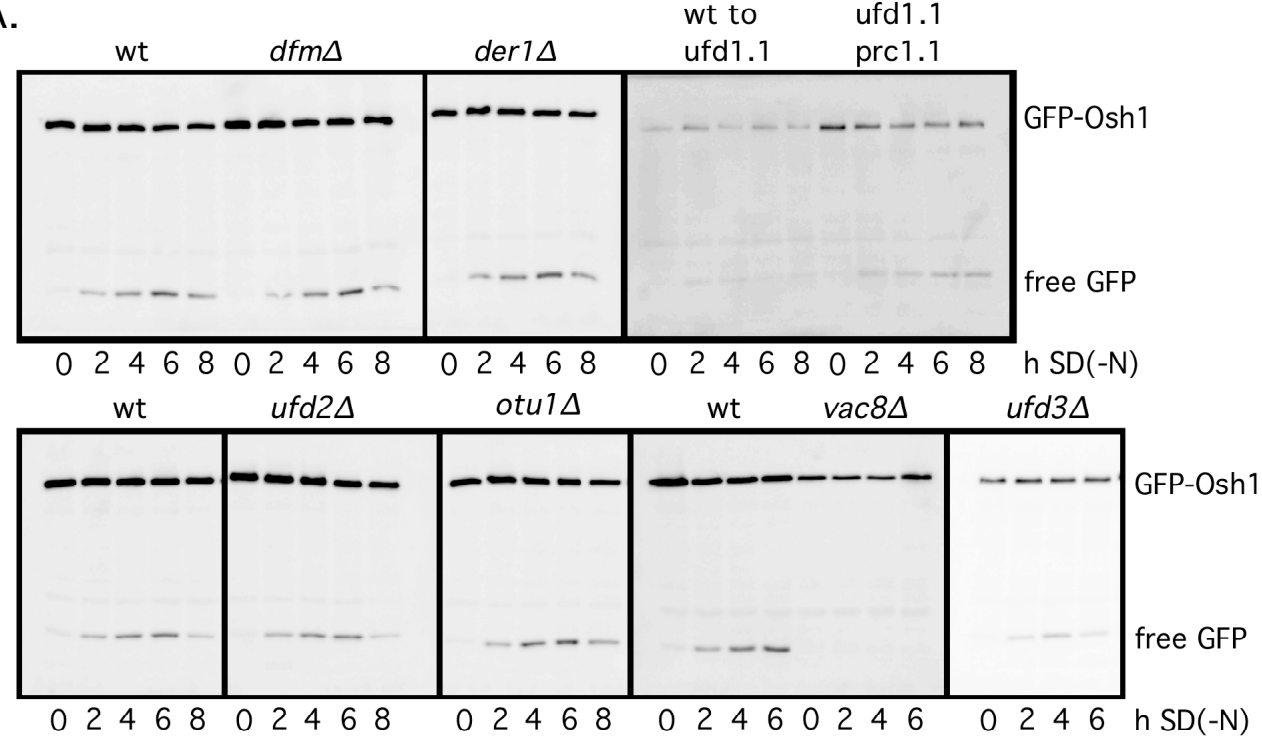

B.

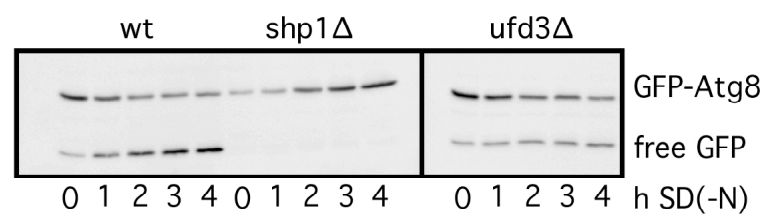

Fig. 31 Complex partners and processing factors of Cdc48

All strains except wt to ufd 1.1 and ufd1.1 prc1.1 were BY4741 background. Cells were transformed with GFP-Osh1 (A.) or GFP-Atg8 (B.). Western blot of alkaline lysed stationary (0 h) and starved (2 $8 \mathrm{~h} \mathrm{SD}(-\mathrm{N}))$ yeast cells. GFP-Osh1, GFP-Atg8 and free GFP were detected using a mouse monoclonal GFP antibody.

$D f m 1 \Delta, \operatorname{der} 1 \Delta$, ufd2 $2 \Delta$ and otu1s showed the same amount of free GFP as the corresponding wild type cells. The free GFP signal in cells expressing GFP-Osh1 was reduced in ufd $3 \Delta$ cells (this result was reproduced three times) (Fig. 31 (A.)) but only slightly affected in cells expressing GFP-Atg8 (Fig. 31 (B.)). The wild type in BWG1-7a background (wt to ufd1.1) expressed the GFP-Osh1 fusion protein at low level. The strain had hardly any free GFP. The ufd1.1 prc1.1 cells produced free GFP. 


\subsubsection{Monoubiquitin is required for PMN and autophagy}

Cdc48 in combination with Shp1 is described in the literature to interact with ubiquitinated proteins. Doa4 is a ubiquitin isopeptidase, required for recycling of ubiquitin from proteasom-bound polyubiquitinated proteins. Its deletion depletes the cellular ubiquitin level (Swaminathan, 1999) (Ren, 2008).

Wild type and doa4 4 cells expressing GFP-Osh1 or GFP-Atg8 were starved in SD($\mathrm{N}$ ). Samples were taken, alkaline lysed and prepared for immunoblots (chapter 3.2.25.1) (Fig. 32 (A.)).

Even monoubiquitin- or polyubiquitin-conjugated proteins can interact with Cdc48 complexes. Ubiquitin is bound on its C-terminal glycine to a target protein. For polyubiquitin chain formation the $\mathrm{C}$-terminus of a free ubiquitin molecule is covalently bound to a intramolecular lysine (one letter code: $\mathrm{K}$ ) of the target protein bound ubiquitin. Ubiquitin has 7 intracellular lysines, three of them are typically used for polyubiquitination (K29, K48 and K63).

To investigate whether polyubiquitin conjugation is required for PMN, cells were cotransformed with pGFP-Osh1 and plasmids expressing modified ubiquitin molecules under the control of an inducible copper promoter. The ubiquitin molecules contained substitutions of lysines to arginines (one letter code: R) at position 29, 48, 63 or all lysines. The cells were shifted to media containing $100 \mu \mathrm{M}$ copper sulfate for $3 \mathrm{~h}$. After induction most of the ubiquitin in the cell was modified and used for normal ubiquitination, but could not be polyubiquitin conjugated at the modified position (dependent on the plasmid used). The cells were transferred to $\mathrm{SD}(-\mathrm{N})$ starvation medium and samples were collected at the indicated time points, alkaline lysed and prepared for immunoblots (chapter 3.2.25.1) (Fig. 32 (B.)). 
A.

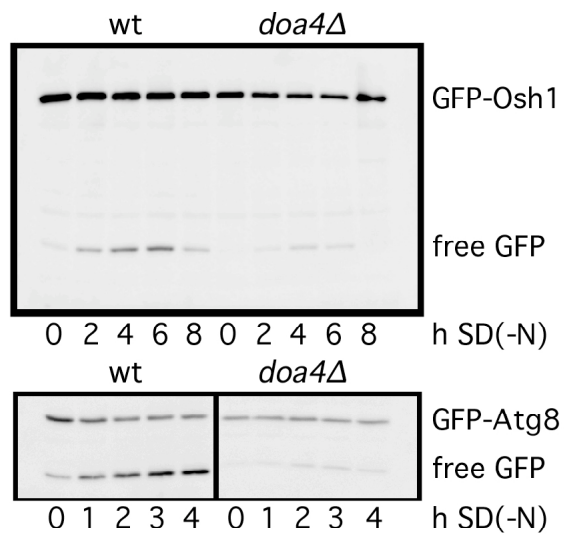

B.

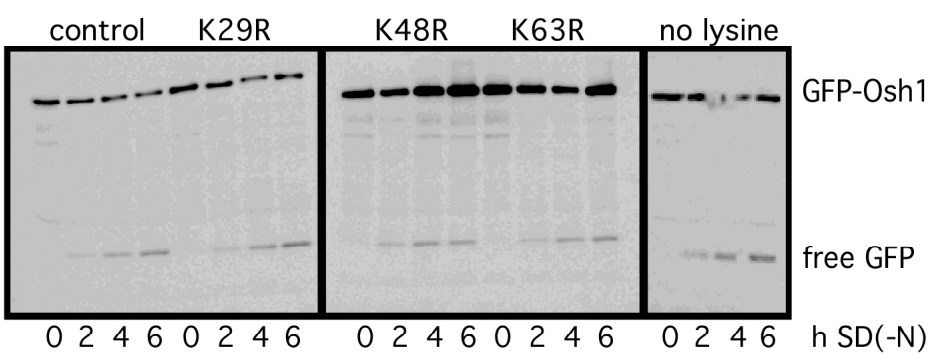

Fig. 32 Monoubiquitin is required for PMN and autophagy

(A.) All strains were BY4741 background. (B.) All strains were SEY background. Cells were transformed with GFP-Osh1 (A.) upper part and (B.) or GFP-Atg8 (A.) lower part. Western blot of alkaline lysed stationary $(0 \mathrm{~h})$ and starved $(2-8 \mathrm{~h} \mathrm{SD}(-\mathrm{N}))$ yeast cells. GFP-Osh1, GFP-Atg8 and free GFP were detected using a mouse monoclonal GFP antibody.

(A.) Three independent experiments and (B.) two independent experiments showed comparable results.

Doa $4 \Delta$ cells showed a clear reduction in free GFP signal compared to wild type.

There was no difference in free GFP signal in control cells compared to one of the modified ubiquitins. Even for the ubiquitin molecule without any lysine the free GFP signal showed no decrease. This points to the requirement of monoubiquitin for PMN and autophagy. 


\subsubsection{Ubp3 and Bre5 are only required for PMN}

The ubiquitin protease Ubp3 and its cofactor Bre5 are required for selective autophagic degradation of the large $60 \mathrm{~S}$ subunit of ribosomes upon starvation (ribophagy). Indeed the catalytic activity of the ubiquitin protease Ubp3 is necessary for its ribophagic function, implying that this process requires the cleavage of ubiquitin from a yet unknown substrate (Kraft, 2008). As ribophagy is a selective variant of autophagy the involvement of Ubp3 or Bre5 was tested in selective degradation of the nucleus.

Wild type, vac8 8 , ubp $3 \Delta$ and bre $5 \Delta$ cells were transformed with GFP-Osh1 (Fig. 33 (A.)) or GFP-Atg8 (Fig. 33 (B.)). Stationary cells were shifted to $\mathrm{SD}(-\mathrm{N})$ starvation medium and samples were collected at the indicated time points, alkaline lysed and prepared for immunoblots (chapter 3.2.25.1).

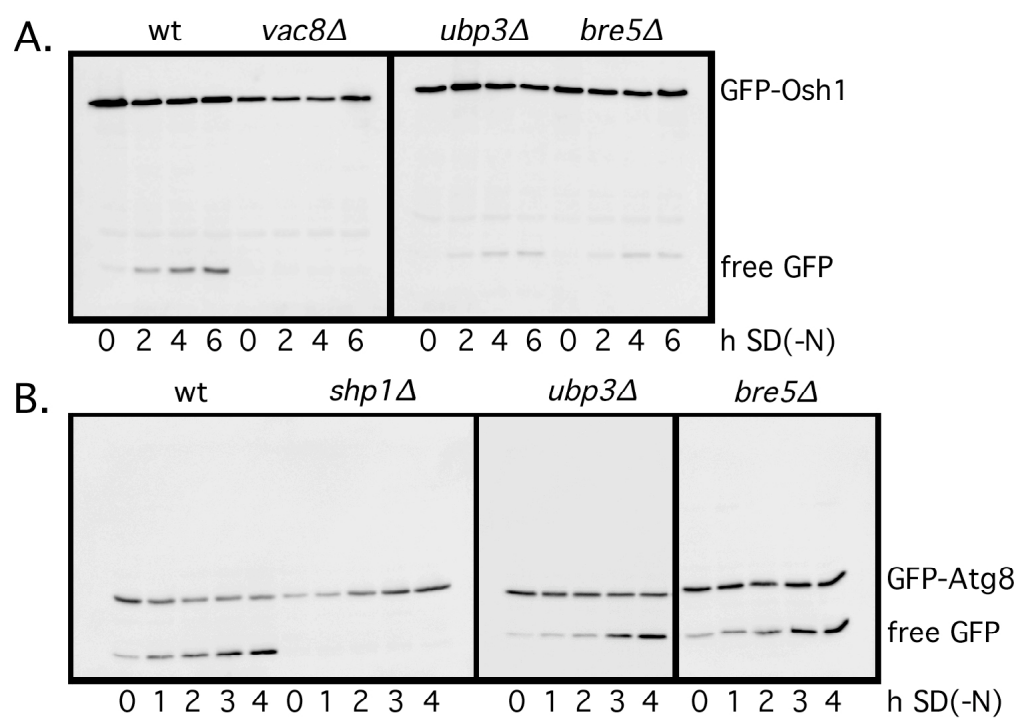

Fig. 33 Ubp3 and Bre5 are only required for PMN

All strains were BY4741 background. Cells were transformed with GFP-Osh1 (A.) or GFP-Atg8 (B.). Western blot of alkaline lysed stationary $(0 \mathrm{~h})$ and starved $(2-6 \mathrm{~h} \mathrm{SD}(-\mathrm{N}))$ yeast cells. GFP-Osh1, GFP-Atg8 and free GFP were detected using a mouse monoclonal GFP antibody. (A.) Three independent experiments showed comparable results.

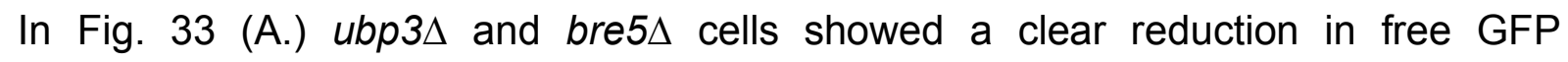
compared to wild type cells. In contrast the free GFP signal was comparable to wild type cells when GFP-Atg8 was expressed (Fig. 33 (B.)). 


\subsubsection{VPS class E genes are only required for PMN}

Vps27 and Vps28 belong to class E vps genes and are required for formation of multivesicular bodies in late endosomes. In class E mutant strains, the structure of the endosomes is abnormally enlarged and transport and retrieval from this compartment is severely affected. Class E mutants are not required for the Cvtpathway or autophagy (Reggiori, 2004), but could be involved in micronucleophagy.

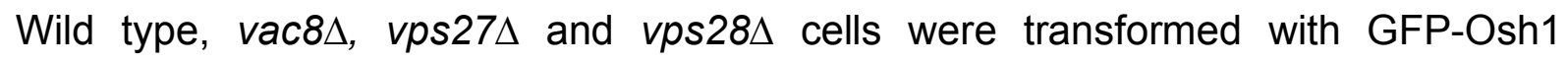
(Fig. 34 (A.)) or GFP-Atg8 (Fig. 34 (B.)). Stationary cells were shifted to SD(-N) starvation medium and samples were collected at the indicated time points, alkaline lysed and prepared for immunoblots (chapter 3.2.25.1).

A.

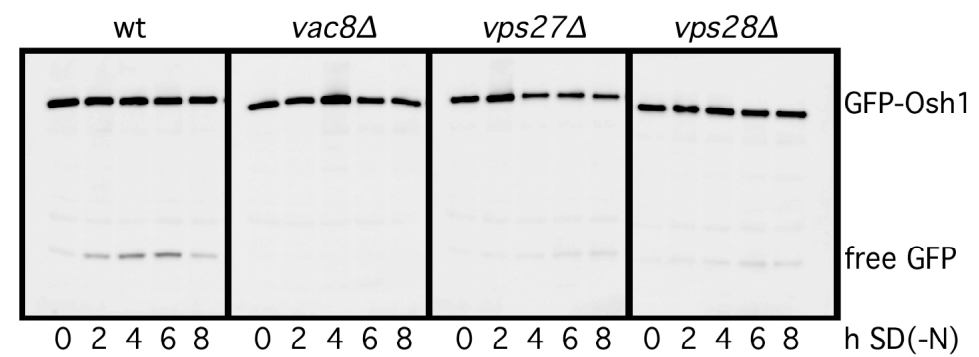

B.

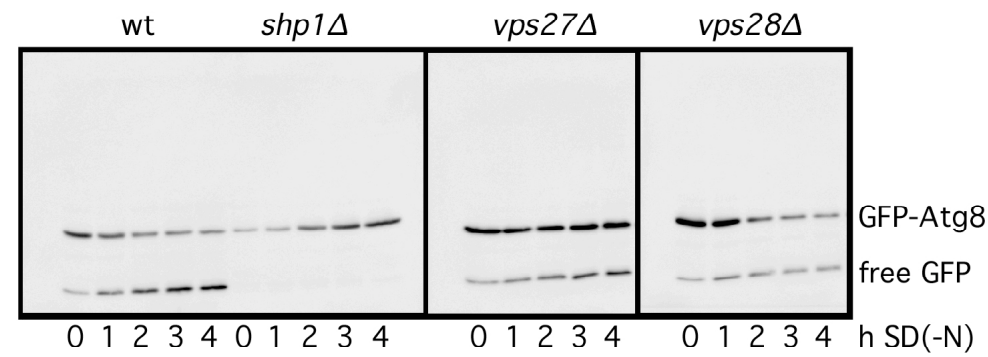

Fig. 34 Vps27 and Vps28 are only required for PMN

All strains were BY4741 background. Cells were transformed with GFP-Osh1 (A.) or GFP-Atg8 (B.). Western blot of alkaline lysed stationary $(0 \mathrm{~h})$ and starved $(2-8 \mathrm{~h} \mathrm{SD}(-\mathrm{N}))$ yeast cells. GFP-Osh1, GFP-Atg8 and free GFP were detected using a mouse monoclonal GFP antibody. (A.) Three independent experiments showed comparable results.

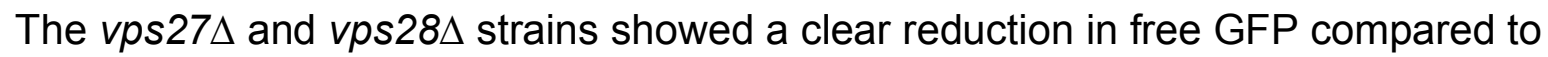
wild type. In contrast the free GFP signal was comparable to wild type cells when GFP-Atg8 was expressed.

Bsd2 and Tul1 are required for efficient ubiquitination of membrane proteins of the MVB pathway and contribute to the removal of misfolded membrane proteins (Hettema, 2004).

Wild type, vac $8 \Delta$ and bsd2 $\Delta$ tul $1 \Delta$ cells were transformed with GFP-Osh1. Stationary 
cells were shifted to $\mathrm{SD}(-\mathrm{N})$ starvation medium and samples were collected at the indicated time points, alkaline lysed and prepared for immunoblots (chapter 3.2.25.1).

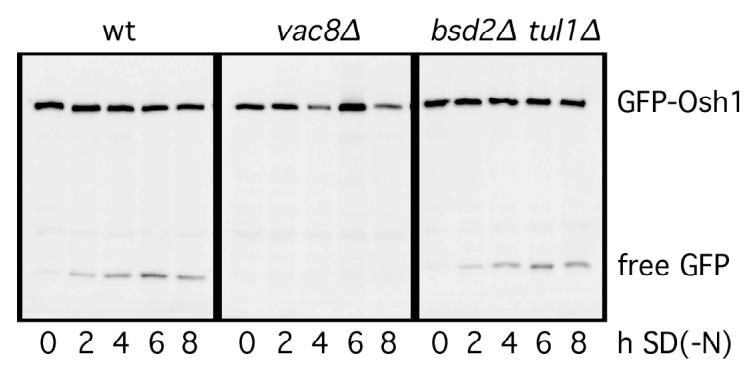

Fig. 35 Further strains involved in MVB transport

All strains were BY4741 background. Cells were transformed with GFP-Osh1. Western blot of alkaline lysed stationary $(0 \mathrm{~h})$ and starved $(2-6 \mathrm{~h} S \mathrm{SD}(-\mathrm{N}))$ yeast cells. GFP-Osh1 and free GFP were detected using a mouse monoclonal GFP antibody.

Bsd2 2 tul1 $1 \Delta$ double mutant cells showed no reduction in free GFP compared to wild type cells. 


\subsubsection{The Fatty acid elongation machinery is not required for PMN}

Fatty acid elongation requires biochemical reactions that are catalyzed by Elo2, Elo3, Tsc13, and Ybr159 (Rössler, 2003). The products of this elongation machinery are so called very-long-chain fatty acids (VLCFAs), which have been proposed to promote highly curved membrane structures (Schneiter and Kohlwein, 1997). Kvam et al. speculated that VLCFAs may be required for the efficient biogenesis of highly curved PMN vesicles. They described a reduced vesicle size in Tsc13-1 mutant cells and Tsc13-1 cells lacking Elo3 (Kvam, 2005).

Tsc13 $\Delta$ cells are not viable and therefore were not used in this study. Wild type,

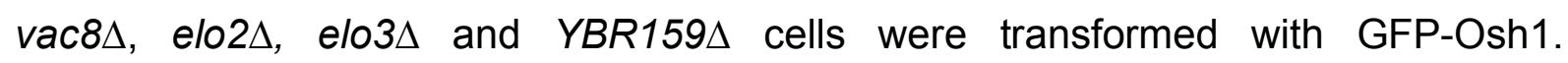
Stationary cells were shifted to $\mathrm{SD}(-\mathrm{N})$ starvation medium and samples were collected at the indicated time points, alkaline lysed and prepared for immunoblots (chapter 3.2.25.1).

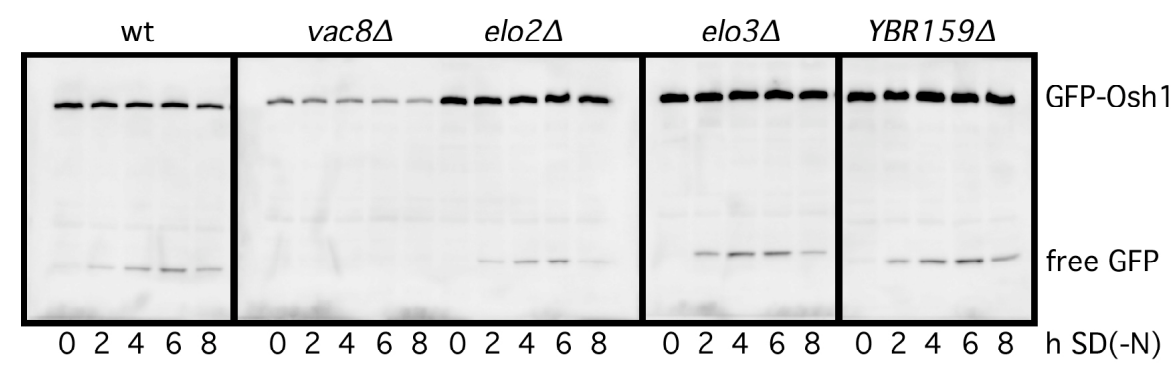

Fig. 36 Fatty acid elongation machinery is not required for PMN

Alls strains were BY4741 background. Cells were transformed with GFP-Osh1. Western blot of alkaline lysed stationary $(0 \mathrm{~h})$ and starved $(2-8 \mathrm{~h}$ SD $(-\mathrm{N}))$ yeast cells. GFP-Osh1 and free GFP were detected using a mouse monoclonal GFP antibody.

Elo2 $\Delta$, elo3 $\Delta$ and YBR159A cells showed no reduction in free GFP compared to wild type cells. 


\subsubsection{Proteins involved in cortical ER inheritance are not required for PMN}

All proteins discussed in this chapter have been described to be involved in the inheritance of the cortical ER. The integral membrane proteins Yop1 and Rtn1 generate the tubular structure of the endoplasmic reticulum (ER) (Hu, 2008).

Scs2 and Ice2 are proteins, which are involved in cortical ER inheritance and in additional perturb septin assembly at the bud neck. Scs2 has a function in targeting Osh1 to NV-junctions, although it is not strictly required for the localization of GFPOsh1p (Loewen, 2003).

Myo4 is a type $V$ myosin motor protein, which is required for the delivery of cortical ER into daughter cells during bud formation in yeast. She2 and She3 interact with Myo4, but only She2 is required for cortical ER inheritance and acts as a linker between cargo proteins and Myo4 (Du, 2004).

Wild type, vac8 $\Delta, r \operatorname{tn} 1 \Delta$, ice $2 \Delta$, yop $1 \Delta, \operatorname{scs} 2 \Delta$, myo4 $\Delta$, she $2 \Delta$ and she $3 \Delta$ cells were transformed with GFP-Osh1. Stationary cells were shifted to $\mathrm{SD}(-\mathrm{N})$ starvation medium and samples were collected at the indicated time points, alkaline lysed and prepared for immunoblots (chapter 3.2.25.1).
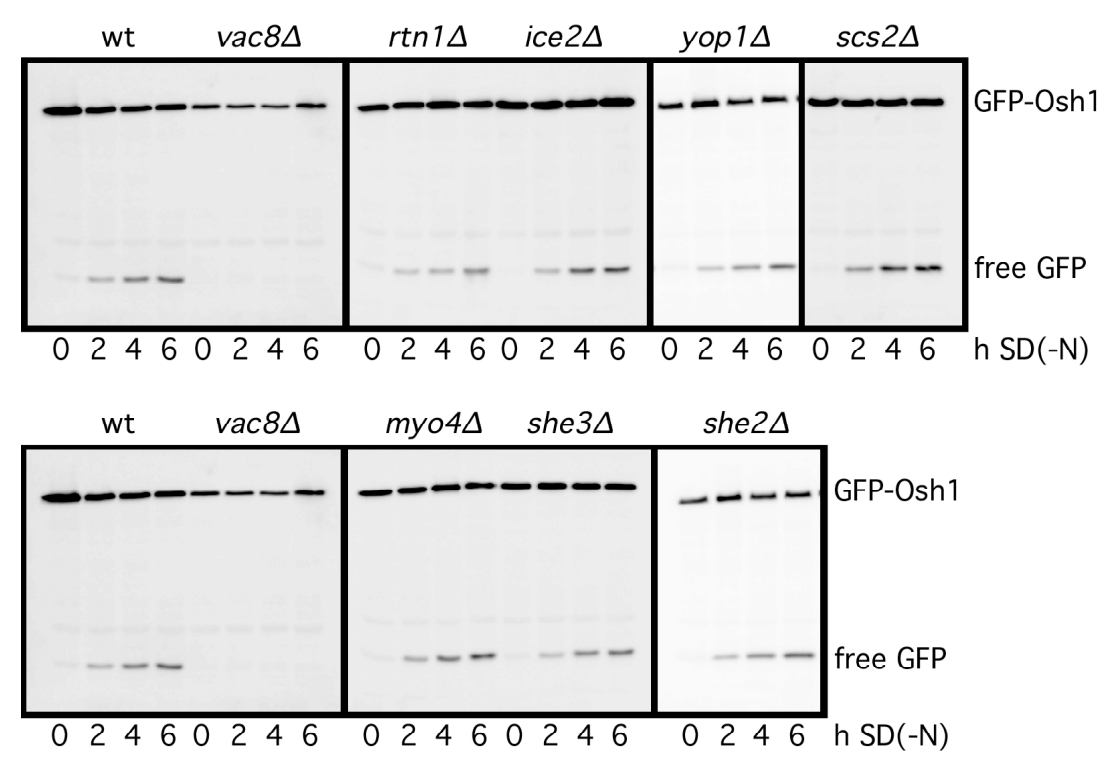

Fig. 37 Proteins involved in cortical ER inheritance are not required for PMN

All strains were BY4741 background. Cells were transformed with GFP-Osh1. Western blot of alkaline lysed stationary $(0 \mathrm{~h})$ and starved $(2-6 \mathrm{~h} \mathrm{SD}(-\mathrm{N}))$ yeast cells. GFP-Osh1 and free GFP were detected using a mouse monoclonal GFP antibody.

Rtn1 1 , ice2 $\Delta$, yop $1 \Delta, \operatorname{scs} 2 \Delta, m y 04 \Delta$, she2 $\Delta$ and she $3 \Delta$ cells showed no reduction in free GFP compared to wild type cells. 


\subsubsection{Analysis of a mutant with misshaped nucleus}

In spo7 $\Delta$ mutants the nucleus is misshaped exhibiting a single protrusion that may be degraded by PMN. The Spo7 protein is part of a phosphatase complex that represses phospholipid biosynthesis (Campbell, 2006).

Wild type, vac8 $\Delta$ and spo7 $\Delta$ cells were transformed with GFP-Osh1. Stationary cells were shifted to $\mathrm{SD}(-\mathrm{N})$ starvation medium and samples were collected at the indicated time points, alkaline lysed and prepared for immunoblots (chapter 3.2.25.1).

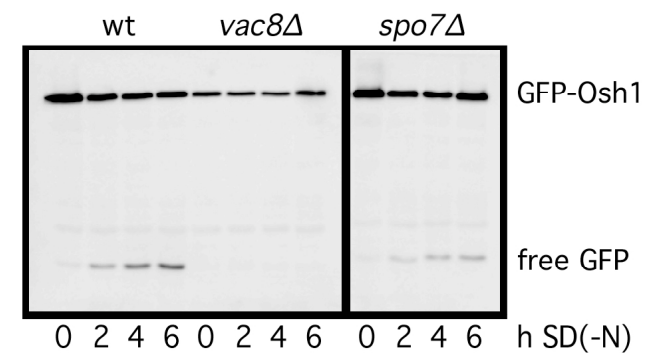

Fig. 38 Analysis of a mutant with misshaped nucleus

All strains were BY4741 background. Cells were transformed with GFP-Osh1. Western blot of alkaline lysed stationary $(0 \mathrm{~h})$ and starved $(2-6 \mathrm{~h} \mathrm{SD}(-\mathrm{N}))$ yeast cells. GFP-Osh1 and free GFP were detected using a mouse monoclonal GFP antibody.

Spo7 $\Delta$ cells showed a reduction in free GFP in 2 of 3 experiments compared to wild type cells.

\subsubsection{Summary of strains required for PMN identified in this study}

Tab. 14 All strains were transformed with GFP-Osh1.

\begin{tabular}{|l|l|l|}
\hline Strain & Free GFP & $\begin{array}{l}\text { Times } \\
\text { reproduced }\end{array}$ \\
\hline
\end{tabular}

\begin{tabular}{|l|c|c|}
\hline \multicolumn{3}{|c|}{ Fig. 29 Cdc48.3 } \\
\hline cdc48.3 & - & $6^{*}$ \\
\hline
\end{tabular}

\begin{tabular}{|l|c|c|}
\hline \multicolumn{3}{|c|}{ Fig. 30 Cdc48 substrate recruiting adaptors } \\
\hline$u b \times 1 \Delta / \operatorname{shp} 1 \Delta$ & - & 3 \\
\hline$u b \times 2 \Delta$ & + & 2 \\
\hline$u b \times 3 \Delta$ & + & 2 \\
\hline$u b \times 4 \Delta$ & + & 2 \\
\hline$u b \times 5 \Delta$ & + & 2 \\
\hline$u b \times 6 \Delta$ & + & 2 \\
\hline$u b \times 7 \Delta$ & + & 2 \\
\hline
\end{tabular}

Fig. 31 complex partners of Cdc48 der1s

\begin{tabular}{l|l}
+ & 1
\end{tabular}




\begin{tabular}{|l|c|c|}
\hline Strain & Free GFP & $\begin{array}{l}\text { Times } \\
\text { reproduced }\end{array}$ \\
\hline dfm1 $\Delta$ & + & 1 \\
\hline otu1 $1 \Delta$ & + & 1 \\
\hline ufd1_1 & $+^{* * *}$ & 1 \\
\hline ufd2 $\Delta$ & + & 1 \\
\hline ufd3 $\Delta /$ doa1 $1 \Delta$ & reduced & 1 \\
\hline
\end{tabular}

\begin{tabular}{|l|c|c|}
\hline \multicolumn{3}{|c|}{ Fig. 32 Ubiquitin } \\
\hline doa4 $\Delta$ & - & 3 \\
\hline
\end{tabular}

\begin{tabular}{|l|c|c|}
\hline \multicolumn{3}{|c|}{ Fig. 33 Ubp3 and Bre5 } \\
\hline bre5s & - & 3 \\
\hline$u b p 3 \Delta$ & - & 3 \\
\hline
\end{tabular}

\begin{tabular}{|l|c|c|}
\hline \multicolumn{3}{|c|}{ Fig.34 VPS class E } \\
\hline$v p s 27 \Delta$ & - & 3 \\
\hline$v p s 28 \Delta$ & - & 3 \\
\hline
\end{tabular}

Fig. 35 Further strains involved in MVB bsd2 $2 \Delta$ tul1 $1 \Delta$ 1

Fig. 36 Fatty acid elongation machinery

\begin{tabular}{|l|c|c|}
\hline elo2 $\Delta$ & + & 1 \\
\hline elo3s & + & 1 \\
\hline otu1 $\Delta$ & + & 1 \\
\hline
\end{tabular}

\begin{tabular}{|l|c|c|}
\hline \multicolumn{3}{|c|}{ Fig. 37 Cortical ER inheritance } \\
\hline$i c e 2 \Delta$ & + & 1 \\
\hline myo4 $\Delta$ & + & 1 \\
\hline rtn1 1 & + & 1 \\
\hline scs $2 \Delta$ & + & 1 \\
\hline she2 $\Delta$ & + & 1 \\
\hline she3 & + & 1 \\
\hline yop1 $1 \Delta$ & + & 1 \\
\hline
\end{tabular}

\begin{tabular}{|l|l|l|}
\hline \multicolumn{3}{|c|}{ Fig. 38 Misshaped nucleus } \\
\hline spo7s & reduced $^{* *}$ & 3 \\
\hline
\end{tabular}

+ = with free GFP $\quad-=$ blocked $/$ reduced free GFP

* in two backgrounds (WCG4a and BY4741)

${ }^{* *}$ in 2 of 3 experiments

${ }^{* * *}$ problems with background 


\subsubsection{Summary of strains required for autophagy identified in this study}

Tab. 15 All strains were transformed with GFP-Atg8.

\begin{tabular}{|c|c|}
\hline Strain & Free GFP \\
\hline \multicolumn{2}{|c|}{ Fig. 29 Cdc48.3 } \\
\hline cdc48.3 & - - \\
\hline
\end{tabular}

\begin{tabular}{|c|c|}
\hline \multicolumn{2}{|c|}{ Fig. 30 Cdc48 substrate recruiting adaptors } \\
\hline$u b \times 1 \Delta / \operatorname{shp} 1 \Delta$ & - \\
\hline
\end{tabular}

\begin{tabular}{|l|c|}
\hline \multicolumn{2}{|c|}{ Fig. 31 complex partners of Cdc48 } \\
\hline$u f d 3 \Delta /$ doa $1 \Delta$ & reduced \\
\hline
\end{tabular}

\begin{tabular}{|l|l|}
\hline \multicolumn{3}{|c|}{ Fig. 32 Ubiquitin } \\
\hline doa4 & \multicolumn{1}{c|}{-} \\
\hline
\end{tabular}

\begin{tabular}{|l|c|}
\hline \multicolumn{2}{|c|}{ Fig. 33 Ubp3 and Bre5 } \\
\hline bre5 $\Delta$ & + \\
\hline$u b p 3 \Delta$ & + \\
\hline
\end{tabular}

\begin{tabular}{|l|c|}
\hline \multicolumn{2}{|c|}{ Fig. 34 VPS class E } \\
\hline$v p s 27 \Delta$ & + \\
\hline$v p s 28 \Delta$ & + \\
\hline
\end{tabular}

$+=$ with free GFP $\quad$ - = blocked / reduced free GFP

* in two backgrounds (WCG4a and BY4741) 


\section{Discussion}

\subsection{Where are the autophagic membranes coming from?}

Autophagy starts at the pre- autophagosomal structure (PAS; phagophore assembly site). Out of this structure double membrane layered vesicles are formed and transported to the vacuole, where their outer membranes fuse with the vacuole, releasing a monolayered vesicle (autophagic body) into the vacuolar lumen. The PAS is believed to be an organelle-like membrane structure. Therefore a membrane source for the PAS itself and the formation of vesicles out of the PAS is required. Different cell compartments have been discussed as potential membrane sources (Ishihara, 2001) (Reggiori, 2004) (Reggiori, 2005) (Young, 2006) (Xie, 2008). The transmembrane protein Atg9 is suggested to be involved in transport of membrane to the PAS (Xie, 2008). It cycles between the PAS and a peripheral pool, which has been proposed to partially colocalizes with mitochondria (Reggiori, 2005) (Reggiori and Klionsky, 2006). Atg27 the second transmembrane protein located at the PAS is involved in the cycling of Atg9 (Yen, 2007). In $\operatorname{atg} 27 \Delta$ and $\operatorname{atg} 1 \Delta \operatorname{atg} 27 \Delta$ double knockout cells the localization of Atg9 to its peripheral pool is increased (Yen, 2007). In this study the stability of the peripheral GFP-Atg9 pool as well as the colocalization of this pool to mitochondria was not reproducibly stable (data not shown). But the peripheral GFP-Atg9 dots were completely lost in $\operatorname{atg} 4 \Delta \operatorname{atg} 27 \Delta$ cells resulting in a diffuse signal (Fig. 16 (B.)). As Atg4 is required for the ubiquitin like conjugation of Atg8 to PE (phosphatidylethanolamine) (chapter 2.5.6.1 and Fig. 5) Atg8 is also a suitable candidate to follow the membrane flow.

During autophagy Atg8 localizes to the PAS. In addition to PE conjugation and the Atg12-Atg5-Atg16 complex, its proper localization requires Atg9 and the autophagyspecific phosphatidylinositol 3-kinase (PI3K) complex I (Xie, 2008). Atg8-PE is used as a common marker for autophagy. It is located to the inside and outside of the forming and completed autophagosomes but the coupling of Atg8 to PE is a reversible event. Atg8 is cleaved of from the outer membrane of the completed vesicles by Atg4 and is reused (Fig. 5).

Furthermore, among the core autophagic machinery, Atg8 is the only protein, which has a significant elevated protein level when autophagy is induced (Kirisako, 1999). 
The enhanced Atg8 level could somehow trigger an enhanced membrane flow.

Legesse-Miller et al. showed that Atg8 plays an additional role in constitutive protein transport pathways from the ER to the Golgi. They demonstrated that overexpression of Atg8 leads to suppression of the temperature sensitive phenotype of the SNARE mutants bet1-1 and sec22-2 (Legesse-Miller, 2000).

The results from Legese-Miller et al. were not reproducible in this study (data not shown).

Wild type cells expressing GFP-Atg8 from a CEN plasmid showed a diffuse vacuolar GFP signal and in some cells a PAS dot. In atg1 $1 \Delta$ cells Atg8 was restricted to the PAS ( $>75 \%$ of cells had a PAS signal). The double knockout strain $\operatorname{atg} 1 \Delta \operatorname{atg} 27 \Delta$, that has been described to enrich GFP-Atg9 at a peripheral pool, showed also a PAS localization and an additional peripheral pool of GFP-Atg8 (Fig. 17).

The peripheral pool of Atg8 was detected at a ring around the vacuole where PI3P is located (Fig. 20). In S. cerevisiae the endomembrane system resides around the vacuole and contains PI3P as a typical lipid component (Di Paolo and De Camilli, 2006) (Gillooly, 2000). The endosomal localization of the peripheral pool of GFP-Atg8 was confirmed by colocalization using the chromosomally tagged endosomal protein

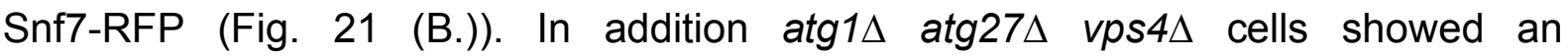
accumulation of GFP-Atg8 at its peripheral pool compared to $\operatorname{atg} 1 \Delta \operatorname{atg} 27 \Delta$ cells (Fig. 21 (A.)). Inactivation of Vps4 results in the enrichment of the ESCRT machinery on the surface of endosomes and enlargement of the compartment (class $E$ compartment) (Babst, 1997).

Thus all three results support a localization of the peripheral pool of Atg8 to endosomes.

The quantification of the peripheral pool of Atg8 showed that $40 \%$ of $\operatorname{atg} 1 \Delta \operatorname{atg} 27 \Delta$ cells had more than two clear GFP dots. In contrast only $2 \%$ of the $\operatorname{atg} 1 \Delta$ cells showed this phenotype. The deletion of Atg1 Atg27 and Vps4 additionally increased the number of cells showing a peripheral pool (Fig. 22).

To confirm these microscopic results subcellular fractionation experiments were done as an independent approach.

As control $\operatorname{atg} 4 \Delta \operatorname{atg} 8 \Delta$ double deletion strains expressing either full length GFP-Atg8 or GFP-Atg8*, lacking the C-terminal arginine were analysed. The cells showed the expected shift of GFP-Atg8 from P100 (100000 g pellet) to P13 (13000 g pellet) as previously described by Kirisako et al. (Kirisako, 2000). No shift could be detected in 
$\operatorname{atg} 1 \Delta \operatorname{atg} 27 \Delta$ cells compared to $\operatorname{atg} 1 \Delta$ cells (Fig. 23 (A.)). An additional experiment using a sucrose gradient to separate the peripheral pool from the PAS pool showed no significant difference between the two strains (Fig. 23 (B.)). The quality of the gradient was tested using the endosomal marker Pep12 that, as expected, primarily located in the same fractions as the main peak of GFP-Atg8.

Both fractionation experiments were unlikely to separate the PAS pool and the peripheral Atg8 pool. But they support the endosomal localization because of the overlap between Pep12 and GFP-Atg8 signal in the sucrose gradient.

Up to now there are no other methods available to clearly separate the PAS from other membranous organelles.

To investigate the involvement of the Atg8 conjugation machinery in the formation of the peripheral pool, two plasmids expressing a full length GFP-Atg8 and a GFPAtg8*, lacking the C-terminal arginine were analysed. In vivo this arginine has to be cleaved of by Atg 4 before Atg8 can be coupled to PE in an ubiquitin like reaction (chapter 2.5.6.1 and Fig. 5). In atg $4 \Delta$ atg8 cells expressing GFP-Atg8 the GFP signal was mainly cytosolic and only a rare PAS signal was detected because Atg8 could not be coupled to PE (Fig. 18 (A.)). In contrast the GFP-Atg8* construct showed membranous structures colocalizing with the endosomal / vacuolar membrane marker FM4-64 (Fig 18 (B.)).

A GFP-Atg8-cherry protein was created to investigate if the cleavage of Atg8 by Atg4 and therefore the coupling to PE is required for the peripheral localisation of Atg8. The GFP-Atg8-cherry protein was expressed in different knockout cells. The cherry protein at the C-terminus of Atg8 did not influence the cleavage of GFP-Atg8-cherry by Atg4 (Fig. 19 (A)). In atg1 $\Delta$ atg27 $\Delta$ cells the GFP signal of GFP-Atg8-cherry was visible at the peripheral pool. This pool vanished in cells additionally lacking Atg4 (Fig. 19 (B.)). But the GFP-Atg8-cherry only showed a diffuse microscopic cherry signal in all strains.

These data suggest that Atg4 and therefore the lipidation of Atg8 is required for the efficient localization of Atg8 to the PAS as well as its peripheral pool.

To show that the slight overexpression of the GFP-Atg8 from a CEN plasmid does not influence its localization, control strains as well as a $\operatorname{atg} 1 \Delta \operatorname{atg} 27 \Delta$ strain expressing a chromosomally GFP-tagged Atg8 were constructed. 
$\operatorname{Atg} 1 \Delta \operatorname{atg} 27 \Delta$ cells often showed membranous GFP structures that did not resemble to endosomal structures but rarely dots (Fig. 24).

The plasmid and chromosomal GFP-Atg8 differ only in three minor points: the expression level, the remaining lox site between promoter and GFP and the linker connecting GFP with Atg8 (Fig. 25).

Only $\operatorname{atg} 1 \Delta \operatorname{atg} 27 \Delta$ double mutant cells, expressing GFP-Atg8 from the plasmid, show a peripheral pool and not $\operatorname{atg} 1 \Delta$ or atg $27 \Delta$ single mutant cells. This result supports the assumption that the slight overexpression does not influence the localization, because the expression level is the same for all these strains.

The lox site leads to 23 additional amino acids (aa) in front of GFP and therefore may influence the folding of GFP but should not influence the function of Atg8, although this could not be excluded.

The difference between the two linker regions connecting GFP and Atg8 maybe is an explanation for the detected differences in the localization of chromosomally and plasmid expressed GFP-Atg8. Instead of two aa seven aa are inserted. This linker is part of Atg8 and could influence the folding and function of Atg8, which could lead to a mislocalization.

A direct detection of Atg8 with a specific antibody using immunogold EM in $\operatorname{atg} 1 \Delta$ $\operatorname{atg} 27 \Delta$ cells would be the best method to support the localization of Atg8 at endosomes. The antibody available for this study is not suitable for this purpose, because it hardly detects Atg8 in western blot or indirect immunofluorescence and has a high background signal (data not shown). The available antibody could be affinity purified or a new antibody could be generated. Alternatively a GFP monoclonal mouse antibody could be used in cells expressing GFP-Atg8 in immunogold EM, but this GFP-tagging could influence the correct localization of the fusion protein.

In this study GFP-Atg8 expressed from a CEN plasmid showed a peripheral pool colocalizing with endosomes. These results are consistent with the localisation data from Atg9 in mammalian cells pointing to endosomes and TGN (trans Golgi network) (Young, 2006).

\section{Further studies concerning the peripheral pool of Atg8 could answer these questions:}

Which proteins are required for the cycling of Atg8? Is the peripheral pool of GFPAtg8 identical with the GFP-Atg9 pool? How do both cycling events correlate? Is 
there more than one membrane source? May one peripheral pool serve as membrane source for the Cvt-pathway and the other for autophagy?

\subsection{Micronucleophagy in S. cerevisiae}

\subsubsection{Micronucleophagy in S. cerevisiae requires the core autophagic genes}

Autophagy is a highly conserved process in eukaryotes. In S. cerevisiae the autophagic processes can be divided in two fundamentally different subtypes: microautophagy and macroautophagy. During macroautophagic processes double membrane-layered vesicles are formed, that contain cytosolic material as well as whole organells. Through fusion with the vacuolar membrane a still monolayered autophagic body is released into the vacuole.

During microautophagic processes invaginations of the vacuolar membrane are formed, releasing a monolayered vesicle into the vacuole. The cargo of micro- and macroautophagic processes are degraded, recycled and reused for the synthesis of proteins strictly required for survival.

Micronucleophagy (piecemeal microautophagy of the nucleus, PMN) is a bona fide microautophagic process. In S. cerevisiae Nvj1 forms contact sites between the nucleus and the vacuole. This protein spans the outer nuclear ER membrane and interacts with the inner nuclear ER membrane and Vac8 on the vacuolar membrane (Pan, 2000) (Millen, 2008). Micronucleophagy is induced by nutrient depletion. A tethered bleb is formed at the NV-junction, that is limited by three membrane layers: vacuolar membrane, outer nuclear membrane and inner nuclear membrane (Fig. 8 and 9). Upon induction of micronuclophagy Nvj1 recruits two additional proteins to the NV junctions (Kvam, 2005): Tsc13 and Osh1, which are both involved in the lipid metabolism of the cell.

First studies suggested that the autophagic machinery is not required for PMN. The degradation of overexpressed marker proteins coupled to EYFP was measured in different yeast strains by quantifying the fusion protein using immunoblots. Atg7 $\Delta$ cells showed comparable amounts of remaining fusion protein as wild type cells (Roberts, 2003) (Kvam, 2005) (Kvam and Goldfarb, 2006b). Atg7 is part of both 
ubiquitin like conjugation systems during autophagy and is therefore strictly required for autophagic processes (Fig. 5). In contrast Krick et al. (Krick, 2008b) showed in a recent publication that PMN requires the core macroautophagy genes including Atg7. They analysed the degradation of the PMN marker protein GFP-Osh1 by quantifying the release of hydrolase resistant free GFP in the vacuole using western blot analysis.

This study supports the latter finding using another molecular approach. To trace the nuclear content $\operatorname{atg} 15 \Delta$ cells expressing a nuclear resident NLS-2mcherry fusion protein were imaged. Atg15 is a putative lipase, required for the breakdown of intravacuolar vesicles. After starvation atg $15 \Delta$ cells showed intravacuolar free floating cherry vesicles in videomicroscopy. In cells lacking Atg15 and Atg1 no vesicles are formed. This result supported the finding that the core autophagic machinery is required for PMN because Atg1 is essential for autophagosom formation (Fig. 26 (A.)).

The rare red PMN vesicles were clearly distinguishable from the highly enriched autophagosomes in the vacuole of atg15 cells (Fig. 26 (B.) and (C.)).

To analyze further autophagic mutants to their PMN phenotype, the vesicles had to be stabilized in the vacuole. PMSF inhibits the vacuolar hydrolase proteinase $B$ leading to an accumulation of NLS-2mcherry vesicles and autophagosomes in the vacuolar lumen of wild type cells (Fig. 27). Autophagic mutants showed no free floating vesicles even under these stabilizing conditions (Fig. 27). This is in agreement with the western blot analysis from Krick et al. (Krick, 2008b) showing that the autophagic machinery is indeed required for micronucleophagy.

\subsubsection{Induction of micronucleophagy}

Different starvation media were tested to identify the best induction conditions for $P M N$. A quantification of three independent experiments revealed that $S D(-N)-$ medium showed the highest amount of free GFP in western blot analysis. Rapamycin a TOR-kinase (target of rapamycin kinase) inhibitor and known to induce autophagy showed the same amount of free GFP up to $4 \mathrm{~h}$ starvation. Afterwards the free GFP signal decreased to $40 \%$ (Fig. 28). This indicates that rapamycin is either not stable over longer time periods or it also induces other proteins like hydrolases that increase the degradation of free GFP. 
Potassium acetate induces autophagy using other signaling pathways as $\mathrm{SD}(-\mathrm{N})$ (unpublished data of the Thumm group) and showed a slower increase in free GFP compared to SD(-N) starvation. The addition of $2 \%$ glucose even decreased the free GFP measured.

PMN is highest induced under nitrogen starvation conditions $(\mathrm{SD}(-\mathrm{N}))$ and was therefore used for all further experiments in this study.

\subsubsection{Membrane fusion in autophagy and PMN}

All autophagic processes need membrane fusion events. Little is known about the components required for the different membrane fusions.

To set up a common fusion machinery, the two fusing membranes have to first undergo docking and priming, an ATP-dependent process (Klenchin and Martin, 2000) (Geumann, 2008). The required energy for membrane fusion is delivered by interaction of the SNAREs (soluble NSF attachment protein receptor) from opposing membranes and formation of a four-helical bundel in a process termed „zippering“. After fusion, all fused SNAREs are located at the same membrane. They have to be disassembled to provide free SNARE molecules for further rounds of fusion, a process carried out by the $\mathrm{AAA}^{+}$ATPase NSF ( $\mathrm{N}$-ethylmaleimide-sensitive fusion protein; homologue in S. cerevisiae: Sec18) and its cofactor $\alpha$-SNAP (soluble NSF attachment protein; homologue in S. cerevisiae: Sec17), in an energy-dependent process (Jahn and Scheller, 2006).

During PMN three membrane fusion events are necessary: fusion of the vacuolar membrane, the outer nuclear membrane and the inner nuclear membrane (Fig. 8).

Krick et al. reported that the standard homotypic vacuolar fusion machinery is not required for the biogenesis of PMN vesicles. Some of the components seemed to be involved in PMN as Sec18 and Sec17, both fundamentally required for membrane fusion mediated by SNAREs, the HOPS complex, and the Rab-GTPase Ypt7, but this phenotype may only be due to the role of these components in vacuolar biogenesis (Krick, 2008b). The molecular composition of the machinery required for all three membrane fusion events is still unclear.

Autophagy also requires several membrane fusion events: membrane transport to the PAS (Atg9 / Atg8 cycling), sealing of the isolation membrane (autophagosome or 
Cvt-vesicle formation) and fusion of the autophagosome with the vacuole. Ishihara et al. showed that Sec18 and Sec17 are required for the fusion of autophagosomes with the vacuole but are not involved in autophagosome formation (Ishihara, 2001). The involvement of these proteins in autophagy could also be indirect due to the role in vacuolar biogenesis as it is proposed for PMN.

Cdc48, which shows significant homology with Sec18, is also an $\mathrm{AAA}^{+} \mathrm{ATPase}$ known to be required for ER homotypic fusion (Latterich, 1995). In yeast the ER membranes also form the nuclear membrane making Cdc48 a likely candidate to mediate at least one membrane fusion event during PMN.

Ishihara et al. showed that $c d c 48-3 t s$ mutant cells cultured in $\mathrm{SD}(-\mathrm{N})$ at $34^{\circ} \mathrm{C}$ showed normal autophagic function compared to wild-type cells although ER fusion has been reported to be affected at this temperature (Latterich, 1995). Thus they concluded that Cdc48 is not required for autophagy (Ishihara, 2001).

In this study Cdc48-3 was crossed into two backgrounds (WCG: standard strain in the lab and BY4741: commercial available and widely used). In parallel the original strain W303 from the Latterich lab was analysed.

The restrictive temperature for each of the Cdc48.3 strains was determined using a growth phenotype. But the viability was not altered during the experiment at this temperature compared to wild type (data not shown). In the WCG background Cdc48.3 cells indeed showed a reduced PMN rate at the restrictive temperature but interestingly also an autophagic phenotype (Fig. 29 (I.)). This result could be reproduced in the BY4741 background even if the PMN and autophagic rate was also reduced at the permissive temperature (Fig. 29 (II.)).

A similar temperature sensitive-phenotype has been reported from Ye et al.. They tested the involvement of Cdc48 in ER protein degradation. They used the membrane protein substrate $\mathrm{H}-2 \mathrm{~K}^{\mathrm{b}}$, a major histocompatibility complex (MHC) class I heavy chain that is quickly degraded in yeast in a proteasome-dependent manner (Casagrande, 2000). They reported that a significant stabilization of $\mathrm{H}-2 \mathrm{~K}^{b}$ was detected in the Cdc48 mutant (Cdc48-3), even at the permissive temperature. (Ye, 2001).

The wild type strain to the originally described Cdc48-3ts strain from Latterich et al. showed no PMN activity in the GFP-Osh1 assay. But autophagy was also reduced in the Latterich mutant strain at the restrictive temperature compared to wild type and the permissive temperature (Fig. 29 (III.)). 
In contrast to Ishihara et al. this study suggests that Cdc48 is required for efficient autophagy and PMN.

Both studies differ in the determination of the restrictive temperature. Probably the temperature chosen from Ishihara et al. had only been too low to show an autophagic phenotype in the Cdc48.3 mutant in the used background.

Cdc48 is involved in many different cellular processes, including ubiquitin-dependent protein degradation and fusion of homotypic membranes (Ye, 2001) (Latterich, 1995) (chapter 2.6.1). The specificity and function of Cdc48 is regulated by different protein complexes (Tab. 1 Classification of Cdc48 cofactors in yeast).

p97 (the human homologue of Cdc48) and p47 (the human homologue of Shp1) control the fusion of homotypic membranes (Kondo, 1997) while ubiquitin-dependent protein degradation pathways require the Cdc48/p97 Ufd1-Npl4 complex (Braun, 2002) (Meyer, 2000) (Ye, 2001) (Jarosch, 2002).

Shp1 (Ubx1) belongs to the UBX protein family, which consists in S. cerevisiae of 7 proteins. UBX proteins have been described as general Cdc48 interacting proteins.

This study showed that for autophagy as well as PMN, indeed Shp1, a major substrate-recruiting factor, was essential (Fig. 30). The constitutive Cvt-pathway was unaffected in shp1s cells as determined by normal Ape1 maturation (Fig 30 (A.) bottom).

In addition to the UBX domain Shp1 possesses a ubiquitin-binding UBA domain that interacts with ubiquitylated proteins in vivo.

Binding of the human homologue p47 to ubiquitylated proteins via the UBA domain is required for efficient p97 / p47-mediated Golgi membrane fusion in vitro (Meyer, 2002). It has been further hypothesized that this ubiquitylated substrate serves as a fusion inhibitor and has to be extracted out of the membrane by p97 / p47 to mediate membrane fusion. It was postulated that Ufd1 / Npl4 targets multiubiquitylated substrates to $\mathrm{Cdc48}$ destined for proteasomal degradation whereas p47 recruits monoubiquitylated substrates that should not be degraded (Meyer, 2002) (Wang, 2004b).

Loss of Doa4 depletes cellular ubiquitin levels, which causes many cellular defects, including loss of efficient MVB (multi vesicular body) sorting of some integral membrane proteins (Ren, 2008).

Autophagy and PMN were drastically reduced in doa4s cells (Fig. 32 (A.)). Further 
experiments with different ubiquitin mutants showed that polyubiquitination is not necessary for PMN (Fig. 32 (B.)). Therefore free uncoupled ubiquitin is required for both processes (see discussion 5.2.5).

Ufd1 (ubiquitin fusion degradation) and Npl4 are both required for the Cdc48 protein degradation complex. Therefore a point mutant of Ufd1 (Ufd1.1), known to be defective in this function, was tested for PMN. But the corresponding wild type cells expressed the marker protein only at such low level that no free GFP was visible. Maybe the strain was contaminated or harmed during transport. In contrast the Ufd1.1 mutant cells showed free GFP and so Ufd1 may not be required for PMN. The Cdc48 additional substrate recruiting factors Dfm1 and Der1 and the substrateprocessing factor Otu1 were also not required for efficient PMN (Fig. 31). The human deubiquitylating enzyme VCIP135 is part of the human mitotic Golgi reassembly machinery and harbors a domain with clear homology to UBX domains (Fig. 39). It is categorised as a substrate processing factor of Cdc48 and its closest $S$. cerevisiae homologue is Otu1. Ufd $3 \Delta$ cells showed a reproducibly reduced free GFP signal and thereby a reduced PMN rate, but only a slight decrease in autophagy (Fig. 31).

Ufd3 (alias Doa1) contains seven WD40 repeats and two other functional domains. The central PFU domain of Ufd3 mediates interaction with ubiquitin whereas the Cterminal PUL domain interacts with Cdc48 (Ren, 2008). Ufd3 as well as Doa4 play a role in sorting of ubiquitinated membrane proteins into multivesicular bodies. It interacts with the Vps27-Hse1 complex. The loss of Ufd3 or Doa4 decreases cellular ubiquitin levels (Ghislain, 1996) (Mullally, 2006), but the Doa4 deletion leads to a more severe phenotype. The defects observed in ufd3s cells in MVB sorting of ubiquitinated cargo are independent of lower ubiquitin levels, which indicates a more direct role for Ufd3 in controlling the MVB sorting process (Ren, 2008). Ufd3 has the ability to displace Ufd2 from $\mathrm{Cdc48}$ and thereby prevent polyubiquitination (Rumpf and Jentsch, 2006). Ufd3 was required for PMN and autophagy whereas Ufd2 was not required for PMN and not tested for autophagy (Fig. 31).

In contrast to Ufd3, no direct interaction or involvement of Doa4 with Cdc48 has been reported (Ren, 2008).

The requirement of Ufd3 and Doa4 in autophagy and PMN should be verified and the question if the observed reductions in both processes are due to a direct role of one of the proteins or mediated via the low ubiquitin levels should be addressed. Thus $u d f 3 \Delta$ and doa $4 \Delta$ cells could be transformed with ubiquitin overexpressing plasmids 
and then tested for their autophagy and PMN rate in further experiments.

In Fig. 39 the hypothetic components required for membrane fusion of the human system (p97 (A.)) in mitotic Golgi reassembly are compared with the finding from this study concerning autophagy and PMN in S. cerevisiae (Cdc48 (B.)).

A.

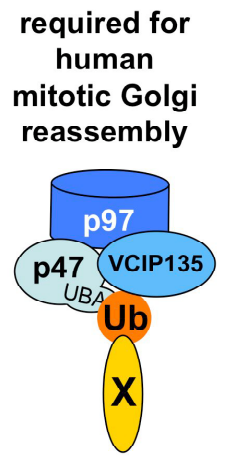

B. required for autophagy and PMN in

S. cerevisiae

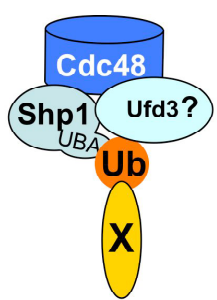

Fig. 39 Composition of CDC48 complexes in membrane fusion events

(A.) Hypothetic model complex for human mitotic Golgi (Meyer, 2005); (B.) Hypothetic Cdc48 model complex for $S$. cerevisiae autophagy and PMN; requirement of Ufd3 has to be validated; $\mathrm{Ub}=$ ubiquitin; $\mathrm{X}=$ unknown fusion inhibitor

The components shown in Fig. 39 (B.) are required for efficient PMN. Further experiments have to confirm their involvement in membrane fusion. One interesting question is which of the membrane fusion events is mediated by the Cdc48 complex. As described earlier in both processes (autophagy and PMN) at least three membrane fusion events have to proceed. Guan et al. published a protease protection assay for autophagy to distinguish between open and closed autophagosomes or fusion with the vacuole using pseudo-maturation of Ape1 via protease K (Guan, 2001) (Strømhaug, 2004). For this purpose a Ape1 maturation assay is not useful, because the Cvt-pathway, which transports Ape1 to the vacuole, is not impaired in Cdc48.3 or shp1د cells. Instead the pseudo-cleavage of GFP-Atg8 by trypsine could be monitored what has to be first established. Another approach could be electromicrographs to distinguish between wild type, ypt7ム (where the autophagosomal fusion with the vacuole is impaired) and e.g. shp1 $1 \Delta$ cells. Using these two methods it would be possible to distinguish if autophagosomes are closed in shp1 $1 \Delta$ cells and still fuse with the vacuolar membrane or accumulate in the cytosol. The latter experiment could also exclude the possibility that the autophagic defect of Cdc48.3 and shp1 $1 \Delta$ cells is due to an indirect effect like the impairment of the ER itself. Because Reggior et al. showed that in some early secretory mutants no autophagosomes are formed at all (Reggiori, 2004). 


\subsubsection{Ubp3 and Bre5 are only required for PMN}

Kraft et al. observed that several GFP-fused ribosomal proteins of both $60 \mathrm{~S}$ and $40 \mathrm{~S}$ subunits, which were functional and correctly assembled into ribosomes, were delivered to and degraded in the vacuole of nitrogen starved yeast cells in an autophagy dependent manner. Thus they reported a selective autophagic process for ribosomes. Kraft et al. identified the ubiquitin deconjugation enzyme Ubp3 and its cofactor Bre5 as proteins required for the selective autophagic degradation of the $60 S$ subunit of ribosomes under starvation conditions. The catalytic activity of Ubp3 is needed for ribophagy, implying the involvement of a deubiquination step from a yet unknown protein. Ubp3 and Bre5 are not required for unspecific macroautophagic breakdown of ribosomes (Kraft, 2008).

Micronucleophagy was also significantly reduced in ubp3 $\Delta$ and bre $5 \Delta$ cells whereas macroautophagy was normal (Fig. 33). Thus Ubp3 and Bre5 are involved in two selective autophagic processes. But not all selective autophagic processes require theses proteins, as the Cvt-pathway is not significantly affected in $u b p 3 \Delta$ or bre5 $\Delta$ cells (Kraft, 2008). The requirement of Ubp3 and Bre5 additionally supports the involvement of (mono-) ubiquitination for PMN.

\subsubsection{VPS class E genes are required for PMN}

Vps27 and Vps28 are involved in the formation of multivesicular bodies and belong to the class $E$ subgroup of vacuolar sorting proteins that are supposed to regulate trafficking between endosomes and the vacuole (Piper, 1995). Vps27 contains two putative ubiquitin-interacting motifs and could play a role in the sorting of monoubiquitinated proteins at endosomes (Stenmark, 2002) (Ren, 2008). Models suggest that the ubiquitinated cargo is captured by the Vps27-Hse1 complex. At a late stage of the sorting process, ubiquitin is removed from the cargo by the deubiquitinating enzyme Doa4 before incorporation of the cargo into intralumenal vesicles of the MVB pathway (Dupré and Haguenauer-Tsapis, 2001). As Ape1 is normally processed in VPS class E mutant strains, Reggiori et al. concluded that late endosomal functions are not required for the formation of Cvt- vesicles or autophagosomes (Reggiori, 
2004).

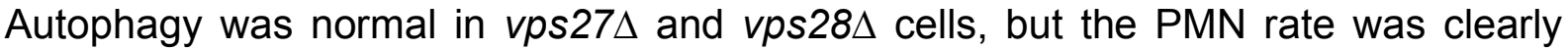
reduced in these strains (Fig. 34). Interestingly doa $4 \Delta$ showed a phenotype for both processes (Fig. 32 (A.)), which could be due to the requirement of free ubiqitin for both processes. However this does not explain the involvement of Vps27 and Vps28 exclusively for PMN. It is likely that membrane proteins needed for PMN are transported via the MVB pathway to the vacuole, where they either interact with the vacuolar membrane, participate in one of the membrane fusion events or in the generation of the $\mathrm{NV}$-junction required for PMN vesicle formation.

Hettema et al. showed that Bsd2 and Tul1 are required for efficient ubiquitination of membrane proteins in the MVB pathway and contribute to the removal of misfolded membrane proteins (Hettema, 2004). Both proteins were not required for PMN (Fig. 35).

Other mutant strains exhibiting a MVB phenotype should be analyzed in further experiments.

\subsubsection{The fatty acid elongation machinery is not required for PMN}

Kvam et al. reported that the lumenal diameters of PMN blebs and vesicles are significantly reduced in tsc13-1 and tsc13-1 elo3s mutant cells (Kvam, 2005). Elo2, Elo3, Tsc13 and YBR159 are proteins required for the elongation of very-long-chain fatty acids (VLCFAs) that localize to NV-junctions in S. cerevisiae (Kohlwein, 2001). These VLCFAs are enriched in lipid rafts and other detergent-insoluble lipid microdomains (Eisenkolb, 2002) (Dupré and Haguenauer-Tsapis, 2003). VLCFAs have been proposed to promote the formation of highly curved membrane structures (Schneiter and Kohlwein, 1997). Kvam et al. speculate that VLCFAs may be required for the efficient biogenesis of highly curved PMN vesicles (Kvam, 2005). Tsc13 is an essential gene and was therefore not analyzed in this study. Cells lacking Elo2, Elo3 or YBR159 showed the same PMN rate as wild type cells (Fig. 36).

The structures Kvam et al. reported were visualized using an overexpressing Nvj1EYFP reporter-construct. However, tagging and overexpression of proteins of the NV-junction apparatus could disturb the normal PMN process and are supposed to influence the size of PMN vesicles. A yeast cell has a diameter of about $5 \mu \mathrm{m}$ and its nucleus about $1.5 \mu \mathrm{m}$. The reported PMN vesicles in wild type cells overexpressing 
Nvj1 were $1.44 \mu \mathrm{m}$ in diameter and therefore as big as the whole nucleus (Kvam, 2005) pointing to an aberrant size of PMN vesicles under these conditions. Kvam et al. further reported a reduction in the size of PMN vesicles to half in tsc13-1 elo3 $\Delta$ mutant cells.

The aberrant size of the PMN vesicles in wild type and mutant cells could be due to overexpression of Nvj1 because in EM (electromicrograph) studies PMN vesicles of wild type cells have a diameter of about $150 \mu \mathrm{m}$ (a tenth of the size reported by Kvam et al.) (Roberts, 2003) (Krick, 2008b). To investigate if the fatty acid elongation machinery has an influence on the size of these vesicles, cells with native Nvj1 levels should be analyzed. GFP-Osh1 could be used as a non-essential component of the NV-junction (Kvam and Goldfarb, 2004) to monitor the PMN vesicle size in fluorescence microscopy. Another approach to clarify this issue could be EM pictures from the corresponding knockout strains.

\subsubsection{Proteins for cortical ER inharitance are not required for PMN}

The cortical ER (cER) inheritance can be divided into three different stages: first, cytoplasmic ER tubules move along actin cables into small buds of the mother-bud axis (proteins tested in this study: Myo4, She3); second, the first domain of the cortical ER forms by attachment to the plasma membrane at the bud tip (proteins tested in this study: Yop1 and Rtn1); and third, cER spreads around the entire bud to form a polygonal tubular network (proteins tested in this study: Scs2 and Ice2) (Loewen, 2007).

Scs2, the yeast homolog of mammalian VAMP-associated protein, is further involved in targeting of Osh1 to cellular membranes, although Scs2 is not strictly required for the localization of GFP-Osh1 to NV junctions (Loewen, 2003).

All proteins tested, involved in the inheritance of cortical ER, were not required for the PMN process (Fig. 37).

\subsubsection{Analysis of a mutant with misshaped nucleus}

Spo7 $\Delta$ cells are described to have a misshaped nucleus and exhibit a single nuclear protrusion (Campbell, 2006). 
These cells showed a reduction in PMN rate in two of three experiments (Fig. 38). The reduction was not drastic and probably an indirect effect. Perhaps the NVjunctions can not be formed correctly as the nucleus is misshaped. The requirement of $\mathrm{Spo} 7$ has to be clarified in further experiments.

\section{Further studies concerning PMN could answer these questions:}

Is PMN a selective process? Which part of the nucleus is degraded? How specific and efficient is PMN? Which volume of the nucleus is degraded per time? How is the membrane curvature of PMN structures generated? In which step of PMN is the autophagic machinery involved? In which step of PMN is Cdc48 reqired? 


\section{Bibliography}

Abeliovich, H., Zhang, C., Dunn, W.A., Shokat, K.M.und Klionsky, D.J. (2003). Chemical genetic analysis of Apg1 reveals a non-kinase role in the induction of autophagy. Mol Biol Cell 14, 477-490.

Amar, N., Lustig, G., Ichimura, Y., Ohsumi, Y.und Elazar, Z. (2006). Two newly identified sites in the ubiquitin-like protein Atg8 are essential for autophagy. EMBO Rep 7, 635-642.

Anderson, D.J.und Hetzer, M.W. (2007). Nuclear envelope formation by chromatinmediated reorganization of the endoplasmic reticulum. Nat Cell Biol 9, 1160-1166.

Baba, M., Osumi, M., Scott, S.V., Klionsky, D.J.und Ohsumi, Y. (1997). Two distinct pathways for targeting proteins from the cytoplasm to the vacuole/lysosome. The Journal of Cell Biology 139, 1687-1695.

Baba, M., Takeshige, K., Baba, N.und Ohsumi, Y. (1994). Ultrastructural analysis of the autophagic process in yeast: detection of autophagosomes and their characterization. The Journal of Cell Biology 124, 903-913.

Babst, M., Sato, T.K., Banta, L.M.und Emr, S.D. (1997). Endosomal transport function in yeast requires a novel AAA-type ATPase, Vps4p. EMBO J 16, 1820-1831.

Barth, H., Meiling-Wesse, K., Epple, U.D.und Thumm, M. (2001). Autophagy and the cytoplasm to vacuole targeting pathway both require Aut10p. FEBS Letters 508, 2328.

Barth, H., Meiling-Wesse, K., Epple, U.D.und Thumm, M. (2002). Mai1p is essential for maturation of proaminopeptidase I but not for autophagy. FEBS Letters 512, 173179.

Braun, S., Matuschewski, K., Rape, M., Thoms, S.und Jentsch, S. (2002). Role of the ubiquitin-selective CDC48(UFD1/NPL4 )chaperone (segregase) in ERAD of OLE1 and other substrates. EMBO J 21, 615-621.

Buchberger, A., Howard, M.J., Proctor, M.und Bycroft, M. (2001). The UBX domain: a widespread ubiquitin-like module. J Mol Biol 307, 17-24.

Campbell, J.L., Lorenz, A., Witkin, K.L., Hays, T., Loidl, J.und Cohen-Fix, O. (2006). Yeast nuclear envelope subdomains with distinct abilities to resist membrane expansion. Mol Biol Cell 17, 1768-1778.

Casagrande, R., Stern, P., Diehn, M., Shamu, C., Osario, M., Zúñiga, M., Brown, P.O.und Ploegh, H. (2000). Degradation of proteins from the ER of S. cerevisiae requires an intact unfolded protein response pathway. Mol Cell 5, 729-735.

Chen, N.und Karantza-Wadsworth, V. (2009). Role and regulation of autophagy in cancer. Biochim Biophys Acta. 
Cheong, H., Yorimitsu, T., Reggiori, F., Legakis, J.E., Wang, C.W.und Klionsky, D.J. (2005). Atg17 regulates the magnitude of the autophagic response. Mol Biol Cell 16, 3438-3453.

Coyle, J.E., Qamar, S., Rajashankar, K.R.und Nikolov, D.B. (2002). Structure of GABARAP in two conformations: implications for $\mathrm{GABA}(\mathrm{A})$ receptor localization and tubulin binding. Neuron 33, 63-74.

Decottignies, A., Evain, A.und Ghislain, M. (2004). Binding of Cdc48p to a ubiquitinrelated UBX domain from novel yeast proteins involved in intracellular proteolysis and sporulation. Yeast 21, 127-139.

Di Paolo, G.und De Camilli, P. (2006). Phosphoinositides in cell regulation and membrane dynamics. Nature 443, 651-657.

Du, Y. (2004). Dynamics and inheritance of the endoplasmic reticulum. Journal of Cell Science 117, 2871-2878.

Dunn, W.A., Cregg, J.M., Kiel, J.A., van der Klei, I.J., Oku, M., Sakai, Y., Sibirny, A.A., Stasyk, O.V.und Veenhuis, M. (2005). Pexophagy: the selective autophagy of peroxisomes. Autophagy 1, 75-83.

Dupré, S.und Haguenauer-Tsapis, R. (2001). Deubiquitination step in the endocytic pathway of yeast plasma membrane proteins: crucial role of Doa4p ubiquitin isopeptidase. Molecular and Cellular Biology 21, 4482-4494.

Dupré, S.und Haguenauer-Tsapis, R. (2003). Raft partitioning of the yeast uracil permease during trafficking along the endocytic pathway. Traffic 4, 83-96.

Eisenkolb, M., Zenzmaier, C., Leitner, E.und Schneiter, R. (2002). A specific structural requirement for ergosterol in long-chain fatty acid synthesis mutants important for maintaining raft domains in yeast. Mol Biol Cell 13, 4414-4428.

Elazar, Z., Scherz-Shouval, R.und Shorer, H. (2003). Involvement of LMA1 and GATE-16 family members in intracellular membrane dynamics. Biochim Biophys Acta $1641,145-156$.

Epple, U.D., Eskelinen, E.L.und Thumm, M. (2003). Intravacuolar membrane lysis in Saccharomyces cerevisiae. Does vacuolar targeting of Cvt17/Aut5p affect its function? J Biol Chem 278, 7810-7821.

Epple, U.D., Suriapranata, I., Eskelinen, E.L.und Thumm, M. (2001). Aut5/Cvt17p, a putative lipase essential for disintegration of autophagic bodies inside the vacuole. $\mathrm{J}$ Bacteriol 183, 5942-5955.

Farré, J.C., Manjithaya, R., Mathewson, R.D.und Subramani, S. (2008). PpAtg30 tags peroxisomes for turnover by selective autophagy. Dev Cell 14, 365-376.

Farré, J.C.und Subramani, S. (2004). Peroxisome turnover by micropexophagy: an autophagy-related process. Trends Cell Biol 14, 515-523. 
Fasshauer, D., Sutton, R.B., Brunger, A.T.und Jahn, R. (1998). Conserved structural features of the synaptic fusion complex: SNARE proteins reclassified as $Q-$ and $R$ SNAREs. Proc Natl Acad Sci USA 95, 15781-15786.

Funakoshi, T., Matsuura, A., Noda, T.und Ohsumi, Y. (1997). Analyses of APG13 gene involved in autophagy in yeast, Saccharomyces cerevisiae. Gene 192, 207213.

Gasch, A.P., Spellman, P.T., Kao, C.M., Carmel-Harel, O., Eisen, M.B., Storz, G., Botstein, D.und Brown, P.O. (2000). Genomic expression programs in the response of yeast cells to environmental changes. Mol Biol Cell 11, 4241-4257.

Gauss, R., Trautwein, M., Sommer, T.und Spang, A. (2005). New modules for the repeated internal and $\mathrm{N}$-terminal epitope tagging of genes in Saccharomyces cerevisiae. Yeast 22, 1-12.

Geumann, U., Barysch, S.V., Hoopmann, P., Jahn, R.und Rizzoli, S.O. (2008). SNARE function is not involved in early endosome docking. Mol Biol Cell 19, 53275337.

Ghislain, M., Dohmen, R.J., Levy, F.und Varshavsky, A. (1996). Cdc48p interacts with Ufd3p, a WD repeat protein required for ubiquitin-mediated proteolysis in Saccharomyces cerevisiae. EMBO J 15, 4884-4899.

Gillooly, D.J., Morrow, I.C., Lindsay, M., Gould, R., Bryant, N.J., Gaullier, J.M., Parton, R.G.und Stenmark, H. (2000). Localization of phosphatidylinositol 3phosphate in yeast and mammalian cells. EMBO J 19, 4577-4588.

Goder, V., Carvalho, P.und Rapoport, T.A. (2008). The ER-associated degradation component Der1p and its homolog Dfm1p are contained in complexes with distinct cofactors of the ATPase Cdc48p. FEBS Letters 582, 1575-1580.

Goffeau, A., Barrell, B.G., Bussey, H., Davis, R.W., Dujon, B., Feldmann, H., Galibert, F., Hoheisel, J.D., Jacq, C., Johnston, M., Louis, E.J., Mewes, H.W., Murakami, Y., Philippsen, P., Tettelin, H.und Oliver, S.G. (1996). Life with 6000 genes. Science 274, 546, 563-547.

Guan, J., Stromhaug, P.E., George, M.D., Habibzadegah-Tari, P., Bevan, A., Dunn, W.A.und Klionsky, D.J. (2001). Cvt18/Gsa12 is required for cytoplasm-to-vacuole transport, pexophagy, and autophagy in Saccharomyces cerevisiae and Pichia pastoris. Mol Biol Cell 12, 3821-3838.

Harding, T.M., Morano, K.A., Scott, S.V.und Klionsky, D.J. (1995). Isolation and characterization of yeast mutants in the cytoplasm to vacuole protein targeting pathway. The Journal of Cell Biology 131, 591-602.

Hartmann-Petersen, R., Wallace, M., Hofmann, K., Koch, G., Johnsen, A.H., Hendil, K.B.und Gordon, C. (2004). The Ubx2 and Ubx3 cofactors direct Cdc48 activity to proteolytic and nonproteolytic ubiquitin-dependent processes. Curr Biol 14, 824-828. 
He, C., Song, H., Yorimitsu, T., Monastyrska, I., Yen, W.L., Legakis, J.E.und Klionsky, D.J. (2006). Recruitment of Atg9 to the preautophagosomal structure by Atg11 is essential for selective autophagy in budding yeast. The Journal of Cell Biology 175, 925-935.

Hettema, E.H., Valdez-Taubas, J.und Pelham, H.R. (2004). Bsd2 binds the ubiquitin ligase Rsp5 and mediates the ubiquitination of transmembrane proteins. EMBO $\mathrm{J} 23$, 1279-1288.

Hitt, R.und Wolf, D.H. (2004). Der1p, a protein required for degradation of malfolded soluble proteins of the endoplasmic reticulum: topology and Der1-like proteins. FEMS Yeast Res 4, 721-729.

Hu, J., Shibata, Y., Voss, C., Shemesh, T., Li, Z., Coughlin, M., Kozlov, M., Rapoport, T.und Prinz, W. (2008). Membrane Proteins of the Endoplasmic Reticulum Induce High-Curvature Tubules. Science 319, 1247-1250.

Huang, J.und Klionsky, D.J. (2007). Autophagy and human disease. Cell Cycle 6, 1837-1849.

Hurley, J.H.und Emr, S.D. (2006). The ESCRT complexes: structure and mechanism of a membrane-trafficking network. Annual review of biophysics and biomolecular structure 35, 277-298.

Hutchins, M.U.und Klionsky, D.J. (2001). Vacuolar localization of oligomeric alphamannosidase requires the cytoplasm to vacuole targeting and autophagy pathway components in Saccharomyces cerevisiae. J Biol Chem 276, 20491-20498.

Ichimura, Y., Kirisako, T., Takao, T., Satomi, Y., Shimonishi, Y., Ishihara, N., Mizushima, N., Tanida, I., Kominami, E., Ohsumi, M., Noda, T.und Ohsumi, Y. (2000). A ubiquitin-like system mediates protein lipidation. Nature 408, 488-492.

Ishihara, N., Hamasaki, M., Yokota, S., Suzuki, K., Kamada, Y., Kihara, A., Yoshimori, T., Noda, T.und Ohsumi, Y. (2001). Autophagosome requires specific early Sec proteins for its formation and NSF/SNARE for vacuolar fusion. Mol Biol Cell 12, 3690-3702.

Jahn, R.und Scheller, R.H. (2006). SNAREs--engines for membrane fusion. Nat Rev Mol Cell Biol 7, 631-643.

Jarosch, E., Taxis, C., Volkwein, C., Bordallo, J., Finley, D., Wolf, D.H.und Sommer, T. (2002). Protein dislocation from the ER requires polyubiquitination and the AAAATPase Cdc48. Nat Cell Biol 4, 134-139.

Kabeya, Y., Kamada, Y., Baba, M., Takikawa, H., Sasaki, M.und Ohsumi, Y. (2005). Atg17 functions in cooperation with Atg1 and Atg13 in yeast autophagy. Mol Biol Cell 16, 2544-2553.

Kamada, Y., Funakoshi, T., Shintani, T., Nagano, K., Ohsumi, M.und Ohsumi, Y. (2000). Tor-mediated induction of autophagy via an Apg1 protein kinase complex. The Journal of Cell Biology 150, 1507-1513. 
Kano, F., Kondo, H., Yamamoto, A., Kaneko, Y., Uchiyama, K., Hosokawa, N., Nagata, K.und Murata, M. (2005). NSF/SNAPs and p97/p47/VCIP135 are sequentially required for cell cycle-dependent reformation of the ER network. Genes Cells 10, 989-999.

Katzmann, D.J., Babst, M.und Emr, S.D. (2001). Ubiquitin-dependent sorting into the multivesicular body pathway requires the function of a conserved endosomal protein sorting complex, ESCRT-I. Cell 106, 145-155.

Kawamata, T., Kamada, Y., Kabeya, Y., Sekito, T.und Ohsumi, Y. (2008). Organization of the pre-autophagosomal structure responsible for autophagosome formation. Mol Biol Cell 19, 2039-2050.

Kihara, A., Noda, T., Ishihara, N.und Ohsumi, Y. (2001). Two distinct Vps34 phosphatidylinositol 3-kinase complexes function in autophagy and carboxypeptidase Y sorting in Saccharomyces cerevisiae. The Journal of Cell Biology 152, 519-530.

Kirisako, T., Baba, M., Ishihara, N., Miyazawa, K., Ohsumi, M., Yoshimori, T., Noda, T.und Ohsumi, Y. (1999). Formation process of autophagosome is traced with Apg8/Aut7p in yeast. The Journal of Cell Biology 147, 435-446.

Kirisako, T., Ichimura, Y., Okada, H., Kabeya, Y., Mizushima, N., Yoshimori, T., Ohsumi, M., Takao, T., Noda, T.und Ohsumi, Y. (2000). The reversible modification regulates the membrane-binding state of Apg8/Aut7 essential for autophagy and the cytoplasm to vacuole targeting pathway. The Journal of Cell Biology 151, 263-276.

Kissová, I., Deffieu, M., Manon, S.und Camougrand, N. (2004). Uth1p is involved in the autophagic degradation of mitochondria. J Biol Chem 279, 39068-39074.

Klenchin, V.A.und Martin, T.F. (2000). Priming in exocytosis: attaining fusioncompetence after vesicle docking. Biochimie 82, 399-407.

Klionsky, D.J., Cregg, J.M., Dunn, W.A., Emr, S.D., Sakai, Y., Sandoval, I.V., Sibirny, A., Subramani, S., Thumm, M., Veenhuis, M.und Ohsumi, Y. (2003). A unified nomenclature for yeast autophagy-related genes. Dev Cell 5, 539-545.

Klionsky, D.J., Cuervo, A.M.und Seglen, P.O. (2007). Methods for monitoring autophagy from yeast to human. Autophagy 3, 181-206.

Kohlwein, S.D., Eder, S., Oh, C.S., Martin, C.E., Gable, K., Bacikova, D.und Dunn, T. (2001). Tsc13p is required for fatty acid elongation and localizes to a novel structure at the nuclear-vacuolar interface in Saccharomyces cerevisiae. Molecular and Cellular Biology 21, 109-125.

Kondo, H., Rabouille, C., Newman, R., Levine, T.P., Pappin, D., Freemont, P.und Warren, G. (1997). p47 is a cofactor for p97-mediated membrane fusion. Nature 388, 75-78. 
Kraft, C., Deplazes, A., Sohrmann, M.und Peter, M. (2008). Mature ribosomes are selectively degraded upon starvation by an autophagy pathway requiring the Ubp3p/Bre5p ubiquitin protease. Nat Cell Biol 10, 602-610.

Krick, R., Henke, S., Tolstrup, J.und Thumm, M. (2008a). Dissecting the localization and function of Atg18, Atg21 and Ygr223c. Autophagy 4, 896-910.

Krick, R., Muehe, Y., Prick, T., Bremer, S., Schlotterhose, P., Eskelinen, E.L., Millen, J., Goldfarb, D.S.und Thumm, M. (2008b). Piecemeal microautophagy of the nucleus requires the core macroautophagy genes. Mol Biol Cell 19, 4492-4505.

Krick, R., Mühe, Y., Prick, T., Bredschneider, M., Bremer, S., Wenzel, D., Eskelinen, E.L.und Thumm, M. (2009). Piecemeal microautophagy of the nucleus: Genetic and morphological traits. Autophagy 5.

Krick, R., Tolstrup, J., Appelles, A., Henke, S.und Thumm, M. (2006). The relevance of the phosphatidylinositolphosphat-binding motif FRRGT of Atg18 and Atg21 for the Cvt pathway and autophagy. FEBS Letters 580, 4632-4638.

Kuma, A., Mizushima, N., Ishihara, N.und Ohsumi, Y. (2002). Formation of the approximately 350-kDa Apg12-Apg5.Apg16 multimeric complex, mediated by Apg16 oligomerization, is essential for autophagy in yeast. J Biol Chem 277, 18619-18625.

Kvam, E., Gable, K., Dunn, T.M.und Goldfarb, D. (2005). Targeting of Tsc13p to nucleus-vacuole junctions: a role for very-long-chain fatty acids in the biogenesis of microautophagic vesicles. Mol Biol Cell 16, 3987-3998.

Kvam, E.und Goldfarb, D. (2004). Nvj1p is the outer-nuclear-membrane receptor for oxysterol-binding protein homolog Osh $1 \mathrm{p}$ in Saccharomyces cerevisiae. Journal of Cell Science 117, 4959-4968.

Kvam, E.und Goldfarb, D. (2006a). Structure and function of nucleus-vacuole junctions: outer-nuclear-membrane targeting of Nvj1p and a role in tryptophan uptake. Journal of Cell Science 119, 3622-3633.

Kvam, E.und Goldfarb, D. (2007). Nucleus-vacuole junctions and piecemeal microautophagy of the nucleus in S. cerevisiae. Autophagy 3, 85-92.

Kvam, E.und Goldfarb, D.S. (2006b). Nucleus-vacuole junctions in yeast: anatomy of a membrane contact site. Biochem. Soc. Trans 34, 340-342.

Laemmli, U.K. (1970). Cleavage of structural proteins during the assembly of the head of bacteriophage T4. Nature 227, 680-685.

Lang, T., Schaeffeler, E., Bernreuther, D., Bredschneider, M., Wolf, D.H.und Thumm, M. (1998). Aut2p and Aut7p, two novel microtubule-associated proteins are essential for delivery of autophagic vesicles to the vacuole. EMBO J 17, 3597-3607.

Latterich, M., Fröhlich, K.U.und Schekman, R. (1995). Membrane fusion and the cell cycle: Cdc48p participates in the fusion of ER membranes. Cell 82, 885-893. 
Legesse-Miller, A., Sagiv, Y., Glozman, R.und Elazar, Z. (2000). Aut7p, a soluble autophagic factor, participates in multiple membrane trafficking processes. J Biol Chem 275, 32966-32973.

Levine, B.und Kroemer, G. (2009). Autophagy in aging, disease and death: the true identity of a cell death impostor. Cell Death Differ 16, 1-2.

Loewen, C., Young, B., Tavassoli, S.und Levine, T. (2007). Inheritance of cortical ER in yeast is required for normal septin organization. The Journal of Cell Biology 179, 467-483.

Loewen, C.J., Roy, A.und Levine, T.P. (2003). A conserved ER targeting motif in three families of lipid binding proteins and in Opi1p binds VAP. EMBO J 22, 20252035.

Longtine, M.S., McKenzie, A., Demarini, D.J., Shah, N.G., Wach, A., Brachat, A., Philippsen, P.und Pringle, J.R. (1998). Additional modules for versatile and economical PCR-based gene deletion and modification in Saccharomyces cerevisiae. Yeast 14, 953-961.

Ma, J., Jin, R., Jia, X., Dobry, C.J., Wang, L., Reggiori, F., Zhu, J.und Kumar, A. (2007). An interrelationship between autophagy and filamentous growth in budding yeast. Genetics 177, 205-214.

Majeski, A.E.und Dice, J.F. (2004). Mechanisms of chaperone-mediated autophagy. Int J Biochem Cell Biol 36, 2435-2444.

Mariño, G.und López-Otín, C. (2008). Autophagy and aging: new lessons from progeroid mice. Autophagy 4, 807-809.

Massey, A., Kiffin, R.und Cuervo, A.M. (2004). Pathophysiology of chaperonemediated autophagy. Int J Biochem Cell Biol 36, 2420-2434.

Meyer, H.H. (2005). Golgi reassembly after mitosis:

The AAA family meets the ubiquitin family. Biochimica et Biophysica Acta (BBA) Molecular Cell Research 1744, 465-517.

Meyer, H.H., Shorter, J.G., Seemann, J., Pappin, D.und Warren, G. (2000). A complex of mammalian ufd1 and npl4 links the AAA-ATPase, p97, to ubiquitin and nuclear transport pathways. EMBO J 19, 2181-2192.

Meyer, H.H., Wang, Y.und Warren, G. (2002). Direct binding of ubiquitin conjugates by the mammalian p97 adaptor complexes, p47 and Ufd1-Npl4. EMBO J 21, 56455652.

Millen, J., Pierson, J., Kvam, E., Olsen, L.und Goldfarb, D. (2008). The Luminal NTerminus of Yeast Nvj1 is an Inner Nuclear Membrane Anchor. Traffic 9, 1653-1664.

Mizushima, N., Noda, T., Yoshimori, T., Tanaka, Y., Ishii, T., George, M.D., Klionsky, D.J., Ohsumi, M.und Ohsumi, Y. (1998). A protein conjugation system essential for autophagy. Nature 395, 395-398. 
Monastyrska, I.und Klionsky, D.J. (2006). Autophagy in organelle homeostasis: peroxisome turnover. Mol Aspects Med 27, 483-494.

Mühe, Y. (2007). Mikroautophagischer Abbau von Teilen der Kernhülle und Untersuchungen zum Transport und der Aktivität von Atg15p in der Hefe S. cerevisiae. Doktorarbeit, 132.

Mullally, J.E., Chernova, T.und Wilkinson, K.D. (2006). Doa1 is a Cdc48 adapter that possesses a novel ubiquitin binding domain. Molecular and Cellular Biology 26, 822830.

Nakamura, N., Matsuura, A., Wada, Y.und Ohsumi, Y. (1997). Acidification of vacuoles is required for autophagic degradation in the yeast, Saccharomyces cerevisiae. J Biochem 121, 338-344.

Nakatogawa, H., Ichimura, Y.und Ohsumi, Y. (2007). Atg8, a ubiquitin-like protein required for autophagosome formation, mediates membrane tethering and hemifusion. Cell 130, 165-178.

Nishida, K., Kyoi, S., Yamaguchi, O., Sadoshima, J.und Otsu, K. (2009). The role of autophagy in the heart. Cell Death Differ 16, 31-38.

Obara, K., Noda, T., Niimi, K.und Ohsumi, Y. (2008a). Transport of phosphatidylinositol 3-phosphate into the vacuole via autophagic membranes in Saccharomyces cerevisiae. Genes Cells 13, 537-547.

Obara, K., Sekito, T., Niimi, K.und Ohsumi, Y. (2008b). The Atg18-Atg2 complex is recruited to autophagic membranes via phosphatidylinositol 3-phosphate and exerts an essential function. J Biol Chem 283, 23972-23980.

Oh-oka, K., Nakatogawa, H.und Ohsumi, Y. (2008). Physiological pH and acidic phospholipids contribute to substrate specificity in lipidation of Atg8. J Biol Chem 283, 21847-21852.

Orvedahl, A.und Levine, B. (2009). Eating the enemy within: autophagy in infectious diseases. Cell Death Differ 16, 57-69.

Palmer, G.E., Askew, D.S.und Williamson, P. (2008). The diverse roles of autophagy in medically important fungi. Autophagy 4, 982-988.

Pan, X., Roberts, P., Chen, Y., Kvam, E., Shulga, N., Huang, K., Lemmon, S.und Goldfarb, D.S. (2000). Nucleus-vacuole junctions in Saccharomyces cerevisiae are formed through the direct interaction of Vac8p with Nvj1p. Mol Biol Cell 11, 24452457.

Paz, Y., Elazar, Z.und Fass, D. (2000). Structure of GATE-16, membrane transport modulator and mammalian ortholog of autophagocytosis factor Aut7p. J Biol Chem 275, 25445-25450. 
Piper, R.C., Cooper, A.A., Yang, H.und Stevens, T.H. (1995). VPS27 controls vacuolar and endocytic traffic through a prevacuolar compartment in Saccharomyces cerevisiae. The Journal of Cell Biology 131, 603-617.

Raasi, S.und Wolf, D. (2007). Ubiquitin receptors and ERAD: A network of pathways to the proteasome. Seminars in Cell \& Developmental Biology 18, 780-791.

Rabouille, C., Kondo, H., Newman, R., Hui, N., Freemont, P.und Warren, G. (1998). Syntaxin 5 is a common component of the NSF- and p97-mediated reassembly pathways of Golgi cisternae from mitotic Golgi fragments in vitro. Cell 92, 603-610.

Rapoport, T.A., Rolls, M.M.und Jungnickel, B. (1996). Approaching the mechanism of protein transport across the ER membrane. Curr Opin Cell Biol 8, 499-504.

Raymond, C.K., Howald-Stevenson, I., Vater, C.A.und Stevens, T.H. (1992). Morphological classification of the yeast vacuolar protein sorting mutants: evidence for a prevacuolar compartment in class E vps mutants. Mol Biol Cell 3, 1389-1402.

Reggiori, F.und Klionsky, D.J. (2006). Atg9 sorting from mitochondria is impaired in early secretion and VFT-complex mutants in Saccharomyces cerevisiae. Journal of Cell Science 119, 2903-2911.

Reggiori, F., Shintani, T., Nair, U.und Klionsky, D.J. (2005). Atg9 cycles between mitochondria and the pre-autophagosomal structure in yeasts. Autophagy $1,101-$ 109.

Reggiori, F., Wang, C.W., Nair, U., Shintani, T., Abeliovich, H.und Klionsky, D.J. (2004). Early stages of the secretory pathway, but not endosomes, are required for Cvt vesicle and autophagosome assembly in Saccharomyces cerevisiae. Mol Biol Cell 15, 2189-2204.

Ren, J., Pashkova, N., Winistorfer, S.und Piper, R. (2008). DOA1/UFD3 Plays a Role in Sorting Ubiquitinated Membrane Proteins into Multivesicular Bodies. Journal of Biological Chemistry 283, 21599-21611.

Roberts, P., Moshitch-Moshkovitz, S., Kvam, E., O'Toole, E., Winey, M.und Goldfarb, D. (2003). Piecemeal microautophagy of nucleus in Saccharomyces cerevisiae. Mol Biol Cell 14, 129-141.

Rössler, H., Rieck, C., Delong, T., Hoja, U.und Schweizer, E. (2003). Functional differentiation and selective inactivation of multiple Saccharomyces cerevisiae genes involved in very-long-chain fatty acid synthesis. Mol Genet Genomics 269, 290-298.

Rubinsztein, D.C., DiFiglia, M., Heintz, N., Nixon, R.A., Qin, Z.H., Ravikumar, B., Stefanis, L.und Tolkovsky, A. (2005). Autophagy and its possible roles in nervous system diseases, damage and repair. Autophagy 1, 11-22.

Rumpf, S.und Jentsch, S. (2006). Functional division of substrate processing cofactors of the ubiquitin-selective Cdc48 chaperone. Mol Cell 21, 261-269. 
Sakai, Y., Oku, M., van der Klei, I.J.und Kiel, J.A. (2006). Pexophagy: autophagic degradation of peroxisomes. Biochim Biophys Acta 1763, 1767-1775.

Schneiter, R.und Kohlwein, S.D. (1997). Organelle structure, function, and inheritance in yeast: a role for fatty acid synthesis? Cell 88, 431-434.

Schuberth, C.und Buchberger, A. (2008). UBX domain proteins: major regulators of the AAA ATPase Cdc48/p97. Cell. Mol. Life Sci. 65, 2360-2371.

Schuberth, C., Richly, H., Rumpf, S.und Buchberger, A. (2004). Shp1 and Ubx2 are adaptors of Cdc48 involved in ubiquitin-dependent protein degradation. EMBO Rep $5,818-824$.

Scott, S.V., Baba, M., Ohsumi, Y.und Klionsky, D.J. (1997). Aminopeptidase I is targeted to the vacuole by a nonclassical vesicular mechanism. The Journal of Cell Biology 138, 37-44.

Smith, T.F., Gaitatzes, C., Saxena, K.und Neer, E.J. (1999). The WD repeat: a common architecture for diverse functions. Trends Biochem Sci 24, 181-185.

Stenmark, H., Aasland, R.und Driscoll, P.C. (2002). The phosphatidylinositol 3phosphate-binding FYVE finger. FEBS Letters 513, 77-84.

Strømhaug, P.E., Reggiori, F., Guan, J., Wang, C.W.und Klionsky, D.J. (2004). Atg21 is a phosphoinositide binding protein required for efficient lipidation and localization of Atg8 during uptake of aminopeptidase I by selective autophagy. Mol Biol Cell 15, 3553-3566.

Sugawara, K., Suzuki, N.N., Fujioka, Y., Mizushima, N., Ohsumi, Y.und Inagaki, F. (2004). The crystal structure of microtubule-associated protein light chain 3, a mammalian homologue of Saccharomyces cerevisiae Atg8. Genes Cells 9, 611-618.

Suriapranata, I., Epple, U.D., Bernreuther, D., Bredschneider, M., Sovarasteanu, K.und Thumm, M. (2000). The breakdown of autophagic vesicles inside the vacuole depends on Aut4p. Journal of Cell Science 113 ( Pt 22), 4025-4033.

Suzuki, K., Kirisako, T., Kamada, Y., Mizushima, N., Noda, T.und Ohsumi, Y. (2001). The pre-autophagosomal structure organized by concerted functions of APG genes is essential for autophagosome formation. EMBO J 20, 5971-5981.

Suzuki, K., Kubota, Y., Sekito, T.und Ohsumi, Y. (2007). Hierarchy of Atg proteins in pre-autophagosomal structure organization. Genes Cells 12, 209-218.

Swaminathan, S., Amerik, A.Y.und Hochstrasser, M. (1999). The Doa4 deubiquitinating enzyme is required for ubiquitin homeostasis in yeast. Mol Biol Cell 10, 2583-2594.

Takeshige, K., Baba, M., Tsuboi, S., Noda, T.und Ohsumi, Y. (1992). Autophagy in yeast demonstrated with proteinase-deficient mutants and conditions for its induction. The Journal of Cell Biology 119, 301-311. 
Tal, R., Winter, G., Ecker, N., Klionsky, D.J.und Abeliovich, H. (2007). Aup1p, a yeast mitochondrial protein phosphatase homolog, is required for efficient stationary phase mitophagy and cell survival. J Biol Chem 282, 5617-5624.

Thumm, M., Egner, R., Koch, B., Schlumpberger, M., Straub, M., Veenhuis, M.und Wolf, D.H. (1994). Isolation of autophagocytosis mutants of Saccharomyces cerevisiae. FEBS Letters 349, 275-280.

Tsukada, M.und Ohsumi, Y. (1993). Isolation and characterization of autophagydefective mutants of Saccharomyces cerevisiae. FEBS Letters 333, 169-174.

Uchiyama, K., Jokitalo, E., Kano, F., Murata, M., Zhang, X., Canas, B., Newman, R., Rabouille, C., Pappin, D., Freemont, P.und Kondo, H. (2002). VCIP135, a novel essential factor for p97/p47-mediated membrane fusion, is required for Golgi and ER assembly in vivo. The Journal of Cell Biology $159,855-866$.

Wang, Q., Song, C.und Li, C.C. (2004a). Molecular perspectives on p97-VCP: progress in understanding its structure and diverse biological functions. J Struct Biol 146, 44-57.

Wang, Y., Satoh, A., Warren, G., Meyer, H.H.und Wang, Y. (2004b). VCIP135 acts as a deubiquitinating enzyme during p97-p47-mediated reassembly of mitotic Golgi fragments. The Journal of Cell Biology 164, 973-978.

Woodman, P.G. (2003). p97, a protein coping with multiple identities. Journal of Cell Science 116, 4283-4290.

Wurmser, A.E.und Emr, S.D. (2002). Novel Ptdlns(3)P-binding protein Etf1 functions as an effector of the Vps34 Ptdlns 3-kinase in autophagy. The Journal of Cell Biology $158,761-772$.

Xie, Z.und Klionsky, D.J. (2007). Autophagosome formation: core machinery and adaptations. Nat Cell Biol 9, 1102-1109.

Xie, Z., Nair, U.und Klionsky, D.J. (2008). Atg8 controls phagophore expansion during autophagosome formation. Mol Biol Cell 19, 3290-3298.

Yamada, T., Carson, A.R., Caniggia, I., Umebayashi, K., Yoshimori, T., Nakabayashi, K.und Scherer, S.W. (2005). Endothelial nitric-oxide synthase antisense (NOS3AS) gene encodes an autophagy-related protein (APG9-like2) highly expressed in trophoblast. J Biol Chem 280, 18283-18290.

Yang, Q., She, H., Gearing, M., Colla, E., Lee, M., Shacka, J.J.und Mao, Z. (2009). Regulation of neuronal survival factor MEF2D by chaperone-mediated autophagy. Science 323, 124-127.

Yang, Z., Huang, J., Geng, J., Nair, U.und Klionsky, D.J. (2006). Atg22 recycles amino acids to link the degradative and recycling functions of autophagy. Mol Biol Cell 17, 5094-5104. 
Ye, Y., Meyer, H.H.und Rapoport, T.A. (2001). The AAA ATPase Cdc48/p97 and its partners transport proteins from the ER into the cytosol. Nature 414, 652-656.

Yen, W.L., Legakis, J.E., Nair, U.und Klionsky, D.J. (2007). Atg27 is required for autophagy-dependent cycling of Atg9. Mol Biol Cell 18, 581-593.

Yorimitsu, T.und Klionsky, D.J. (2005). Autophagy: molecular machinery for selfeating. Cell Death Differ 12 Suppl 2, 1542-1552.

Young, A.R., Chan, E.Y., Hu, X.W., Köchl, R., Crawshaw, S.G., High, S., Hailey, D.W., Lippincott-Schwartz, J.und Tooze, S.A. (2006). Starvation and ULK1dependent cycling of mammalian Atg9 between the TGN and endosomes. Journal of Cell Science 119, 3888-3900.

Yu, L., Wan, F., Dutta, S., Welsh, S., Liu, Z., Freundt, E., Baehrecke, E.H.und Lenardo, M. (2006). Autophagic programmed cell death by selective catalase degradation. Proc Natl Acad Sci USA 103, 4952-4957.

Yuan, W., Tuttle, D.L., Shi, Y.J., Ralph, G.S.und Dunn, W.A. (1997). Glucoseinduced microautophagy in Pichia pastoris requires the alpha-subunit of phosphofructokinase. Journal of Cell Science 110 ( Pt 16), 1935-1945. 


\section{Danksagung}

Ein ganz besonderer Dank geht an Prof. Michael Thumm, für die Bereitstellung des sehr interessanten Themas und die Betreuung dieser Arbeit, sowie für die Unterstützung in den letzten drei Jahren.

Prof. Gerhard Braus möchte ich für seine Tätigkeit als Co-Referent meiner Arbeit danken.

Neben Prof. Thumm danke ich den beiden weiteren Mitgliedern meines Thesis Committees, Prof. Gerhard Braus und Dr. Dirk Fasshauer für ihre Anregungen und wertvollen Vorschläge zu meinem Projekt.

Herzlich danken möchte ich Rosi für ihre Unterstützung in allen Situationen und ihre Diskussionsbereitschaft zu dieser Arbeit.

Besonders danken möchte ich Prof. Doenecke für sein Engagement im Graduiertenkolleg 521. Dank geht auch an die anderen Doktoranden des Graduiertenkollegs, für die lehrreichen Seminare und die schöne gemeinsame Zeit.

In den drei Jahren in der Biochemie II habe ich viel Neues gelernt und Schönes erlebt. Besonders bedanken möchte ich mich bei meinen Kolleginnen und Kollegen Anika, Jörn, Sandra, Tanja, Yvonne, Jenny, Tanja, Petra und allen anderen Mitarbeitern der Biochemie II.

Evelyn, Petra und Rosi, die es bis zum Ende mit mir im Keller ausgehalten und für ein angenehmes Arbeitsklima gesorgt haben, sind besonders hervorzuheben!

Ein riesengroßes Dankeschön geht an meine Eltern und meine Schwester für ihren Glauben an mich und ihre immer andauernde Unterstützung.

Dir, Johanna danke ich für Deine liebevolle Unterstützung seit schon fast 7 Jahren! 


\section{Persönliche Angaben}

$\begin{array}{ll}\text { Name: } & \text { Sebastian Bremer } \\ \text { Geburtsdatum: } & \text { 13. Februar 1979 } \\ \text { Geburtsort: } & \text { Hannover } \\ \text { Staatsangehörigkeit: } & \text { deutsch }\end{array}$

\section{Ausbildung}

Seit 03.2006

$10.2000-02.2006$

$08.1999-6.2000$

$08.1991-06.1999$

$08.1985-08.1991$
Dissertation an der Georg-August-Universität Göttingen Institut für Biochemie II, Zentrum Biochemie und Molekulare Zellbiologie, Prof. Dr. Michael Thumm

Thema: Molecular analysis of vesicle biogenesis in autophagy

Studium der Biologie an der Leibniz Universität Hannover Hauptfach: Mikrobiologie Nebenfächer: Genetik und Immunologie

Diplomarbeit an der Medizinischen Hochschule Hannover Klinische Immunologie, Prof. Dr. Roland Jacobs Thema: Untersuchungen zur Aktivierbarkeit von Subpopulationen natürlicher Killerzellen des Menschen

Ausbildung zum Rettungssanitäter beim Deutschen Roten Kreuz im Rahmen des Zivildienstes

Gymnasium Bad Nenndorf und Ratsgymnasium Stadthagen, Humanistischer Zweig

Grundschule und Orientierungsstufe in Bad Nenndorf 